\title{
ipen
}

AUTARQUIA ASSOCIADA À UNIVERSIDADE DE SÃO PAULO

DESENVOLVIMENTO DE UMA METODOLOGIA DE CALIBRAÇÃO DE MONITORES DE CONTAMINAÇÃO DE SUPERFÍCIE CONSIDERANDO O MAPEAMENTO DA UNIFORMIDADE DAS FONTES EXTENSAS DE REFERÊNCIA

IREMAR ALVES DA SILVA JÚNIOR

Tese apresentada como parte dos requisitos para obtenção do Grau de Doutor em Ciências na Área de Tecnologia Nuclear Aplicações.

Orientadora:

Dra. Maria da Penha Albuquerque Potiens

São Paulo 


\title{
INSTITUTO DE PESQUISAS ENERGÉTICAS E NUCLEARES
}

AUTARQUIA ASSOCIADA À UNIVERSIDADE DE SÃO PAULO

\section{DESENVOLVIMENTO DE UMA METODOLOGIA DE CALIBRAÇÃO DE MONITORES DE CONTAMINAÇÃO DE SUPERFÍCIE CONSIDERANDO O MAPEAMENTO DA UNIFORMIDADE DAS FONTES EXTENSAS DE REFERÊNCIA}

\author{
IREMAR ALVES DA SILVA JÚNIOR
}

Tese apresentada como parte dos requisitos para obtenção do Grau de Doutor em Ciências na Área de Tecnologia Nuclear Aplicações.

Orientadora:

Dra. Maria da Penha Albuquerque Potiens

Versão Corrigida

Versão Original disponível no IPEN

São Paulo 
Nome: SILVA JR, Iremar Alves

Título: Desenvolvimento de uma metodologia de calibração de monitores de contaminação de superfície considerando o mapeamento da uniformidade das fontes extensas de referência.

Tese apresentada ao Instituto de Pesquisas Energéticas e Nucleares como parte dos requisitos para obtenção do Grau de Doutor em Ciências na Área de Tecnologia Nuclear Aplicações.

Aprovado em: 06/12/2017

Banca Examinadora

Prof. Dra. Maria da Penha Albuquerque Potiens

Instituição: Instituto de Pesquisas Energéticas e Nucleares

Julgamento: Aprovado

Prof. Dra. $\quad$ Linda Viola Ehlin Caldas

Instituição: Instituto de Pesquisas Energéticas e Nucleares

Julgamento: Aprovado

Prof. Dr. Vitor Vivolo

Instituição: Instituto de Pesquisas Energéticas e Nucleares

Julgamento: Aprovado

Prof. Dr. Teógenes Augusto da Silva

Instituição: Centro de Desenvolvimento da Tecnologia Nuclear

Julgamento: Aprovado

Prof. Dr. Márcio Bottaro

Instituição: Instituto de Energia e Ambiente

Julgamento: Aprovado 


\section{AGRADECIMENTOS}

Várias são as pessoas (corpo de funcionários do LCI-IPEN), amigos e entidades a quem agradeço pelo muito que me ajudaram no desenvolvimento de minha tese.

À professora Dra. Maria da Penha Albuquerque Potiens, por todo seu empenho, pela inestimável orientação, apoio e confiança demonstrados durante a realização do trabalho.

Ao Instituto de Pesquisas Energéticas e Nucleares (IPEN), Comissão Nacional de Energia Nuclear (CNEN), Coordenação de Aperfeiçoamento de Pessoal de Nível Superior (Capes), Fundação de Amparo à Pesquisa do Estado de São Paulo (FAPESP), Conselho Nacional de Desenvolvimento Cientifico e Tecnológico (CNPq) e Institutos Nacionais de Ciência e tecnologia - Ministério da Ciência, Tecnologia, Inovação e Comunicações (INCT-MCTIC) pelo apoio financeiro.

Aos funcionários que por várias vezes não pouparam esforços em atender às demandas do meu trabalho. Em especial aos técnicos, Marcos Xavier, que muitas vezes me auxiliou com idéias e sugestões, Claudinei Cescon, que tanto contribuiu, inicialmente com um espaço em seu laboratório de eletrônica e depois com diversos apoios durante a realização de experimentos.

Aos colegas Gelson, Rafael, Aldo, Letícia, Ana Maria e Teresa que sempre estiveram do meu lado dando apoio e ajudando.

Ao amigo Dr. Lucas Rodrigues dos Santos, pela imensa ajuda na parte de cálculo das incertezas e por tantas outras ajudas no decorrer do trabalho.

Ao Dr. Gian-Maria Agostino Angelo Sordi, pela imensa ajuda dada durante esse trabalho, com diversas contribuições e recomendações.

Ao Dr. Eduardo Nascimento, que tanto ajudou com discussões sobre o trabalho e simulações.

Ao Dr. Vitor Vivolo, que tanto me ajudou com sua experiência, viabilizando diversas atividades.

À Dra. Linda V. E. Caldas que sempre me deu um imenso apoio. 
Em especial ao Dr. Paulo de Tarso D. Siqueira (Paulão) do CEN, que detém a licença do código MCNP utilizado neste trabalho, pela imensa ajuda durante praticamente todas as etapas do meu trabalho, sempre lhe serei grato.

A todos os funcionários do setor de Projetos do IPEN, em especial ao Sr. Roberto Mauro Schoueri, responsável pela elaboração das partes adicionais do contador proporcional sem janela e com fluxo de gás que desenvolvemos durante este trabalho.

Aos colaboradores do Reator, Mauro da Silva Dias, Francisco de Assis Souza, Frederico Antonio Genezini e Maurício Moralles.

Aos meus amigos de moradia do CRUSP, Esdras e Vinícius, dentre tantos outros.

Ao Ronaldo da empresa Promec (Confecção do setup de calibração).

A empresa METROBRAS - MRA Comércio de instrumentos eletrônicos Ltda (Centro de Ensaios e Pesquisas em Metrologia) e em especial ao José Luiz Bruçó e a Marina A. Pires, que muito ajudaram, desde fornecer equipamentos (aquisição de cabo USB para multicanal 920E da Ortec) até possibilitar realizar medidas em seus laboratórios (medida de uniformidade de fontes extensas de referência).

Em especial agradeço a minha esposa Andréa pela imensa paciência e compreensão, uma vez que estive ausente por tanto tempo e às minhas filhas Samanta, Sabrina e Natalia. 


\section{RESUMO}

SILVA JR, Iremar Alves. Desenvolvimento de uma metodologia de calibração de monitores de contaminação de superfície considerando o mapeamento da uniformidade das fontes extensas de referência. 2017.129 páginas. Tese (Doutorado em Tecnologia Nuclear - Aplicações) - Instituto de Pesquisas Energéticas e Nucleares, Universidade de São Paulo, São Paulo, 2017.

Uma das exigências na calibração de monitores de radiação de contaminação de superfície consiste no uso de fontes extensas de referência com um valor de uniformidade superior a $90 \%$. Entretanto, foi verificado em alguns laboratórios de calibração que suas fontes não atendiam essa exigência, o que obrigaria esses laboratórios a não utilizarem tais fontes em suas calibrações. Foi neste contexto que foi desenvolvido um estudo para propor o uso dessas fontes, desde que sejam utilizados fatores de correção, que são propostos neste trabalho, que foram avaliados e desenvolvidos usando o código de transporte MCNP como ferramenta de análise e avaliação, a partir dos dados de mapeamento da uniformidade. Também foi desenvolvido um software para calcular esses fatores de correção, utilizando o mapeamento da uniformidade das fontes como dados de entrada e um sistema automatizado para calibração de monitores de radiação de contaminação de superfície. $O$ grande ganho com esse trabalho foi poder utilizar fontes extensas de referência, mesmo quando essas estão em desacordo com as exigências de uniformidade da norma ABNT ISO 8769:2016.

Palavras-chave: Monitor de contaminação de superfície, calibração, fonte extensa de referência, uniformidade, fator de correção, MCNP. 


\section{ABSTRACT}

SILVA JR, Iremar Alves. Development of a calibration methodology of surface contamination monitors considering the uniformity mapping of the large area reference sources. 2017.129 pages. Ph.D. Thesis (Graduate program in Nuclear Technology - Applications) - Energy and Nuclear Research Institute, University of Sao Paulo, Sao Paulo, 2017.

One of the requirements in the calibration of surface contamination radiation monitors is the use of wide area reference sources with a uniformity value greater than $90 \%$. However, it has been found, in some calibration laboratories, that their sources were not meeting this requirement, which would not allow these laboratories to use such sources in their calibration procedures. It was in this context that a study was developed to propose the use of these sources, provided that correction factors are used, which are proposed in this work, which were evaluated and developed using the MCNP radiation transport code as an evaluation tool, from the uniformity mapping data. A software was also developed to calculate these correction factors using the source uniformity mapping as an input data along with an automated system for calibration of surface contamination radiation monitors. The great gain in this work was to be able to use wide area reference sources, even when they are in disagreement with the uniformity requirements of ISO 8769:2016.

Keywords: Surface contamination monitor, calibration, large-area reference source, uniformity, correction factor, MCNP. 


\section{LISTA DE FIGURAS}

Páginas

Figura 1 - Esquema do processo de emissão da superfície de uma fonte. 40

Figura 2 - Esquema de hierarquia dos padrões de medição.

Figura 3 - a) Monitor de radiação FH40GX e b) Sonda tipo panqueca FHZ732GM.

Figura 4 - a) Gabarito em papel para fonte $100 \mathrm{~mm} X 150 \mathrm{~mm}$ e b) Gabarito em papel para fonte de $100 \mathrm{~mm} \times 100 \mathrm{~mm}$. .57

Figura 5 - Máscara em alumínio com uma abertura em seu centro. .57

Figura 6 - Arranjo experimental. 58

Figura 7 - Gráficos de distribuição superficial das intensidades das taxas de contagens das fontes extensas de referência de $150 \mathrm{~cm}^{2}$. .59

Figura 8 - Gráficos de distribuição superficial das intensidades das taxas de contagens das fontes extensas de referência de $100 \mathrm{~cm}^{2}$. 60

Figura 9 - Diagrama das divisões em células da fonte extensa de referência circular.

Figura 10 - Distribuição das intensidades das taxas de contagens por unidade de área das fontes extensas de referência circulares.

Figura 11 - Representação geométrica do sistema simulado. .71

Figura 12 - Detalhes da representação do detector, (a) visão geral e (b) detalhes da grade.

Figura 13 - Diagrama esquemático da representação da fonte extensa de referência. .73

Figura 14 - Representação geométrica do sistema simulado para o conjunto detector $15 \mathrm{~mm}$ afastado da fonte. .76

Figura 15 - Comparação entre as taxas de contagens normalizadas em função da distância obtidas experimentalmente e por simulação com MCNP......77 
Figura 16 - Desenho esquemático da sobreposição da área sensível do detector à fonte extensa de referência segmentada em 24 regiões. .80

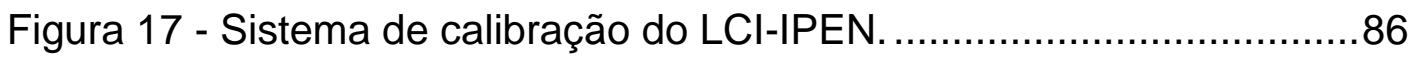

Figura 18 - Itens utilizados no protótipo. 87

Figura 19 - (a) Protótipo do sistema automatizado e (b) roda de posicionamento das fontes extensas de referência. .88

Figura 20 - (a) Projeto do sistema automatizado de calibração e (b) equipamento produzido

Figura 21 - (a) Visão da parte superior do equipamento e (b) detalhe do local de posicionamento da sonda. 89

Figura 22 - Tela inicial do software para calcular os fatores de correção. ..90

Figura 23 - Tela da opção: Quadrada de 100mm x 100 mm. 91

Figura 24 - Tela da opção: Retangular de 100mm x 150mm. 91

Figura 25 - Tela da opção: Circular de $90 \mathrm{~mm}$. 92

Figura 26 - Distribuições de intensidade de emissão da fonte de ${ }^{99} \mathrm{Tc}$ : a) experimental, b) rampa, c) central e d) marginal. 95

Figura 27 - Distribuições de intensidade de emissão da fonte de ${ }^{90} \mathrm{Sr}+{ }^{90} \mathrm{Y}$ : a) experimental, b) rampa, c) central e d) marginal. 96

Figura 28 - Contador Proporcional de pequena dimensão. 125

Figura 29 - (a) Janela do contador proporcional a gás e com janela e (b) parte interna. 126

Figura 30 - Fios que foram substituídos. 127

Figura 31 - Projeto em Solid Edge. 127

Figura 32 - (a) Partes do contador proporcional usinadas e (b) Peças montadas encaixadas. 128

Figura 33 - Contador proporcional com fluxo de gás e sem janela montado. 


\section{LISTA DE TABELAS}

Páginas

Tabela 1 - Características das fontes extensas de referência utilizadas pelo LCI-IPEN para calibração de monitores de radiação de contaminação de superfície. 18

Tabela 2 - Características da filtração adicional para fontes emissoras de radiação gama. .29

Tabela 3 - Principais diferenças entre fontes Classes 1 e 2. 33

Tabela 4 - Resumo das equações que descrevem o instrumento. 38

Tabela 5 - Resumo das equações que descrevem a superfície. 39

Tabela 6 - Fontes utilizadas em calibração de contaminação de superfície.

Tabela 7 - Fontes extensas de referência do LCI-IPEN. .58

Tabela 8 - Tabela das medições de mapeamento da uniformidade da fonte de ${ }^{99} \mathrm{Tc}$ e suas respectivas componentes de incerteza. 62

Tabela 9 - Matriz com a distribuição dos valores de taxa de contagens (cps) obtidos no mapeamento da fonte de ${ }^{14} \mathrm{C}$. .66

Tabela 10 - Matriz dos valores de área ativa da fonte extensa de referência $\left(\mathrm{cm}^{2}\right)$. .66

Tabela 11 - Matriz dos valores de taxa de contagens por unidade de área ativa $\left(\mathrm{cps} . \mathrm{cm}^{-2}\right)$. 66

Tabela 12 - Valores de uniformidade total e parcial (região central) da fonte.

Tabela 13 - Taxa de contagens e taxa de emissão superficial das fontes extensas de referência circulares.

Tabela 14 - Valores calculados de eficiência do instrumento e suas diferenças. 68

Tabela 15 - Especificação dos materiais utilizados na simulação. 71 
Tabela 16 - Dados da distribuição geométrica das fontes não uniformes, onde em vermelho temos a numeração da seção, em preto os dados experimentais e em azul a intensidade de cada porção.

Tabela 17 - Diferenças entre os valores de intensidade obtidos nas simulações.

Tabela 18 - Matriz da distribuição das taxas de contagem da fonte extensa de referência de ${ }^{14} \mathrm{C}$.

Tabela 19 - Matriz da distribuição das taxas de contagem da fonte extensa de referência de ${ }^{14} \mathrm{C}$.

Tabela 20 - Valores de eficiência do instrumento calculados para cada uma das fontes avaliadas.

Tabela 21 - Valores de taxa de contagens obtidos com as simulações e seus respectivos fatores de correção, calculados a partir da diferença. .83

Tabela 22 - Valores de eficiência do instrumento, sem correção, com correção pelo método do NPL e pelo MCNP5.

Tabela 23 - Efeito da variabilidade das fontes de ${ }^{99} \mathrm{Tc}$ e ${ }^{90} \mathrm{Sr}+{ }^{90} \mathrm{Y}$ usando o método MCNP .96

Tabela 24 - Efeito da variabilidade das fontes de ${ }^{99} \mathrm{Tc} e{ }^{90} \mathrm{Sr}_{+}{ }^{90} \mathrm{Y}$ usando o método do NPL. 


\section{SUMÁRIO}

1 INTRODUÇÃO 16

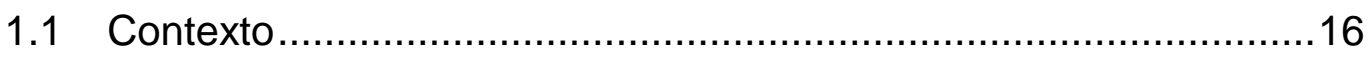

1.2 Justificativa, originalidade e relevância .......................................19

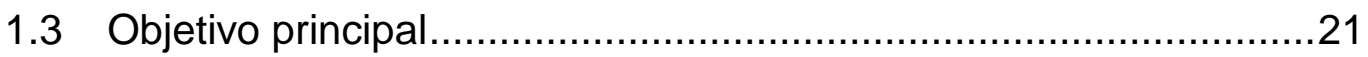

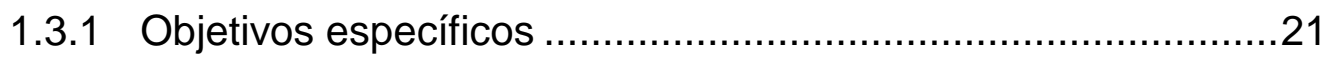

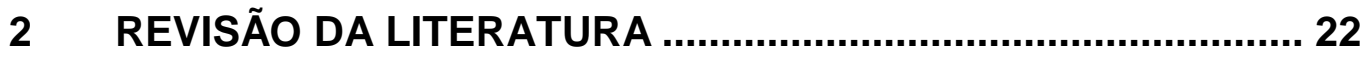

2.1 Revisão de artigos (período 1980 até 2017) …............................22

2.1.1 Calibração de monitores de contaminação de superfície .........22

2.1.2 Caracterização de fontes extensas de referência ....................22

2.1.3 Fabricação e preparação de fontes..........................................25

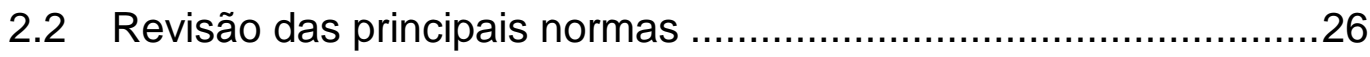

2.2.1 Norma ISO 8769 (1988) - Primeira edição ...............................26

2.2.2 Norma ISO 8769-2 (1996) - Primeira edição ............................27

2.2.3 Norma ISO 8769 (2010) - Segunda edição ............................27

2.2.4 Norma ISO 8769 (2014) - "Draft for Public Comment" ............28

2.2.5 Norma ABNT NBR ISO 8769:2016 …………….................28

2.2.5.1 Especificações das fontes extensas de referência.................28

2.2.5.2 Fontes padrões de referência Classe 1 …...........................30

2.2.5.3 Fontes padrões de referência Classe 2 2...............................32

2.2.6 Norma ISO 7503 (1988 e 1996) - Primeira edição ...................34

2.2.7 Norma ISO 7503 (2014) - "Draft for Public Comment" .............34

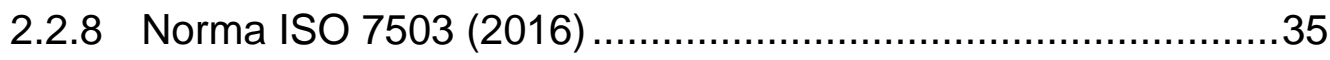

2.2.8.1 Norma ISO 7503-1 / Princípios gerais...................................35

2.2.8.2 Norma ISO 7503-3 / Instrumentos de calibração ...................36 


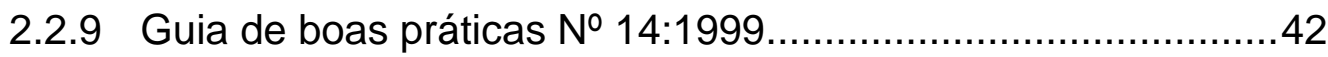

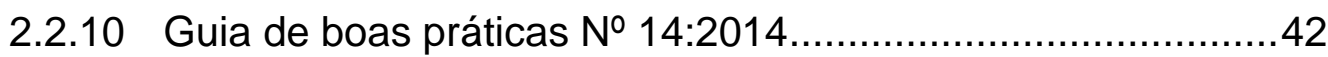

2.2 .11 RT-LCl-001/2011 .................................................... 43

$3 \quad$ FUNDAMENTOS.................................................................. 44

3.1 Proteção Radiológica .........................................................44

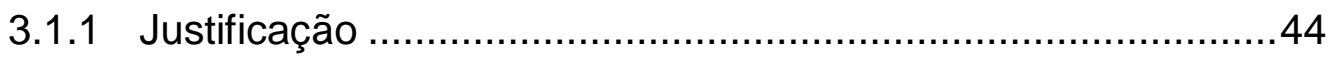

3.1.2 Limitação de dose individual ..........................................44

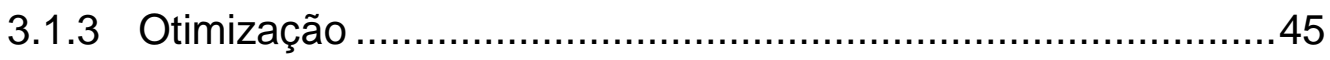

3.2 Contaminação radioativa................................................. 45

3.3 Termos e definições ....................................................... 45

3.3.1 Atividade por unidade de área .....................................45

3.3.2 Taxa de emissão superficial da fonte ..............................46

3.3.3 Eficiência do instrumento .........................................46

3.3.4 Resposta do instrumento em termos da emissão ..................46

3.3.5 Fator de calibração em termos da emissão ........................46

3.3.6 Fator de calibração em termos da atividade .......................46

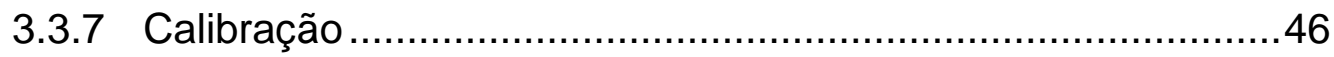

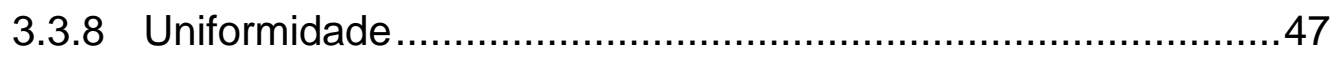

3.3.9 Rastreabilidade de fontes de referência............................47

3.3.10 Tipos de fontes extensas de referência...........................4 47

3.4 Calibração de Monitores de Contaminação de Superfície .............48

3.4.1 Princípio do Método de Calibração ...................................48

3.4.2 Procedimento de Calibração ........................................48

3.5 Principais Detectores de Radiação ........................................49

3.5.1 Contador Geiger-Müller .........................................49

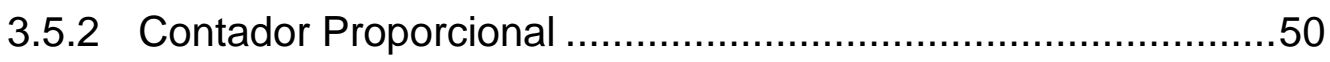


3.6 MCNP - Código de Transporte de Radiação .50

3.7 Arduino 51

4 CRONOLOGIA DO TRABALHO 52

5 AVALIAÇÃO DA UNIFORMIDADE DAS FONTES 55

5.1 Avaliação da Uniformidade das Fontes Retangulares .55

5.1.1 Estimativa de Incertezas 61

5.1.2 Conclusões Específicas 63

5.2 Avaliação de Uniformidade de Fontes Extensas Circulares 64

5.2.1 Mapeamento da Uniformidade ..............................................

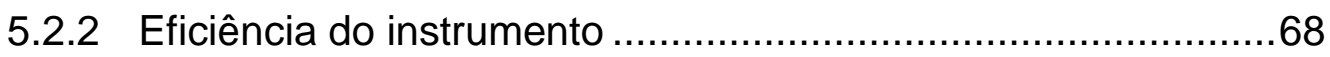

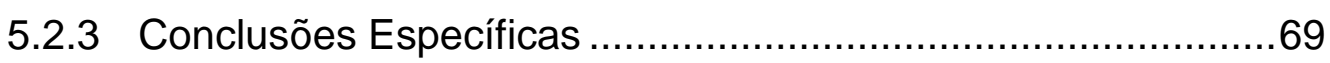

6 DESENVOLVIMENTO EM MCNP............................................... 70

6.1 Descrição do Conjunto Sonda e Suporte Simulados .....................70

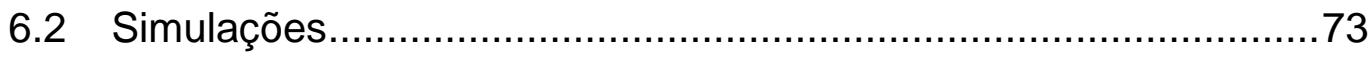

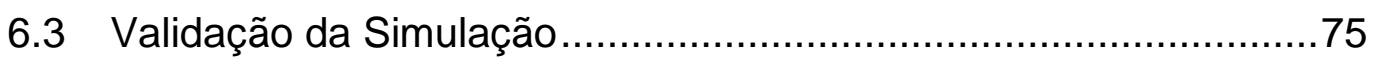

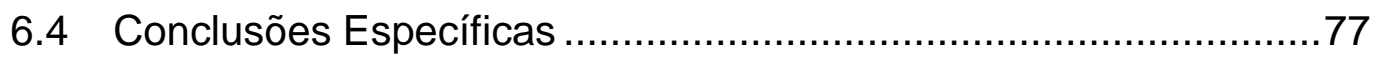

7 COMPARAÇÃO ENTRE DOIS TIPOS DE CORREÇÃO.............. 79

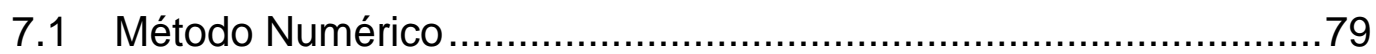

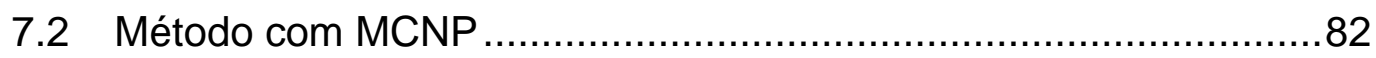

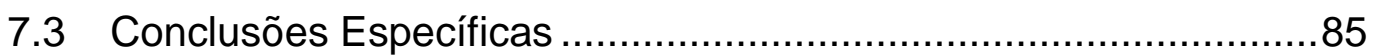

8 NOVA METODOLOGIA DE CALIBRAÇÃO ……........................... 86

8.1 Sistema Automatizado de Calibração ……………………….......86

8.1.1 Sistema de Calibração do LCI-IPEN ........................................86

8.1.2 Protótipo do Sistema Automatizado de Calibração ...................87

8.1.3 Sistema Automatizado de Calibração .......................................8

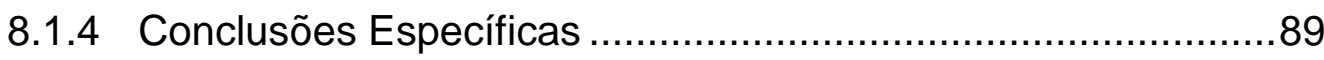


8.2 Software de Cálculo dos Fatores de Correção .89

8.2.1 Conclusões Específicas .......................................................92

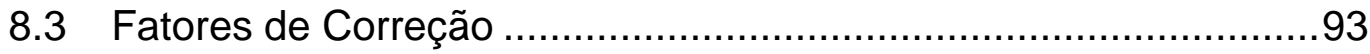

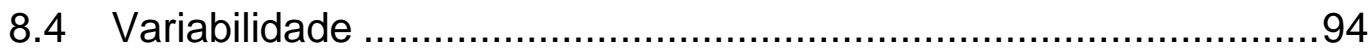

8.5 Método de Calibração Direto .......................................................98

8.6 Cálculo do Fator de Calibração ....................................................99

8.7 Proposta de Nova Metodologia de Calibração ................................99

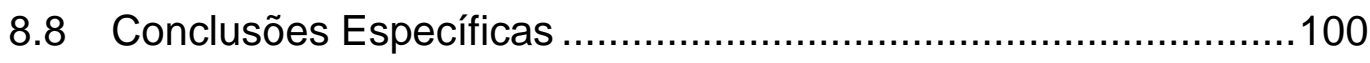

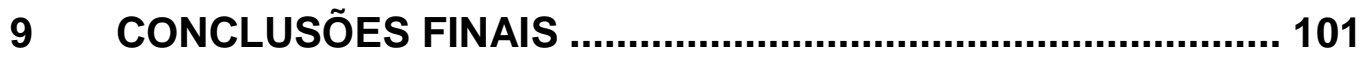

10 REFERÊNCIAS BIBLIOGRÁFICAS ....................................... 103

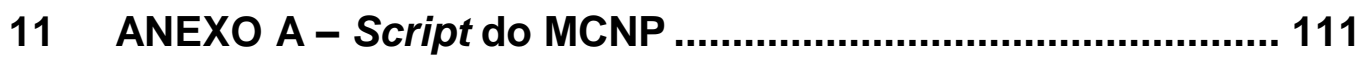

11.1 Input do MCNP ....................................................................

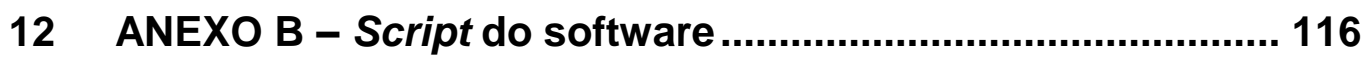

12.1 Cálculo para fonte extensa de referência 100X100 mm. .........116

12.2 Cálculo para fonte extensa de referência $100 \times 150 \mathrm{~mm}$..........118

12.3 Cálculo para fonte extensa de referência $90 \mathrm{~mm}$.....................122

13 ANEXO C - Contador Proporcional ........................................ 125

13.1 Contador Proporcional Comercial .........................................125

13.2 Instrumentação Eletrônica .....................................................126

13.3 Desenvolvimento do Contador Proporcional............................126

13.4 Conclusões Específicas .....................................................128 


\section{INTRODUÇÃO}

\subsection{Contexto}

O Laboratório de Calibração de Instrumentos do IPEN (LCI-IPENCNEN/SP) realiza desenvolvimento de metodologias, pesquisa científica, formação de recursos humanos, e ainda a calibração de instrumentos de dosimetria, que são utilizados em medições de radioproteção, radiodiagnóstico e radioterapia (VIVOLO, 2000; VIVOLO, COSTA, et al., 2000; CALDAS e POTIENS, 1992).

Os monitores de radiação utilizados em radioproteção representam a grande maioria dos testes e calibrações realizadas (DAMATTO, 2015). Entre esses, temos aqueles monitores de radiação de contaminação de superfície, que são utilizados em medições de contaminação de superfície (de equipamentos, pele ou vestimentas), pertencentes principalmente aos serviços de Medicina Nuclear (SMN).

Ao longo dos anos, a medicina nuclear vem vivenciando um crescimento tanto no número de procedimentos realizados, quanto no número de clínicas que oferecem serviços na área (RAMOS, 2014). Para o funcionamento adequado, as clínicas precisam adotar procedimentos de radioproteção que assegurem a integridade física de seus funcionários e dos pacientes. Uma das atividades necessárias é a monitoração da contaminação de superfícies nos locais onde se manipulam radiofármacos ou radiotraçadores. Os instrumentos medidores de radiação utilizados em proteção radiológica devem ter suas respostas testadas satisfatoriamente para cada tipo particular de radiação alfa, beta ou gama. A Norma ISO 8769 (ASSOCIAÇÃO BRASILEIRA DE NORMAS TÉCNICAS, 2016) especifica as principais características das fontes extensas de referência que devem ser utilizadas nos testes operacionais e calibração dos monitores de contaminação de superfície e que devem ser rastreadas a padrões nacionais e/ou internacionais de medições. Para o propósito de testes operacionais e calibração, as fontes de referência devem ser do tipo planas e emissoras de radiação alfa, beta ou gama. A publicação Safety Report Series No.16 (INTERNATIONAL ATOMIC ENERGY AGENCY, 2000), que fornece um guia para o estabelecimento 
de instalações de testes operacionais e calibração de instrumentos seguindo os princípios e práticas aceitos internacionalmente em procedimentos de calibração; também recomenda os tipos de radionuclídeos que devem ser utilizados como referência tanto para a calibração como para os testes de desempenho de instrumentos.

A norma CNEN-NN-3.05 (COMISSÃO NACIONAL DE ENERGIA NUCLEAR, 2013) estabelece os requisitos de radioproteção e de segurança aos Serviços de Medicina Nuclear e aplica-se às atividades relativas ao uso de radiofármacos e radiotraçadores para fins terapêuticos e diagnósticos "in vivo". Esta norma estabelece que o SMN tenha, entre outros equipamentos, um monitor de contaminação de superfície principal e um reserva e que sejam calibrados, em datas distintas a cada dois anos, por um laboratório autorizado pelo órgão competente em metrologia para realizar os ensaios e calibração, assim como devidamente autorizado pela Comissão Nacional de Energia Nuclear (CNEN).

De acordo com os requisitos para operação de um laboratório de calibração de instrumentos (ASSOCIAÇÃO BRASILEIRA DE NORMAS TÉCNICAS, 2005; COMISSÃO NACIONAL DE ENERGIA NUCLEAR, 2011), um laboratório autorizado deve realizar testes e a calibração de instrumentos utilizados para medições de contaminação de superfície com fontes de referência emissoras alfa, beta e gama. No Brasil temos um laboratório designado pelo INMETRO como Laboratório Nacional de Metrologia das Radiações lonizantes (LNMRI/IRD/CNEN/RJ) e seis laboratórios autorizados pelo CASEC/IRD/CNEN: CDTN-CNEN/MG, ELETRONUCLEAR/RJ, IPEN-CNEN/SP, IPR-DEN-UFPE/PE, METROBRAS/SP e LCR-UERJ/RJ) para realizar esta atividade.

As principais características das fontes extensas de referência utilizadas pelo LCI-IPEN estão relacionadas na Tabela 1. As medições das grandezas são referenciadas às fontes de referência produzidas pela Amersham Buchler $\mathrm{GmbH}$ \& Co KG. e calibradas pelo DEUTSCHER KALIBRIERDIENST (DKD), sendo este credenciado pelo laboratório padrão primário PHYSIKALISCH - TECHNISCHE BUNDESANSTALT (PTB), Alemanha. 
Tabela 1 - Características das fontes extensas de referência utilizadas pelo LCI-IPEN para calibração de monitores de radiação de contaminação de superfície.

\begin{tabular}{ccccc}
\hline \multicolumn{5}{c}{ Emissor alfa } \\
\hline Fonte & Área Ativa $\left(\mathrm{cm}^{2}\right)$ & $\begin{array}{c}\text { Taxa de Emissão } \\
\text { Superficial Beta } \\
\left(\mathrm{s}^{-1} \text { em } 2 \pi\right)\end{array}$ & Incerteza (\%) & Data de Referência \\
\hline${ }^{241} \mathrm{Am}$ & 150 & 442 & 26.11 .96 \\
\hline \multicolumn{5}{c}{ Emissores betas } \\
\hline Fonte & Área Ativa $\left(\mathrm{cm}^{2}\right)$ & $\begin{array}{c}\text { Taxa de Emissão } \\
\text { Superficial Beta } \\
\left(\mathrm{s}^{-1} \text { em } 2 \pi\right)\end{array}$ & Incerteza (\%) & Data de Referência \\
\hline${ }^{14} \mathrm{C}$ & 150 & 406 & 26.11 .96 \\
\hline${ }^{99} \mathrm{Tc}$ & 150 & 572 & 5,0 & 13.12 .96 \\
\hline${ }^{36} \mathrm{Cl}$ & 150 & 643 & 5,0 & 14.01 .97 \\
\hline${ }^{137} \mathrm{Cs}$ & 150 & 586 & 5,0 & 26.11 .96 \\
\hline${ }^{90} \mathrm{Sr}+{ }^{90} \mathrm{Y}$ & 150 & 1300 & 5,0 & \\
\hline
\end{tabular}

Fonte: autor da tese.

Os procedimentos de testes e calibrações dos monitores de radiação de contaminação de superfície são realizados com as fontes extensas de referência apresentadas na Tabela 1, independente do tipo do detector utilizado (portátil ou fixo) e estes monitores apresentam geralmente unidades de escala em taxa de contagens e possuem sondas apropriadas ao tipo de radiação medida. Outros parâmetros de influência sobre o processo, como temperatura, pressão e umidade relativa do ar, precisam ser medidos e registrados.

Atualmente, os monitores de radiação de contaminação de superfície são calibrados em um arranjo desenvolvido pelo próprio LCI-IPEN, utilizando-se as fontes extensas de referência alfa e beta, que são posicionadas manualmente no arranjo para se realizar as medições (DIAS e CALDAS, 1990).

O LCI-IPEN é um dos laboratórios autorizados pelo LNMRI que possui arranjos para calibração e testes, nos três níveis de aplicação de monitores de radiação (Radioproteção, Radioterapia e Radiodiagnóstico), com radiações alfa, beta, gama e $\mathrm{X}$, que atende à grande maioria de clientes nestas áreas, por estar localizado no estado de São Paulo.

O aperfeiçoamento de suas metodologias (VIVOLO, 2000) e arranjos (BETTI, 2007; SILVA JR, 2012; SILVA JR, SANTOS e POTIENS, 2011), tem sido uma preocupação constante nos projetos de pesquisa e desenvolvimento no LCl- 
IPEN, proporcionando diversas melhorias em seus processos de testes e calibrações. Nos últimos anos, a utilização de sistemas automatizados e softwares específicos para auxiliar laboratórios de medições, inclusive de calibração de instrumentos vêm aumentando consideravelmente (YEUNG e HUANG, 2003; BEDOGNI e MONTEVENTI, 2005; GARCIA-HERNANDEZ, MONDRAGON-CONTRERAS, et al., 2009).

\subsection{Justificativa, originalidade e relevância}

Um dos problemas identificados na atual metodologia de calibração de monitores de radiação de contaminação de superfície, utilizada pela grande maioria dos laboratórios de calibração de instrumentos, consiste em não considerar o mapeamento da uniformidade ${ }^{1}$ das fontes extensas de referência, utilizadas nesse tipo de calibração.

O mapeamento da uniformidade desse tipo de fonte extensa de referência é um dos itens que deve ser incorporado na metodologia, pois diversos trabalhos mostram a importância dessa caracterização (JANSSEN e KLEIN, 1994; NAHLE e KOSSERT, 2012; VIVOLO e POTIENS, 2010). A norma ISO 8769 (ASSOCIAÇÃO BRASILEIRA DE NORMAS TÉCNICAS, 2016) apresenta como requisitos gerais para as fontes extensas de referência, a necessidade de uma tabela da taxa de emissão relativa de todas as partes individuais relacionando posição e taxa de emissão, mostrando a importância do conhecimento dessa distribuição de intensidade de emissão. Estudos demonstraram problemas de não uniformidade de algumas fontes extensas de referência (VIVOLO e POTIENS, 2010).

Utilizar o mapeamento da uniformidade das fontes extensas de referência será uma importante realização para a qualidade das calibrações e atividades de pesquisa em geral que utilizam essas fontes de referência.

É nesse contexto que foi desenvolvido o projeto, que visa contribuir para melhorar o processo de calibração e testes de monitores de radiação de contaminação de superfície com uma nova metodologia de calibração que

\footnotetext{
${ }^{1}$ Uniformidade de uma fonte é obtida pela diferença entre um (1) e a razão entre o desvio padrão dos valores das porções medidas da fonte pela média desses valores.
} 
considere a caracterização das fontes extensas de referência, assim como demais aspectos que se mostrarem importantes para esse tipo de calibração, apoiada em simulação computacional utilizando o código MCNP como ferramenta, possibilitando uma maior qualidade nos testes, calibrações e uso em experimentos voltados à pesquisa.

A originalidade do trabalho está na proposta de uso de fontes extensas de referência independente dos valores de uniformidade que elas possam ter, desde que se usem fatores de correção, possibilitando assim o uso de fontes que estejam em desacordo com as exigências da norma ABNT ISO 8769:2016 no quesito uniformidade. Essa vantagem irá evitar o descarte de tais fontes por não atenderem a essa exigência, possibilitando um uso por um período maior.

Também visando melhorar o processo de calibração será apresentado o desenvolvimento de um sistema automatizado, para garantir as condições de reprodutibilidade no posicionamento destas fontes extensas de referência, assim como dos instrumentos a serem calibrados.

É um importante passo na proteção radiológica, pois os técnicos responsáveis pelas calibrações não necessitarão mais manipular as fontes de forma direta, uma vez que essas ficarão confinadas dentro do sistema de calibração, sendo posicionadas via controle do sistema.

Existem sistemas comerciais de calibração para outras metodologias, como os sistemas, Beta Secondary Standard (AMBROSI, BUCHHOLZ e HELMSTADTER, 2014), Gamma Beam Irradiators (ATOMTEX, 2014) e o Calibration Facility for Radiological Calibration (PTW, 2014). No entanto ainda não foi identificado no mercado nenhum sistema específico para calibração de monitores de contaminação de superfície, pois um sistema dedicado especifico, proporciona um melhor controle do processo, garantindo a reprodutibilidade.

A experiência na calibração de detectores e monitores de radiação de contaminação de superfície adquirida pelo LCI-IPEN fez com que o laboratório percebesse a necessidade de aprimorar sua atual metodologia a partir dos diversos aspectos particulares desse tipo de calibração. 


\subsection{Objetivo principal}

Desenvolver uma metodologia de calibração de monitores de radiação de contaminação de superfície, que permita o uso de fontes extensas de referência independente de seus valores de uniformidade, desde que seja utilizado fator de correção calculado a partir do mapeamento da fonte.

\subsubsection{Objetivos específicos}

Realizar o mapeamento da uniformidade das fontes extensas de referência, conforme recomenda o Guia de Boas Práticas №14 do National Physical Laboratory (NPL) (LEE e BURGESS, 2014);

Validar uma simulação computacional desenvolvida em código MCNP (TEAM, 2003), com o objetivo de simular as fontes extensas de referência em condições de $100 \%$ uniformes e demais situações de uniformidades.

Desenvolver um sistema automatizado para posicionar as fontes extensas de referência utilizadas nas calibrações.

Desenvolver um software que possibilite o cálculo dos fatores de correção devido aos valores de uniformidade das fontes extensas de referência, melhorando as calibrações e demais atividades de pesquisa desenvolvidas com esse tipo de fonte. 


\section{REVISÃO DA LITERATURA}

\subsection{Revisão de artigos (período 1980 até 2017)}

Diversos artigos foram analisados com o objetivo de compreender 0 avanço do conhecimento nessa área de calibração de monitores de contaminação de superfície que utilizam fontes extensas de referência alfa, beta e gama.

A seguir serão apresentados três grupos de temas e os respectivos artigos relacionados, assim como seus autores:

\subsubsection{Calibração de monitores de contaminação de superfície}

Em 1980 foi publicado um trabalho por Dunscombe, Bhattacharyya e Dunn, apresentando uma preocupação com o crescimento do uso de radionuclídeos em hospitais e com a monitoração de eventuais contaminações de superfície, focando na análise das calibrações dos instrumentos de monitoração de contaminação de superfície (DUNSCORNBE, BHATTACHARYYA e DUNN, 1980).

Em 2012, Yunoki e Hino publicaram um artigo onde relatam uma comparação internacional entre valores de taxa de emissão superficial de uma fonte extensa de referência beta $\left({ }^{36} \mathrm{Cl}\right)$, realizada pelo Programa de Metrologia Ásia-Pacífico (APMP), tendo 7 institutos participantes, todos com contador proporcional a gás e sem janela, mostrando a importância da padronização entre essas medições. Todos os resultados dos participantes concordaram com uma precisão de 1\% (YUNOKI e HINO, 2012).

\subsubsection{Caracterização de fontes extensas de referência}

Sobre esse tema foram publicados diversos artigos em um longo período, mostrando a importância de se fazer uma caracterização das fontes extensas de referência, embora a caracterização não seja utilizada no processo de calibração.

Em 1990, Dias e Caldas publicaram um artigo que apresenta o projeto e construção de um sistema de detecção de radiação alfa e beta, utilizando um 
plástico cintilador, com objetivo de possibilitar o controle das fontes utilizadas na calibração de detectores de contaminação de superfície (DIAS e CALDAS, 1990).

Janssen e Klein publicaram dois artigos juntos sobre o tema. $O$ primeiro artigo foi publicado em 1994, onde é apresenta a caracterização das fontes extensas de referência, por meio de um método relativamente simples para determinar a atividade da fonte extensa de referência alfa com uma incerteza inferior a $10 \%$. Foi utilizado um contador proporcional de grande área para realizar a medição do fluxo de partículas alfa para se chegar a um fator $k$ de correção (JANSSEN e KLEIN, 1994). O segundo artigo, publicado em 1996, relata a caracterização das fontes extensas de referência beta, utilizando um método baseado na medição da taxa de contagens e a distância entre fonte e sonda do detector (JANSSEN e KLEIN, 1996).

Em 1998, Berger publicou um artigo que mostra uma preocupação com a eficiência das fontes extensas de referência beta, procurando realizar uma combinação entre medições experimentais e cálculos de transporte de energia utilizando o método de Monte Carlo, para calcular os valores de eficiência das fontes extensas de referência beta (BERGER, 1998).

Em 2000, Janssen e Thieme apresentaram em detalhes a confecção de fontes extensas de referência, emissoras de radiação alfa, bem como a determinação de sua atividade (JANSSEN e THIEME, 2000).

Stanga e Felice, no ano de 2002, estudaram e determinaram métodos para a realização com exatidão das medições de taxa de emissão de fontes extensas de referência alfa e beta que são utilizadas na calibração de monitores de contaminação de superfície (STANGA e FELICE, 2002).

Em 2006, Sevec, Janssen, et al, propuseram um método de caracterização de fontes extensas de referência alfa e beta, reconhecendo as dificuldades de construção de tais fontes e que problemas de não uniformidade de distribuição da atividade podem causar alterações não só em relação à taxa de emissão de partículas e atividade, mas também nas distribuições de partículas dos espectros emitidos (SVEC, JANSSEN, et al., 2006).

Mostert publicou um artigo em 2008, onde apresenta um equipamento padrão primário desenvolvido para medição de fontes extensas de referência alfa 
e beta, sendo esse um contador proporcional a gás e sem janela. Este equipamento foi validado por comparação entre as medições obtidas com ele e as do NPL em fontes extensas de referência ${ }^{241} \mathrm{Am},{ }^{90} \mathrm{Sr}+{ }^{90} \mathrm{Y},{ }^{36} \mathrm{Cl}$ e ${ }^{14} \mathrm{C}$, mostrando a importância de se ter um padrão primário para medir esse tipo de fonte (MOSTERT, 2008).

Ainda em 2008, Grigorescu, Sahagia, et al, publicaram um artigo apresentando um equipamento padrão para medição de fontes extensas de referência alfa e beta, doado pelo Laboratório Nacional Henri Becquerel (LNHB) da França, sendo utilizado para padronização de fontes extensas de referência alfa e beta (GRIGORESCU, SAHAGIA, et al., 2008).

Em 2009, Stanga e Felice publicaram um artigo que apresenta um método para realizar medição de fontes extensas de referência, onde se considera as condições de fluxo de gás e outros itens em um contador proporcional com a finalidade de diminuir os valores de incertezas nas medições (STANGA e FELICE, 2009).

Em 2010, Vivolo e Potiens apresentaram um método simplificado de caracterização das fontes extensas de referência alfa e beta, utilizadas no processo de calibração de monitores de contaminação de superfície, constatando problemas de não uniformidade de distribuição da atividade em algumas fontes do LCI-IPEN (VIVOLO e POTIENS, 2010).

Nahle e Kossert em 2012 publicaram um procedimento para caracterização de fonte extensa de referência gama em termos de sua atividade, taxa de emissão e uniformidade, considerando modificações sofridas pela norma ISO 8769 em 2010 (INTERNATIONAL ORGANIZATION FOR STANDARDIZATION, 2010). Esse método usou um detector de Nal (lodeto de sódio), um sistema de digitalização e um sistema de radiografia e também foram aplicadas técnicas de Monte Carlo para avaliar a taxa de emissão de superfície. Esse artigo tem uma extrema importância, pois já identifica problemas nas exigências mais rígidas da norma ISO 8769 (2010), como a redução do tamanho de cada porção da fonte que é utilizada para determinação da medição da uniformidade da fonte (de $10 \mathrm{~cm}^{2}$ para $5 \mathrm{~cm}^{2}$ ), além da exigência de $5 \%$ ao invés dos $10 \%$ da versão anterior 
da Norma, para valores de uniformidade da fonte, sugerindo inclusive uma nova revisão (NAHLE e KOSSERT, 2012).

Ainda em 2012, Duarte, Cardoso, et al, realizaram um estudo com o objetivo de determinar a eficiência de detecção de um monitor de contaminação e analisar a influência da distância e da atividade. A eficiência de detecção de um monitor de contaminação portátil é dependente da distância deste à contaminação bem como do tipo de radiação emitida e energia dos radioisótopos presentes na contaminação (DUARTE, CARDOSO, et al., 2012).

Em 2014, Javorník e Svec desenvolveram um método para determinação da atividade de fontes extensas de referência beta. A principal vantagem do método consiste na possibilidade de estimar atividades de fontes seladas reais, tais como revestimento de verniz de espessura conhecida ou desconhecida em um invólucro de proteção, etc. (JAVORNIK e SVEC, 2014).

\subsubsection{Fabricação e preparação de fontes}

Em 2002, Tsoupko-Sitnikov, Picolo, et al publicaram um artigo que demonstra detalhes da confecção das fontes extensas de referência alfa e beta que são utilizadas na calibração de monitores de contaminação de superfície (TSOUPKO-SITNIKOV, PICOLO, et al., 2002).

Sato, Hino, et al, publicaram em 2004 um artigo apresentando uma maneira inovadora de fabricação de fontes extensas em papel utilizando uma impressora jato de tinta, conseguindo uma boa uniformidade da atividade nesse método (SATO, HINO, et al., 2004).

Em 2011, Stanga, Maringer, et al, descreveram um método pelo qual a eficiência de uma fonte extensa de referência é determinada pela medição do coeficiente de transmissão de partículas beta, através de uma folha de alumínio fina, que cobre a fonte. Antes de descrever este método, é definida e calculada a eficiência da fonte e o coeficiente de transmissão. A eficiência foi calculada pelo método de Monte Carlo usando um pacote de simulação PENÉLOPE (STANGA, MARINGER, et al., 2011). 
Stanga em 2012 desenvolveu uma modelagem numérica para construção de fontes extensas de referência beta, que foi utilizado para comparar com as recomendações da ISO 8769 (2010) (STANGA, 2012).

Os autores Kumar, Gandhi, et al, no ano de 2013, apresentaram um novo método de preparação de fontes extensas de referência; o método descrito pode ser usado para preparação de fontes extensas de referência de ampla variedade de radionuclídeos (KUMAR, GANDHI, et al., 2013).

Em 2014 mais uma vez o autor Stanga publicou um novo artigo apresentando um método que utiliza a simulação de transporte de energia baseado no método de Monte Carlo, para determinar a atividade de fontes extensas de referência beta; o modelo foi validado com dados experimentais, embora ainda precise de mais pesquisas (STANGA, 2014).

\subsection{Revisão das principais normas}

As normas internacionais ABNT ISO 8769 (ASSOCIAÇÃO BRASILEIRA DE NORMAS TÉCNICAS, 2016) e ISO 7503 (BRITISH STANDARD INTERNATIONAL, 2016; BRITISH STANDARD INTERNATIONAL, 2016), descritas a seguir são particularmente dirigidas para a determinação da radioatividade presente em superfícies sólidas.

A norma ISO 8769 está voltada às especificações das fontes utilizadas nas calibrações de instrumentos utilizados em medição de contaminação de superfície, enquanto a ISO 7503 está voltada à medição de áreas contaminadas, assim como aos aspectos envolvidos nas calibrações de instrumentos utilizados nessas medições.

No anexo 3 é apresentada uma comparação entre as principais mudanças ocorridas nessas normas de forma mais detalhada.

\subsubsection{Norma ISO 8769 (1988) - Primeira edição}

Essa norma estabelece critérios e características das fontes de referência: 
ISO 8769 - Reference sources for the calibration of surface contamination monitors - Beta-emitters (maximum beta energy greater than 0,15 MeV) and alpha-emitters.

Nessa versão a uniformidade da fonte extensa de referência devia ser melhor que 10\%, para Classes 1 e 2 (INTERNATIONAL ORGANIZATION FOR STANDARDIZATION, 1988).

\subsubsection{Norma ISO 8769-2 (1996) - Primeira edição}

Essa norma estabelece critérios e características das fontes de referência, tendo sido acrescidas as fontes de fótons:

ISO 8769-2 - Reference sources for the calibration of surface contamination monitors - Part 2: Electrons of energy less than 0,15 MeV and photons of energy less than 1,5 MeV.

Essa versão manteve os valores de uniformidade definidos na versão anterior (INTERNATIONAL ORGANIZATION FOR STANDARDIZATION, 1996)

\subsubsection{Norma ISO 8769 (2010) - Segunda edição}

BS ISO 8769:2010 - Reference sources - Calibration of surface contamination monitors - Alpha, beta and photon emitters.

Essa norma é uma revisão da ISO 8769-2 (1996), procurando detalhar melhor diversos pontos da primeira edição. Foram incluídos itens como:

Atualização das referências normativas;

Foi especificado o tamanho das porções que podem ser utilizadas na medição da uniformidade das fontes extensas de referência e;

Foram alterados os valores de uniformidade das fontes extensas de referência Classe 1 para melhor que $5 \%$ e manteve Classe 2 para melhor que 10\% (INTERNATIONAL ORGANIZATION FOR STANDARDIZATION, 2010). 


\subsubsection{Norma ISO 8769 (2014) - "Draft for Public Comment"}

Reference sources - Calibration of surface contamination monitors - Alpha, beta and photon emitters.

Essa proposta de revisão da segunda edição visa corrigir alguns pontos da versão anterior, como valores de uniformidade e tamanho das porções utilizadas para o mapeamento da uniformidade.

O valor de uniformidade da fonte extensa de referência Classe 1 voltou ao valor de melhor que $10 \%$, assim como a Classe 2 .

O tamanho das porções utilizadas para medir a uniformidade da fonte, foram alteradas de $5 \mathrm{~cm}^{2}$ para $10 \mathrm{~cm}^{2}$ o valor máximo, além de melhorar o detalhamento do procedimento de medição.

Outra modificação importante foi o valor exigido para eficiência do instrumento de transferência de referência, sendo que esse valor antes deveria ser melhor que $50 \%$ e nesta revisão passou a ser melhor que 35\%, utilizando um contador proporcional de grande área, sem janela e com fluxo de gás controlado (INTERNATIONAL ORGANIZATION FOR STANDARDIZATION, 2014).

\subsubsection{Norma ABNT NBR ISO 8769:2016}

ABNT NBR ISO 8769:2016 - Fontes de referência - Calibração de monitores de contaminação de superfície - Emissores de alfa, beta e fótons.

Serão detalhadas as principais informações da norma que está atualmente em vigor e que serviram de guia para este trabalho.

\subsubsection{Especificações das fontes extensas de referência}

Nesta revisão da norma, as fontes de referência para calibração de monitores de contaminação de superfície podem ser especificadas em dois tipos:

a) Fontes com um revestimento de material eletricamente condutor, com um dado radionuclídeo permanentemente depositado em apenas um dos lados; a espessura do material de revestimento deve ser suficiente para evitar a emissão da radiação de partículas através da parte traseira da fonte. 
b) Fontes com uma camada de material dentro do qual está um radionuclídeo distribuído uniformemente e com espessura pelo menos igual à espessura da camada de saturação da radiação de partículas. Para fins do padrão da norma, a atividade da fonte deve ser tomada como a atividade contida dentro de uma camada superficial de espessura igual à espessura da camada de saturação.

As fontes extensas emissoras gama devem incorporar filtros especiais para serem utilizadas na calibração de monitores de contaminação de superfície. As características destas fontes descritas pela norma e os respectivos filtros estão relacionados na Tabela 2.

Tabela 2 - Características da filtração adicional para fontes emissoras de radiação gama.

\begin{tabular}{ccccc}
\hline $\begin{array}{c}\text { Valor aproximado } \\
\text { da energia média } \\
\text { do fóton }(\mathrm{keV})\end{array}$ & Radionuclídeo & $\begin{array}{c}\text { Meia-vida } \\
\text { (dias) }\end{array}$ & $\begin{array}{c}\text { Material dos } \\
\text { filtros }\end{array}$ & Espessura dos filtros \\
\hline 5,9 & ${ }^{55} \mathrm{Fe}$ & $1,00 \times 10^{3}$ & sem & \\
\hline 16 & ${ }^{238} \mathrm{Pu}$ & $3,20 \times 10^{4}$ & zircônio & $0,05 \mathrm{~mm}-32,5 \mathrm{mg} \cdot \mathrm{cm}^{-2}$ \\
\hline 32 & ${ }^{129} \mathrm{I}$ & $5,88 \times 10^{9}$ & alumínio & $0,03 \mathrm{~mm}-81 \mathrm{mg} \cdot \mathrm{cm}^{-2}$ \\
\hline 60 & ${ }^{241} \mathrm{Am}$ & $1,58 \times 10^{5}$ & aço inox & $0,25 \mathrm{~mm}-200 \mathrm{mg} \cdot \mathrm{cm}^{-2}$ \\
\hline 124 & ${ }^{57} \mathrm{Co}$ & 272 & aço inox & $0,25 \mathrm{~mm}-200 \mathrm{mg} \cdot \mathrm{cm}^{-2}$ \\
\hline 660 & ${ }^{137} \mathrm{Cs}$ & $1,10 \times 10^{4}$ & aço inox & $1 \mathrm{~mm}-800 \mathrm{mg} \cdot \mathrm{cm}^{-2}$ \\
\hline 1250 & ${ }^{60} \mathrm{Co}$ & $1,93 \times 10^{3}$ & alumínio & $0,3 \mathrm{~mm}-81 \mathrm{mg} \cdot \mathrm{cm}^{-2}$ \\
\hline
\end{tabular}

Fonte: Adaptado da norma ABNT NBR ISO 8769:2016 pelo autor da tese.

Fontes extensa de referência devem ser adequadas a sua finalidade e o fabricante tem a responsabilidade de determinar e relatar as impurezas radioativas e garantir que a utilização da fonte não seja comprometida pelas emissões a partir de qualquer impureza. Todas as impurezas radioativas com uma atividade de pelo menos $1 \%$ da atividade do radionuclídeo principal devem ser determinadas e registradas.

Em relação às fontes que podem conter impurezas radioativas, os usuários devem ter em devida conta que o nível relativo da impureza muda com o tempo e pode produzir um efeito significativo sobre a taxa de emissão da fonte. 


\subsubsection{Fontes padrões de referência Classe 1}

Com o objetivo de manter os requisitos especificados na Norma internacional, as fontes Classe 1 devem ter área ativa de pelo menos $10^{4} \mathrm{~mm}^{2}$, sendo os tamanhos recomendados de $100 \mathrm{~mm} \times 100 \mathrm{~mm}, 100 \mathrm{~mm} \times 150 \mathrm{~mm}$ e $150 \mathrm{~mm} \times 200 \mathrm{~mm}$.

As fontes emissoras de radiação gama devem incluir a filtração especificada na Tabela 2. A filtração deve ser uma parte integrante da fonte e não deve ser removível. A área do filtro deve ser tal que se estenda por pelo menos $10 \mathrm{~mm}$ além da área ativa da fonte. A espessura da filtração deve estar dentro de $10 \%$ do valor especificado na Tabela 2.

As fontes devem ser acompanhadas de um certificado de calibração com as seguintes informações:
a) Radionuclídeo ${ }^{2}$;
b) Número de identificação da fonte;
c) Taxa de emissão superficial e sua incerteza;
d) Atividade e sua incerteza;
e) Data de referência, deve ser idêntica para os itens (c) e (d);
f) Dimensões da fonte e medição de sua área ativa;
g) Natureza, espessura, densidade e dimensões do substrato;
h) Natureza, espessura, densidade e dimensões da filtração (quando tiver);
i) Uniformidade e incerteza;
j) Classe da fonte.

A atividade de uma fonte de referência Classe 1 deve possibilitar uma taxa de emissão superficial de aproximadamente $2000 \mathrm{~s}^{-1}$ a $10000 \mathrm{~s}^{-1}$ para otimizar a relação entre radiação de fundo, incerteza estatística e o erro de tempo morto. A atividade deve ser indicada com uma incerteza relativa não superior a $10 \%(k=1)$.

\footnotetext{
${ }^{2}$ Devem constar os valores de meia-vida e outros dados nucleares que são fornecidos pelo Decay Data Evaluation Project (DDEP) (ASSOCIAÇÃO BRASILEIRA DE NORMAS TÉCNICAS, 2016).
} 
A medição da taxa de emissão superficial deve ser realizada em um instituto de metrologia nacional com uma incerteza relativa não superior a:

a) $3 \%$ para fontes alfa;

b) $3 \%$ para fontes beta com energia máxima superior a $150 \mathrm{keV}$;

c) $5 \%$ para fontes beta com energia máxima inferior a $150 \mathrm{keV}$;

d) $10 \%$ para as fontes gama.

As fontes de referência Classe 1 devem ser recalibradas em termos da atividade, taxa de emissão e uniformidade superficial com uma frequência de pelo menos uma vez a cada quatro anos ${ }^{3}$.

A uniformidade de uma fonte deve ser expressa como o desvio padrão das taxas de emissão superficial das porções individuais de toda a fonte dividida pelo valor médio destas taxas de emissão.

A uniformidade de uma fonte de referência menos sua incerteza padrão relativa ${ }^{4}$ deve ser superior a $90 \%$.

Para especificar a uniformidade de uma fonte em relação às taxas de emissão superficial por unidade de área, a fonte deve ser considerada como tendo um número de porções de igual área e forma. Para fontes retangulares, a forma das porções deve ser retangular também.

A área das porções deve ser de $10 \mathrm{~cm}^{2}$ ou menos. Para as dimensões recomendadas na norma, uma fonte de referência com área ativa de $100 \mathrm{~cm}^{2}$ será dividida em 16 partes quadradas e uma fonte de $150 \mathrm{~cm}^{2}$ será dividida em 16 partes retangulares.

As taxas de emissão individuais devem ser determinadas com uma incerteza relativa consistente com a especificada para toda a fonte. Estas incertezas devem ser consideradas no cálculo do desvio padrão experimental para determinar a incerteza da uniformidade da fonte como um todo.

\footnotetext{
${ }^{3}$ A frequência de recalibração de uma fonte de referência pode ser diferente de país para país, dependendo das regulamentações nacionais.

${ }^{4}$ No item 5.1.1 (Estimativa de Incertezas) é apresentada a fórmula para calcular a incerteza padrão relativa.
} 
A medição da uniformidade pode ser realizada usando as técnicas de placa de imagem, sistemas de medição sensível de posição, ou através da inserção de uma placa como máscara entre a fonte e o detector. A máscara deve ter uma abertura de dimensão que proporcione uma proteção suficiente do detector. Para a técnica que usa a placa como máscara, deve-se ter o cuidado de usar sempre a mesma porção do detector para minimizar os efeitos devido à possível falta de uniformidade da resposta à radiação através da superfície do detector. Para as outras técnicas, deve-se tomar cuidado para minimizar os efeitos devidos à possível falta de uniformidade da eficiência de detecção em todo o detector.

No Anexo 2 da norma são fornecidas mais orientações sobre as medições de uniformidade e as incertezas associadas à sua utilização, quando a área da janela do detector é menor que a área ativa da fonte.

No Anexo 3 são fornecidas orientações para situações em que a área da janela do detector é menor do que a área da fonte ativa, sendo possível evitar a obrigação de ter um conhecimento detalhado da uniformidade ao se caracterizar a fonte.

NOTA 1- Quando a maior dimensão de uma fonte não for maior que $5 \mathrm{~cm}$ não é necessário determinar a uniformidade.

NOTA 2- É de responsabilidade do laboratório de ensaio poder utilizar uma fonte de referência com as características que se encaixam às do equipamento utilizado e do propósito da medição. Assim, deve-se tomar muito cuidado se as áreas parciais são usadas para calibrar detectores menores do que a superfície da fonte de referência por causa da influência de áreas vizinhas.

As fontes de referência Classe 1 devem ser preparadas, se possível, a partir de qualquer um dos radionuclídeos das Tabelas 1, 2 e 3 da norma.

\subsubsection{Fontes padrões de referência Classe 2}

As fontes de referência Classe 2 deverão cumprir os mesmos requisitos gerais conforme especificado para fontes de referência Classe 1. Elas devem fornecer a mesma informação que as fontes de referência Classe 1 e devem ser acompanhadas cada uma de um certificado de calibração. 
A taxa de emissão de uma fonte de referência Classe 2 deve ser conforme requerido pelo usuário e depende do tipo de instrumento a ser calibrado e o teste particular a ser realizado. A atividade deve ter sido determinada de maneira que permita a rastreabilidade ao Sistema Internacional de Unidades (SI) e deve ser indicada com uma incerteza relativa não superior a 10\% $(\mathrm{k}=1)$. A taxa de emissão superficial será determinada por meio de um instrumento de transferência de referência com uma incerteza relativa não superior a:

a) $5 \%$ para fontes alfa;

b) $5 \%$ para fontes beta com energia de máxima superior a $150 \mathrm{keV}$;

c) $10 \%$ para fontes beta com energia máxima inferior a $150 \mathrm{keV}$;

d) $15 \%$ para as fontes gama.

As fontes de referência Classe 2 devem ser recalibradas em termos de atividade, taxa de emissão e uniformidade superficial com uma frequência de pelo menos uma vez a cada quatro anos.

A uniformidade de uma fonte de referência Classe 2 menos sua incerteza padrão relativa deve ser superior a $90 \%$.

As fontes de referência Classe 2 serão preparadas a partir dos mesmos radionuclídeos previstos para as fontes de referência Classe 1 .

A Tabela 3 apresenta um resumo das principais diferenças entre as fontes classe 1 e 2, sendo apresentado os métodos de calibração de cada tipo de fonte e suas respectivas incertezas.

Tabela 3 - Principais diferenças entre fontes Classes 1 e 2.

\begin{tabular}{cccc}
\hline & Fontes Classe 1 & Fontes Classe 2 \\
\hline \multirow{2}{*}{ Método de calibração } & $\begin{array}{c}\text { Taxa de emissão deve ser } \\
\text { medida em um } \\
\text { laboratório primário }\end{array}$ & $\begin{array}{c}\text { Taxa de emissão deve ser } \\
\text { determinada por instrumento de } \\
\text { transferência de referência }\end{array}$ \\
\hline Incertezas & Alfa & $3 \%$ & $3 \%$ \\
\cline { 2 - 4 } & Beta & $3 \%($ Energia $>150 \mathrm{keV})$ & $5 \%$ (Energia $>150 \mathrm{keV})$ \\
\cline { 2 - 4 } & Beta & $5 \%($ Energia $<150 \mathrm{keV})$ & $10 \%$ (Energia $<150 \mathrm{keV})$ \\
\hline
\end{tabular}

Fonte: Adaptado da norma BS ISO 8769:2016 pelo autor da tese. 


\subsubsection{Norma ISO 7503 (1988 e 1996) - Primeira edição}

Esta edição é composta por três partes distintas que especifica detalhes da medição de contaminação de superfícies para intervalos de energias diferentes e estão divididas da seguinte forma:

ISO 7503-1 (1988) Beta-emitters (maximum beta energy greater than $0,15 \mathrm{MeV}$ ) and alpha-emitters (INTERNATIONAL ORGANIZATION FOR STANDARDIZATION, 1988).

ISO 7503-2 (1988) Tritium surface contamination (INTERNATIONAL ORGANIZATION FOR STANDARDIZATION, 1988).

ISO 7503-3 (1996) Isomeric transition and electron capture emitters, low energy beta-emitters $\left(E_{\beta m a ́ x}<0,15 \mathrm{MeV}\right.$ ) (INTERNATIONAL ORGANIZATION FOR STANDARDIZATION, 1996).

\subsubsection{Norma ISO 7503 (2014) - "Draft for Public Comment"}

Esta revisão da primeira edição do documento apresenta uma diferença grande já na disposição das três partes:

ISO 7503-1 (2014) General principles (INTERNATIONAL ORGANIZATION FOR STANDARDIZATION, 2014).

ISO 7503-2 (2014) Test method using wipe-test samples (INTERNATIONAL ORGANIZATION FOR STANDARDIZATION, 2014).

ISO 7503-3 (2014) Apparatus calibration (INTERNATIONAL ORGANIZATION FOR STANDARDIZATION, 2014).

Este documento tem uma preocupação com a estimativa e medição dos níveis de radioatividade, não apresentando orientações sobre técnicas de descontaminação de áreas contaminadas.

A contaminação de superfície é especificada em termos de atividade por área e os limites são baseados nas recomendações da Comissão Internacional de Proteção Radiológica (INTERNATIONAL COMMISSION ON RADIATION PROTECTION, 2007). 
Esta norma aplica-se à radiação alfa, beta e gama e destina-se para uso em hospitais, universidades, polícia e estabelecimentos industriais, além de poder ser utilizada em qualquer setor que utilize materiais radioativos.

No geral a norma ISO 7503 é utilizada para contaminações em superfícies planas e bem definidas, mas pode ser utilizada para superfícies que não sejam planas; neste caso se utiliza o método indireto (esfregaço).

Esta norma não é indicada para situações de emergências, nem para instalações nucleares, avaliação de contaminação da pele, de roupas e materiais soltos, como cascalho.

\subsubsection{Norma ISO 7503 (2016)}

Esta revisão da primeira edição foi extremamente ampla, pois praticamente gerou um novo documento, muito mais completo.

A seguir serão detalhados os principais pontos das partes 1 e 3 desta norma, que se aplicam diretamente ao escopo deste trabalho, não iremos tratar aqui a parte 2, que está voltada ao método do teste de esfregaço.

\subsubsection{Norma ISO 7503-1 / Princípios gerais}

BS ISO 7503-1:2016 - Measurement of radioactivity - Measurement and evaluation of surface contamination Part 1: General principles.

Esta parte da norma trata principalmente da avaliação da contaminação de superfície por medição direta, utilizando instrumentos medidores de contaminação de superfície.

Apresenta os princípios de calibração de instrumentos de medição de contaminação de superfície.

O objetivo das medições de contaminação de superfície é identificar a presença de contaminação superficial, podendo ser utilizado o método de medição direta ou indireta (esfregaço).

O método de medição direto é o melhor a ser utilizado, quando possível. 
Neste método pode-se manter a sonda fixa ou em movimento sobre a área contaminada a uma distância não inferior a 3mm (BRITISH STANDARD INTERNATIONAL, 2016).

\subsubsection{Norma ISO 7503-3 / Instrumentos de calibração}

BS ISO 7503-1:2016 - Measurement of radioactivity — Measurement and evaluation of surface contamination Part 3: Apparatus calibration.

Esta terceira parte da norma está centrada no detalhamento de uma metodologia de calibração específica para determinados radionuclídeos, considerando suas devidas correções.

Fornece métodos de calibração simplificados, mas que são conservadores em relação aos requisitos de proteção radiológica.

O método de calibração considera que haverá apenas um único decaimento do radionuclídeo, ou seja, que ocorre uma única emissão de partícula por decaimento, por exemplo, para uma emissão beta puro, decai diretamente para o estado fundamental do radionuclídeo filho.

Se um detector infinitamente fino de um monitor ideal, com uma sonda de área eficaz $A_{P}$, é colocado diretamente sobre a superfície a ser monitorada, 0 detector apenas detectaria partículas vindas da superfície diretamente sob 0 instrumento.

A probabilidade de uma partícula que emerge a partir da superfície é dada por $\mathrm{p}_{\mathrm{e}}$ e cada partícula que chega ao instrumento é detectada com uma probabilidade k, que para simplificação é considerado como sendo independente da energia da partícula.

Para calibrar o monitor ideal, ele é colocado sobre uma fonte de calibração com taxa de emissão superficial conhecida $R_{c}$ e área de superfície $S_{c}$ (com área maior que a janela do detector), área da sonda $\left(S_{p}\right)$ e eficiência do instrumento $(\varepsilon)$. Essa fonte deve ter uma área superficial maior ou igual à da janela da sonda. Considerando que a taxa de contagem da radiação de fundo (BG) seja zero, a taxa de contagem observada será: 


$$
\rho_{c}=\varepsilon \frac{R_{c}}{S_{c}} S_{p}
$$

Se a atividade da fonte de calibração é $A_{c}$, pode ser visto que $R_{c}=A_{c}$. $p_{c}$, onde $p_{c}$ é a probabilidade de uma partícula emergir de cima da fonte extensa de referência e a fórmula torna-se:

$$
\rho_{c}=\varepsilon \frac{A_{c} \cdot p_{c}}{S_{c}} S_{p}
$$

O instrumento é agora colocado sobre uma superfície que é contaminada uniformemente (que tem área maior que a janela do detector) com o mesmo radionuclídeo que a fonte de calibração, a taxa de contagem observada é:

$$
\rho^{\prime}=\varepsilon \frac{R^{\prime}}{S^{\prime}} S_{p}
$$

Onde o primeiro termo $\left(\rho^{\prime}\right)$ relaciona-se a contaminação da superfície.

A taxa de emissão por unidade de área da superfície contaminada é dada por:

$$
\frac{R^{\prime}}{S^{\prime}}=\rho^{\prime}\left(\frac{A_{c}}{S_{c}}\right)\left(\frac{p_{c}}{\rho_{c}}\right)
$$

Considerando que a atividade sobre a superfície contaminada está relacionada com medição da taxa de emissão, $R^{\prime}=A_{S}{ }^{\prime} \cdot p_{\mathrm{e}}{ }^{\prime}$, é evidente que:

$$
\frac{A_{S}^{\prime}}{S^{\prime}}=\rho^{\prime} \cdot \frac{1}{p_{e}^{\prime}}\left(\frac{A_{c}}{S_{c}}\right)\left(\frac{p_{c}}{\rho_{c}}\right)
$$

Pode ser visto que as equações acima contêm termos que descrevem o instrumento ( $\varepsilon$ e $S_{p}$ ) e que descrevem a superfície monitorada $\left(\mathrm{p}_{\mathrm{e}}\right)$. O último termo é relacionado com o fator- $\mathrm{P}$, que será definido adiante. 
As grandezas nas fórmulas podem ser combinadas para se conseguir um parâmetro que descreva o instrumento. $O$ fator de resposta do instrumento é um parâmetro que descreve a superfície a ser monitorada. $O$ fator de resposta do instrumento tem sido definido de várias maneiras ao longo do tempo.

A Tabela 4 apresenta um resumo das equações que descrevem o instrumento. Três das definições apresentadas nesta tabela são independentes da natureza da superfície da fonte de calibração com a condição de que os fatores de resposta são determinados utilizando fontes de calibração que emitem uma única partícula por decaimento. Contudo, a atividade relacionada à resposta do instrumento $I(A)$ e a atividade relacionada com o fator de calibração $C(A)$ dependem ambas das características do instrumento e da natureza da superfície da fonte de calibração (descrito por $p_{c}$ ).

Tabela 4 - Resumo das equações que descrevem o instrumento.

\begin{tabular}{cccc}
\hline Definição & Símbolo & Fórmula & Descrição \\
\hline $\begin{array}{c}\text { Eficiência do } \\
\text { Instrumento }\end{array}$ & $\varepsilon$ & $\varepsilon=\rho_{\mathrm{c}} \cdot\left(\frac{S_{\mathrm{c}}}{R_{\mathrm{c}}}\right) \cdot\left(\frac{1}{S_{\mathrm{p}}}\right)$ & $\begin{array}{c}\text { Eficiência do instrumento = taxa de contagens } \\
\text { observada por taxa de emissão superficial abaixo da } \\
\text { janela do detector }\end{array}$ \\
\hline $\begin{array}{c}\text { Resposta do } \\
\text { Instrumento } \\
\text { (Emissão) }\end{array}$ & $\mathrm{I}(\mathrm{E})$ & $I(E)=\varepsilon \cdot S_{\mathrm{p}}=\rho_{\mathrm{c}} \cdot\left(\frac{S_{\mathrm{c}}}{R_{\mathrm{c}}}\right)$ & $\begin{array}{c}\text { Eficiência do instrumento vezes a área da janela }= \\
\text { taxa de contagens observada pela taxa de emissão } \\
\text { superfícial por unidade de área }\end{array}$ \\
\hline $\begin{array}{c}\text { Resposta do } \\
\text { Instrumento } \\
\text { (Atividade) }\end{array}$ & $\mathrm{I}(\mathrm{A})$ & $I(A)=\varepsilon \cdot S_{\mathrm{p}} \cdot p_{\mathrm{c}}=\rho_{\mathrm{c}} \cdot\left(\frac{S_{\mathrm{c}}}{R_{\mathrm{c}}}\right) \cdot p_{\mathrm{c}}$ & $\begin{array}{c}\text { Eficiência do instrumento vezes a área da janela } \\
\text { vezes a probabilidade da partícula ter saído da } \\
\text { superficie da fonte e taxa de contagens observada por }\end{array}$ \\
\hline $\begin{array}{c}\text { Fator de } \\
\text { Calibração } \\
\text { (Emissão) }\end{array}$ & $\mathrm{C}(\mathrm{E})$ & $C(E)=\frac{1}{\varepsilon \cdot S_{\mathrm{p}}}=\frac{1}{\rho_{\mathrm{c}}} \cdot\left(\frac{R_{\mathrm{c}}}{S_{\mathrm{c}}}\right)$ & $\begin{array}{c}\text { Inverso da eficiência do instrumento vezes a área da } \\
\text { janela }\end{array}$ \\
\hline $\begin{array}{c}\text { Fator de } \\
\text { Calibração } \\
\text { (Atividade) }\end{array}$ & $\mathrm{C}(\mathrm{A})$ & $C(A)=\frac{1}{\varepsilon \cdot S_{\mathrm{p}} \cdot p_{\mathrm{c}}}=\frac{1}{\rho_{\mathrm{c}}} \cdot\left(\frac{R_{\mathrm{c}}}{S_{\mathrm{c}}}\right) \cdot \frac{1}{p_{\mathrm{c}}}$ & $\begin{array}{c}\text { Inverso da eficiência do instrumento vezes a área da } \\
\text { janela vezes a probabilidade da partícula ter saído } \\
\text { da superfície da fonte }\end{array}$ \\
\hline
\end{tabular}

Fonte: Adaptado da norma BS ISO 7503-3:2016 pelo autor da tese.

A Tabela 5 apresenta a grandeza e a equação que descrevem a superfície: 
Tabela 5 - Resumo das equações que descrevem a superfície.

\begin{tabular}{ccc}
\hline Grandeza & Símbolo & Descrição \\
\hline $\begin{array}{c}\text { Taxa de emissão superficial da } \\
\text { fonte de calibração }\end{array}$ & $\mathrm{R}_{\mathrm{C}}$ & Taxa de emissão superficial de partículas ou fótons \\
\hline Fator-P & $P\left(=\frac{1}{P_{e}}\right)$ & Inverso da probabilidade de emissão da partícula \\
\hline
\end{tabular}

Fonte: Adaptado da norma BS ISO 7503-3:2016 pelo autor da tese.

As definições do Fator-P citado neste item da norma serão descritas a seguir:

Fator-P para radionuclídeos com esquema de decaimento simples:

Para fins de radioproteção, é necessário determinar os níveis de contaminação em termos de becquerel por centímetro quadrado $\left.(\mathrm{Bq} \mathrm{cm})^{-2}\right)$. No entanto, geralmente não é possível calibrar o instrumento monitor de radiação diretamente em termos de Bq. $\mathrm{cm}^{-2}$, porque a atividade da fonte de calibração não é conhecida: apenas sua taxa de emissão superficial pode ser determinada com precisão e é feita com base em normas nacionais e internacionais.

O processo de medição descrito fornece o resultado em termos da resposta do instrumento ou eficiência de detecção, mas estes não são grandezas úteis para o usuário final na maioria das circunstâncias.

O conceito do fator-P foi inicialmente introduzido no desenvolvimento do guia de boas práticas (LEE e BURGESS, 2014), sendo que o fator-P basicamente é o inverso de $p_{e}$.

"O fator- $P$ é a razão entre a atividade por unidade de área de uma fonte e sua taxa de emissão superficial por unidade de área", que é uma simplificação para uso somente em ambiente de calibração.

O fator-P foi definido no guia de boas práticas para converter a medição de taxa de emissão de radionuclídeo monoenergético de fonte de calibração de referência em medição da atividade.

Cada fonte de calibração de referência deve ter um único tipo de radionuclídeo com uma única emissão com probabilidade de 100\%. 
O fator-P pode ser utilizado de maneira muito simples para realizar esta conversão.

A ilustração na Figura 2 mostra os diversos processos de emissão a partir de uma superfície contaminada que são utilizados para estimar o fator- $P$.

Figura 1 - Esquema do processo de emissão da superfície de uma fonte.

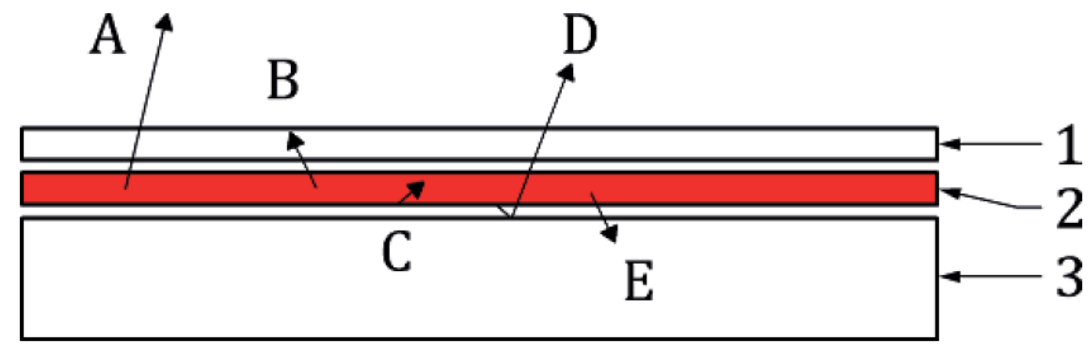

Fonte: (BRITISH STANDARD INTERNATIONAL, 2016)

A = Partícula/fóton emitido da superfície;

$\mathrm{B}=$ Partícula/fóton absorvido na sujeira da superfície;

C = Partícula/fóton absorvido na camada ativa;

$\mathrm{D}$ = Partícula/fóton que volta por espalhamento do substrato;

$\mathrm{E}=$ Partícula/fóton absorvido no substrato;

$1=$ Sujeira superficial;

2 = Camada ativa;

$3=$ Substrato

$\mathrm{Na}$ situação ideal, em que a contaminação ocorre em uma camada infinitamente fina e que não é absorvida para dentro da superfície em que se encontra, de modo que nenhuma das emissões sofre atenuação emergindo da superfície, e não há nenhum efeito de espalhamento, exatamente metade das emissões resultante das desintegrações radioativas surgirão com probabilidade de entrar no detector. Para os casos em que há apenas uma emissão por desintegração, o fator-P tem um valor igual a 2 (dois) e a atividade por unidade de área é o dobro da taxa de emissão por unidade de superfície fornecida pela resposta do detector. 
Fator-P para radionuclídeos com esquema de decaimento complexo:

A maioria dos radionuclídeos não apresentam esquemas de decaimento simples, e podem ter múltiplos decaimentos até o estado fundamental, incluindo a emissão de fótons, elétrons de conversão e emissões secundárias tais como raios-X e elétrons Auger. Para qualquer evento único de decaimento, também é possível que ocorra mais do que uma emissão, por exemplo, uma partícula beta seguida por um fóton.

O instrumento pode detectar qualquer ou todas as emissões provenientes de um único decaimento, mas apenas um evento é registrado, enquanto várias emissões ocorrem ao mesmo tempo. Esta é a principal razão do porquê interpretar leituras de instrumentos de contaminação de superfície é complexo, uma vez que significa que é incorreto somar as probabilidades de detecção para todas as emissões sem correção para o somatório.

Ao estimar o fator de calibração apropriado $\left(\mathrm{em} \mathrm{Bq} \cdot \mathrm{cm}^{-2} \cdot \mathrm{s}^{-1}\right)$ por um radionuclídeo particular, é necessário ter em conta as probabilidades das várias emissões, o efeito da superfície de cada emissão independente e a probabilidade de detecção em coincidência de qualquer ou todas as emissões de um único decaimento. A estimativa de um fator de resposta do instrumento adequado para a maioria dos radionuclídeos, portanto, é uma questão complexa, porque não é possível aplicar o mesmo fator-P para cada emissão envolvida na desintegração e na verdade a definição simplista do fator-P não é adequada aqui.

$\mathrm{Na}$ prática, as altas incertezas na medição podem ser toleradas, porque normalmente as medições podem ser realizadas apenas com objetivo de triagem ou confirmação. No entanto, ainda é necessário entender os processos físicos envolvidos e os algoritmos de estimativa para verificar que erros grosseiros não estão sendo feitos. A discussão a seguir é destinada a fornecer uma abordagem genérica que coloca estas estimativas em uma base sólida.

Um fator adicional ("fator de emergência") deve ser introduzido, para caracterizar a relação entre as emissões individuais para a fração das emissões, que emergem da superfície.

Este fator é definido como $E_{i, e}$, para a emissão do tipo i $(\alpha, \beta$ ou $\gamma$ ) com energia e. Cada emissão pode ser estimada com um valor apropriado para o $E_{i, e}$, 
combinando a probabilidade de emissão por decaimento com os efeitos combinados de todos as emissões na desintegração, considerando a probabilidade de detecções coincidentes.

\subsubsection{Guia de boas práticas № 14:1999}

Measurement Good Practice Guide №14 - The Examination, Testing \& Calibration of Portable Radiation Protection Instruments.

Este documento do NPL descreve os procedimentos recomendados para o exame, teste e calibração de instrumentos medidores de radiação portáteis. Foi desenvolvido para auxiliar nesses procedimentos.

Apresentam métodos gerais para os responsáveis pela calibração dos instrumentos de proteção radiológica, que podem ser modificados de acordo com a necessidade, para atender à sua finalidade específica desde que se esteja convencido de que a qualidade do teste ou calibração não seja comprometida.

Já é apresentada nesse documento uma forma de correção do fluxo de emissão devido à não uniformidade da fonte extensa de referência e uma justificativa do uso de fontes de área grande, para de se buscar uma geometria de plano semi-infinito (SCOTT, BURGESS e WOODS, 1999).

\subsubsection{Guia de boas práticas № 14:2014}

Measurement Good Practice Guide №14 Issue 2 - The Examination, Testing \& Calibration of Portable Radiation Protection Instruments.

Nessa revisão do guia do NPL o item mais importante fica por conta do Apêndice 5 que trata da falta de uniformidade das fontes extensas de referência, mostrando de forma detalhada, o procedimento de mapeamento da uniformidade de uma fonte extensa de referência e a maneira de calcular um fator de correção para o fluxo de emissão da fonte, para a região que será utilizada no procedimento de calibração do monitor de contaminação de superfície, visando minimizar os efeitos da não uniformidade da fonte extensa de referência (LEE e BURGESS, 2014). 


\subsubsection{RT-LCI-001/2011}

Requisitos Técnicos para Certificação de Laboratório de Calibração de Instrumentos de Medição para Radiação lonizante usados em Radioproteção.

Com o objetivo de estabelecer os requisitos para avaliação e certificação de laboratórios que prestam serviços de calibração de instrumentos de medição empregados para fins de radioproteção, no ano de 2011, o Comitê de Avaliação de Serviços de Ensaios e Calibração (CASEC) publicou um documento, RT-LCI00I/2011 com as principais recomendações. De acordo com este documento os requisitos específicos para a calibração de monitores de contaminação alfa, beta e/ou gama $(\alpha, \beta$ e/ou $\gamma)$ inclui a utilização de fontes de radiação extensas, uniformes e de grande área e indica os radionuclídeos que devem ser utilizados para cada tipo de radiação, como mostra a Tabela 6 . As fontes radioativas devem ser acompanhadas de certificado de calibração estabelecendo a taxa de emissão superficial rastreadas aos padrões nacionais ou internacionais.

Tabela 6 - Fontes utilizadas em calibração de contaminação de superfície.

\begin{tabular}{cccc}
\hline Alfa & Beta & \multicolumn{2}{c}{ Gama } \\
\hline Radionuclídeo & Radionuclídeo & Radionuclídeo & Filtro $\left(\mathrm{mg} / \mathrm{cm}^{2}\right)$ \\
\hline${ }^{241} \mathrm{Am}$ & ${ }^{14} \mathrm{C}$ & ${ }^{55} \mathrm{Fe}$ & - \\
\hline${ }^{239} \mathrm{Pu}$ & ${ }^{147} \mathrm{Pm}$ & ${ }^{238} \mathrm{Pu}$ & $32,5 \mathrm{Al}$ \\
\hline${ }^{238} \mathrm{U}$ & ${ }^{204} \mathrm{Tl}$ & ${ }^{129} \mathrm{l}$ & 81 aço inox \\
\hline & ${ }^{36} \mathrm{Cl}$ & ${ }^{241} \mathrm{Am}$ & 200 aço inox \\
\hline${ }^{90} \mathrm{Sr} /{ }^{90} \mathrm{Y}$ & ${ }^{57} \mathrm{Co}$ & 200 aço inox \\
\hline & & ${ }^{137} \mathrm{Cs}$ & 800 aço inox \\
\hline
\end{tabular}

Fonte: autor da tese.

As fontes radioativas devem ser acompanhadas de certificado de calibração estabelecendo a taxa de emissão superficial rastreadas aos padrões nacionais ou internacionais (COMISSÃO NACIONAL DE ENERGIA NUCLEAR, 2011). 


\section{FUNDAMENTOS}

\subsection{Proteção Radiológica}

A Proteção Radiológica tem como seu principal objetivo proporcionar um padrão de proteção ao ser humano sem limitar os benefícios da utilização dos diversos tipos de radiações ionizantes. A International Comissiono $\mathrm{n}$ Radiation Protection (ICRP) (INTERNATIONAL COMMISSION ON RADIATION PROTECTION, 2007) estabelece recomendações de proteção radiológica que servem como base para programas e regulamentações mais completas emitidas por outras organizações internacionais e nacionais.

No Brasil, a autoridade regulatória na área nuclear é a CNEN, referência na área de radioproteção e responsável pela publicação das normas que regulamentam a utilização da radiação ionizante no Brasil.

O monitoramento de contaminação de superfície pela radiação ionizante é importante devido à dificuldade de avaliar a dose individual a partir de uma contaminação.

Os três princípios básicos que descrevem a radioproteção são:

\subsubsection{Justificação}

Nenhuma prática ou fonte associada a essa prática será aceita, a não ser que essa prática produza benefícios, para os indivíduos expostos ou para a sociedade em geral, de forma a compensar o dano causado (COMISSÃO NACIONAL DE ENERGIA NUCLEAR, 2014).

\subsubsection{Limitação de dose individual}

A exposição normal dos indivíduos deve ser restringida de tal modo que nem a dose efetiva nem a dose equivalente nos órgãos ou tecidos de interesse, causadas pela possível combinação de exposições originadas por práticas autorizadas, excedam o limite de dose especificada em norma da CNEN-NN-3.01. Esses limites de dose não se aplicam às exposições médicas. 


\subsubsection{Otimização}

Em exposições causadas por uma determinada fonte associada a uma prática, com exceção para os casos de exposições médicas, a proteção radiológica deve ser otimizada o máximo possível, o número de pessoas expostas e a probabilidade de ocorrência de exposições devem ser os menores possíveis, tendo em conta os fatores econômicos e sociais. Nesse processo de otimização devem ser observados que as doses nos indivíduos decorrentes de exposição à fonte devem estar sujeitas às restrições de dose relacionadas a essa fonte.

\subsection{Contaminação radioativa}

Contaminação radioativa consiste na presença de material radioativo em local indevido, podendo ocorrer no meio ambiente, nos lugares públicos, nas pessoas, etc.

A contaminação de superfície pode ser estimada de forma direta ou indireta, sendo utilizados monitores de radiação de contaminação de superfície para detectar a contaminação, que pode ser fixa ou removível (BRITISH STANDARD INTERNATIONAL, 2016).

\subsection{Termos e definições}

Serão utilizados os termos e definições dados pelas normas ABNT ISO 8769 (ASSOCIAÇÃO BRASILEIRA DE NORMAS TÉCNICAS, 2016) e ISO 7503 (BRITISH STANDARD INTERNATIONAL, 2016; BRITISH STANDARD INTERNATIONAL, 2016).

\subsubsection{Atividade por unidade de área}

É a razão entre a atividade de um radionuclídeo presente em uma superfície e a área da superfície, expressa em becquerel por centímetro quadrado. 


\subsubsection{Taxa de emissão superficial da fonte}

É o número de partículas ou fótons de um determinado tipo, acima de uma dada energia, que emergem da face da fonte ou da sua janela por unidade de tempo sem influência do ambiente.

\subsubsection{Eficiência do instrumento}

É a razão entre a leitura corrigida do instrumento (contagens por unidade de tempo, após subtração da radiação de fundo) e a taxa de emissão superficial da fonte (partículas ou fótons emitidas por unidade de tempo) para uma geometria especifica em relação à fonte.

\subsubsection{Resposta do instrumento em termos da emissão}

É a eficiência do instrumento vezes a área da janela do detector. É igual à taxa de contagens líquida observada pela taxa de emissão superficial por unidade de área de uma fonte de calibração.

\subsubsection{Fator de calibração em termos da emissão}

É o inverso da eficiência do instrumento, vezes a área da janela do detector, $\left(C(E)=\frac{1}{\varepsilon \cdot S_{p}}\right)$.

\subsubsection{Fator de calibração em termos da atividade}

É o inverso da eficiência do instrumento, vezes a área da janela do detector vezes a probabilidade da partícula deixar a superfície da fonte, $\left(C(A)=\frac{1}{\varepsilon \cdot S_{p} \cdot P_{c}}\right)$.

\subsubsection{Calibração}

É o conjunto de operações que estabelece, sob condições especificadas, a relação entre os valores indicados por um instrumento ou sistema de medição e 
os valores correspondentes das grandezas estabelecidas por padrões de referência.

\subsubsection{Uniformidade}

A uniformidade de uma fonte deve ser expressa como o desvio-padrão das taxas de emissão superficial das diversas partes (frações) da fonte dividido pelo valor médio destas taxas de emissão.

\subsubsection{Rastreabilidade de fontes de referência}

O seguinte esquema é proposto para garantir que os padrões de trabalho utilizados no campo para a calibração de rotina de monitores de contaminação de superfície estejam relacionados a padrões de medição nacionais por meio de uma cadeia de rastreabilidade claramente definida, usando fontes de referência e instrumentos de transferência de referência.

Figura 2 - Esquema de hierarquia dos padrões de medição.

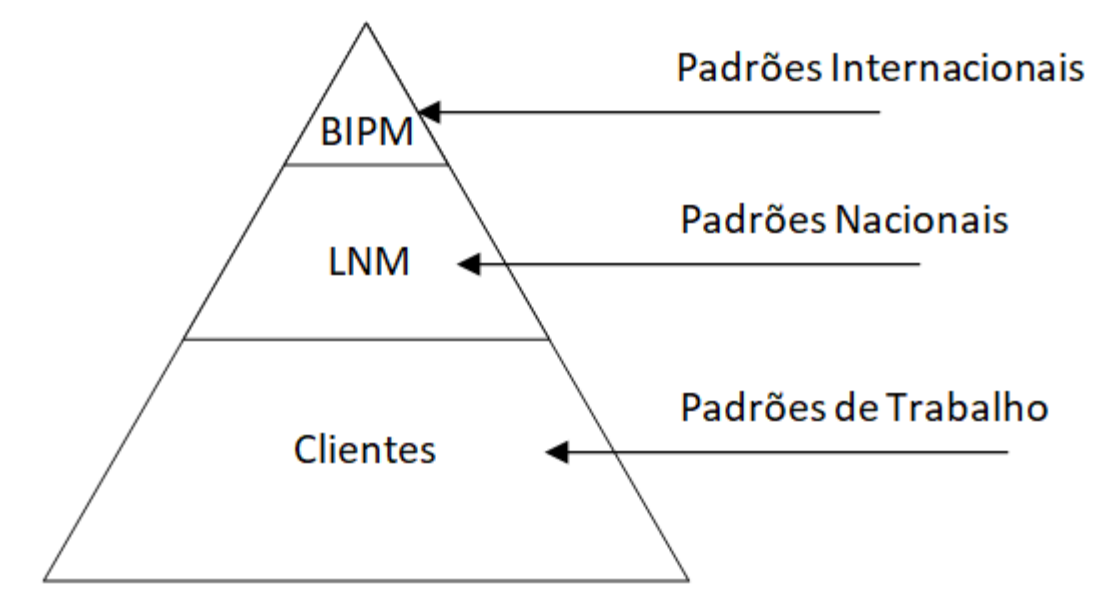

Fonte: autor da tese.

\subsubsection{Tipos de fontes extensas de referência}

As fontes extensas de referência podem ser de dois tipos:

Classe 1: fontes que foram calibradas diretamente em termos de taxa de emissão superficial em um instituto nacional ou internacional de metrologia. 
Classe 2: fontes que foram calibradas em termos de taxa de emissão superficial com um instrumento de transferência de referência, cuja eficiência tenha sido medida por calibração com uma fonte extensa de referência Classe 1 do mesmo radionuclídeo, de características construtivas similares, utilizando a mesma geometria, em um laboratório acreditado para estas medições pela ABNT NBR ISO 17025, conforme especificado na NBR ISO 8769 (ASSOCIAÇÃO BRASILEIRA DE NORMAS TÉCNICAS, 2016) .

\subsection{Calibração de Monitores de Contaminação de Superfície}

\subsubsection{Princípio do Método de Calibração}

O princípio do método de calibração de monitores de contaminação de superfície é definido considerando um esquema de decaimento simples (uma única emissão por desintegração), como por exemplo o decaimento de um emissor beta puro que decai diretamente ao estado fundamental do radionuclídeo filho. Para calibrar um monitor, ele é colocado sobre uma fonte de calibração (fonte extensa de referência) de taxa de emissão de superfície conhecida e com área ativa maior que a área da janela do detector (BRITISH STANDARD INTERNATIONAL, 2016).

\subsubsection{Procedimento de Calibração}

Um procedimento de calibração de um instrumento medidor de contaminação de superfície deve conter uma avaliação física do instrumento e se possível uma calibração eletrônica, para análise da linearidade das escalas. A fonte deve ser posicionada a uma distância de $3 \mathrm{~mm}$ em relação à janela do detector. Recomenda-se pelo menos uma fonte de radiação alfa, três fontes de radiação beta pura (baixa, média e alta energia) e três fontes de fótons ${ }^{5}$ (baixa, média e alta energia).

\footnotetext{
${ }^{5}$ Normalmente não são realizadas as calibrações com fontes extensas de referência de fótons por dificuldades na aquisição desse tipo de fonte e pela baixa eficiência para esse tipo de radiação em monitores do tipo panqueca, que são os mais utilizados.
} 


\subsection{Principais Detectores de Radiação}

Detectores de radiação são dispositivos que, colocados em um meio onde exista um campo de radiação, sejam capazes de indicar a sua presença. Existem diversos processos para medir ou indicar características das radiações, sendo que os mais utilizados são os que envolvem a geração de cargas elétricas, geração de luz, sensibilização de películas fotográficas, criação de traços (buracos) no material, geração de calor e alteração da dinâmica de certos processos químicos. Normalmente um detector de radiação é constituído de um elemento ou material sensível à radiação e um sistema que transforma esses efeitos em um valor relacionado a uma grandeza de medição dessa radiação.

\subsubsection{Contador Geiger-Müller}

Os detectores Geiger-Müller, ou mais comumente chamados de "contador/detector Geiger", foram introduzidos em 1928 e em função de sua simplicidade, baixo custo, facilidade de operação e manutenção, continuam sendo amplamente utilizados até hoje.

Uma característica é apresenta pulsos de saída de igual amplitude, independente do número de íons iniciais; o detector Geiger-Müller funciona como um contador, não sendo capaz de discriminar energias. Para cada partícula que interage com o volume sensível do detector, é criado um número da ordem de $10^{9}$ a $10^{10}$ pares de íons. Assim, a amplitude do pulso de saída formado no detector é da ordem de volts, o que permite simplificar a construção do detector, eliminando a necessidade de um pré-amplificador.

Para a contagem de partículas carregadas, a maior dificuldade é a sua absorção nas paredes do detector. Por esse motivo, são feitas janelas de material leve e fino, que permitam que elétrons e partículas a penetrem no volume sensível do detector.

Para radiação gama, a resposta do detector ocorre de forma mais indireta, através das interações da radiação incidente com as paredes do detector, gerando radiação secundária (normalmente elétrons) que vai interagir com o volume sensível do detector. 
Embora os detectores Geiger não tenham condições de medir nenhuma grandeza radiológica e nem a energia das radiações, eles podem ser utilizados para estimar grandezas como dose e exposição, ou suas taxas, utilizando artifícios de instrumentação e metrologia.

\subsubsection{Contador Proporcional}

Os detectores proporcionais foram introduzidos no início dos anos 40 . Operam quase sempre no modo pulso e baseiam-se no fenômeno de multiplicação de íons no gás para amplificar o número de íons originais criados pela radiação incidente. Os pulsos originados são muitas vezes maiores do que aqueles das câmaras de ionização e, por esse motivo, os detectores proporcionais são muito convenientes para as medições de radiação onde o número de pares de íons é muito pequeno para permitir uma operação satisfatória de uma câmara de ionização.

Dessa forma, uma das aplicações importantes de detectores proporcionais são a detecção e a espectroscopia de raios $X$, elétrons de baixa energia $e$ radiação alfa.

Os detectores proporcionais são construídos na maior parte das vezes de forma cilíndrica. O motivo é que, para uma mesma tensão, o uso de fios finos como anodos pode criar campos elétricos muito maiores do que se forem utilizados anodos em forma de placas.

Alguns tipos especiais de detectores proporcionais são de grande utilidade para usos específicos. Um deles é o detector $4 \pi$, onde a fonte é totalmente inserida dentro do volume sensível, o que permite uma eficiência de contagem de praticamente $100 \%$ para radiações de baixa energia (ordem de até dezenas de $\mathrm{keV})$.

\subsection{MCNP - Código de Transporte de Radiação}

O MCNP é um código de transporte de radiação baseado no método de Monte Carlo para realizar estimativas das respostas dos sistemas simulados. 
O método de Monte Carlo se baseia em amostragens aleatórias massivas para obter resultados numéricos, isto é, repetindo sucessivas simulações em um elevado número de vezes para calcular probabilidades.

O MCNP utiliza o método de Monte Carlo para modelar as interações das radiações com objetos a partir de funções de probabilidades para diferentes interações possíveis, conseguindo fornecer soluções de sistemas macroscópicos através de simulações das interações microscópicas (CAVALIERI, 2013).

\subsection{Arduino}

O Arduino é uma plataforma eletrônica de computação física aberta, baseada em placas simples de entradas/saídas (input/output - I/O) e com um ambiente de desenvolvimento próprio.

O Arduino é uma pequena placa de microcontrolador contendo um plugue de conexão USB que permite a ligação com um computador. Além disso, contém diversos outros terminais que permitem a conexão com dispositivos externos, como motores, relés, sensores luminosos, diodos a laser, alto-falantes e outros. A placa do Arduino pode ser energizada por um computador através do plugue USB, por uma bateria de $9 \mathrm{~V}$ ou por uma fonte de alimentação. Eles podem ser controlados diretamente pelo computador, ou então podem ser programados pelo computador e, em seguida, desconectados, permitindo assim trabalharem independentemente do computador. O projeto da placa é aberto (Open Source), isso significa que qualquer um pode construir placas compatíveis com o Arduino, possibilitando o desenvolvimento de placas de baixo custo (SARTORI, MOLINA, et al., 2015). 


\section{CRONOLOGIA DO TRABALHO}

Com o objetivo de facilitar a compreensão será apresentado a ordem cronológica de alguns eventos, que vão ajudar a entender os rumos que o trabalho foi tomando na medida em que avançava e tivemos diversos acontecimentos simultâneos.

2010 - É publicada uma nova versão da norma ISO 8769 (INTERNATIONAL ORGANIZATION FOR STANDARDIZATION, 2010), sendo essa muito restritiva em suas exigências e recomendações.

2011 - É publicada uma nova versão da norma IEC 62363 (BRITISH STANDARD INTERNATIONAL, 2011), sendo essa norma específica para monitores de radiação gama (fóton), embora não tenha sido realizada uma análise detalhada dessa norma, pois tanto essa quanto a IEC 60325:2002 (BRITISH STANDARD INTERNATIONAL, 2002) (específica para monitores alfa, beta e alfa/beta), são muito mais voltadas aos testes e ensaios de monitores e medidores de radiação nas suas exigências na parte técnica, para fabricantes.

2014 - É publicada uma nova versão do Guia de Boas Práticas №14 (LEE e BURGESS, 2014) pelo NPL, detalhando a forma de realizar o mapeamento da uniformidade e descrevendo um método de correção do fluxo de emissão das fontes extensas de referência por conta da falta de uniformidade.

2014 - São publicados os drafts de revisão das normas ISO 8769 e ISO 7503 (BRITISH STANDARD INTERNATIONAL, 2016; BRITISH STANDARD INTERNATIONAL, 2016), mudando quase por completo a ISO 7503; ambas as normas foram mais detalhadas.

2016 - São publicadas as versões finais das normas ISO 8769 (ASSOCIAÇÃO BRASILEIRA DE NORMAS TÉCNICAS, 2016) e ISO 7503 (BRITISH STANDARD INTERNATIONAL, 2016; BRITISH STANDARD INTERNATIONAL, 2016), que demonstram uma preocupação em uniformizar os procedimentos, detalhando quase tudo que recomendam e exemplificando nos seus anexos. 
O intervalo de tempo entre 2010 e 2016 foi de extrema importância para os documentos da área de contaminação de superfície, sendo possível constatar pelas diversas revisões realizadas nesse período.

A proposta da tese foi definida em 2013, ou seja, pouco após a publicação da revisão da norma ISO 8769:2010 (INTERNATIONAL ORGANIZATION FOR STANDARDIZATION, 2010) e antes das publicações das revisões da norma ISO 7503 (BRITISH STANDARD INTERNATIONAL, 2016; BRITISH STANDARD INTERNATIONAL, 2016) e do documento Guia de Boas Práticas №14 (LEE e BURGESS, 2014) e uma nova revisão da norma ISO 8769. Por isto é possível dizer que esse trabalho começa tomando por base a ISO 8769:2010 como referência e com a vantagem dessa revisão da norma ser muito recente.

Em apenas um ano após o início desse trabalho de doutorado, praticamente todas as normas importantes para a área de contaminação de superfície sofreram grandes alterações, obrigando aos que utilizam essas normas a estudarem todas as modificações.

Em 2016 todas as principais normas já foram publicadas com todas as suas alterações.

Foi nesse contexto que esse trabalho foi se desenvolvendo.

A proposta inicial que se manteve até o término foi buscar uma metodologia de calibração de monitores de radiação de contaminação de superfície que permitisse a utilização de fontes extensas de referência independente de seus valores de uniformidade.

Simultaneamente ao desenvolvimento desse trabalho, o Guia de Boas Práticas №14 do NPL, traz na sua revisão de 2014, um método para corrigir o fluxo de emissão das fontes extensas de referência, utilizando o mapeamento da uniformidade como base.

Em um primeiro momento, parecia ser o mesmo que estava sendo feito nesse trabalho, mas depois ficou claro que ambas as propostas foram desenvolvidas por caminhos diferentes, pois o Guia de Boas Práticas №14 (LEE e BURGESS, 2014) traz um método que corrige o fluxo de emissão da fonte extensa de referência sob a área sensível da sonda, enquanto o método 
desenvolvido nesse trabalho corrige a taxa de contagens medida pela sonda, como será apresentado adiante.

A vantagem do método utilizando o MCNP é poder conferir mais segurança aos resultados, porque consegue simular situações impossíveis de serem obtidas por experimentos e tendo valores de incertezas muito baixos também.

Uma observação importante é que o NPL no Guia de Boas Práticas №14 (LEE e BURGESS, 2014) não faz qualquer comentário sobre seu método poder ser utilizado para fontes extensas de referência que não atendam as recomendações da norma ISO 8769 (ASSOCIAÇÃO BRASILEIRA DE NORMAS TÉCNICAS, 2016), quanto aos valores de uniformidade das fontes. 


\section{AVALIAÇÃO DA UNIFORMIDADE DAS FONTES}

\subsection{Avaliação da Uniformidade das Fontes Retangulares}

Com o objetivo de confirmar problemas de baixa uniformidade ${ }^{6}$ encontrados nas fontes extensas de referência utilizadas pelo LCI-IPEN (VIVOLO e POTIENS, 2010), foi realizado um mapeamento da uniformidade dessas fontes.

Nessa etapa do trabalho existia um conflito entre duas propostas de mapeamento, definidas em dois documentos, o Guia de Boas Práticas № 14:1999 (SCOTT, BURGESS e WOODS, 1999) que definia as porções da fonte como tendo que ser iguais ou menores que $10 \mathrm{~cm}^{2}$, enquanto a nova edição da ISO 8769:2010 (INTERNATIONAL ORGANIZATION FOR STANDARDIZATION, 2010) dizia que essas porções deveriam ser iguais ou menores que $5 \mathrm{~cm}^{2}$. Optou-se por seguir as recomendações do Guia de Boas Práticas e foram definidos porções de $6,25 \mathrm{~cm}^{2}(2,5 \mathrm{~cm} \times 2,5 \mathrm{~cm})$, pois realizar as medidas com porções muito pequenas era muito difícil, considerando que seria utilizado um monitor do tipo panqueca (Geiger) e nesse caso os valores de taxa de contagens seriam muito baixos.

Com as novas versões da norma ISO 8769:2016 (ASSOCIAÇÃO BRASILEIRA DE NORMAS TÉCNICAS, 2016) e o Guia de Boas Práticas №14:2014 (LEE e BURGESS, 2014), a escolha se mostrou acertada, pois esse valor de $5 \mathrm{~cm}^{2}$ passou a ser de $10 \mathrm{~cm}^{2}$ em ambos os documentos.

Uma questão importante na realização do mapeamento das fontes foi às definições da técnica e do tipo de detector que seriam adotados. Por questões de simplicidade e facilidade, foi escolhida a técnica que utiliza uma máscara sobre a fonte extensa de referência e uma sonda do tipo panqueca (Geiger-Müller); essas escolhas também se mostraram adequadas, uma vez que a nova versão do Guia de Boas Práticas №14:2014 apresenta essa forma de realizar o mapeamento da uniformidade de forma bem detalhada (LEE e BURGESS, 2014).

O valor de uniformidade da fonte extensa de referência nas versões anteriores da Norma ABNT ISO 8769:2016 (ASSOCIAÇÃO BRASILEIRA DE NORMAS TÉCNICAS, 2016) era calculado pela razão entre o desvio padrão das medidas das porções individuais pela média da taxa de contagens desses

\footnotetext{
${ }^{6}$ Fontes com baixa uniformidade são as que não atendem as recomendações da Norma ABNT ISO 8769:2016, ou seja, as que tem valor de uniformidade inferior à $90 \%$.
} 
valores, sendo expresso esse resultado em porcentagem, os valores de uniformidade deveriam ser menores que $10 \%$.

A partir da última versão da Norma ABNT ISO 8769:2016 (ASSOCIAÇÃO BRASILEIRA DE NORMAS TÉCNICAS, 2016), esse cálculo sofreu uma pequena mudança, sendo necessário fazer $100 \%$ menos o valor obtido pelo método anterior, assim o novo valor teria que ser melhor que $90 \%$ de uniformidade, é uma mudança sutil, mas que melhora o entendimento dos valores de uniformidade.

Nesse trabalho será utilizado o termo homogeneidade como sinônimo de uniformidade, porque foi utilizado inicialmente o termo homogeneidade e depois passou a ser utilizado o termo uniformidade.

Para a realização do mapeamento da uniformidade da fonte extensa de referência, foram utilizados: um monitor de radiação de contaminação de superfície da Thermo, modelo FH40GX e uma sonda tipo panqueca modelo FHZ732GM ( Figura 3).

Figura 3 - a) Monitor de radiação FH40GX e b) Sonda tipo panqueca FHZ732GM.

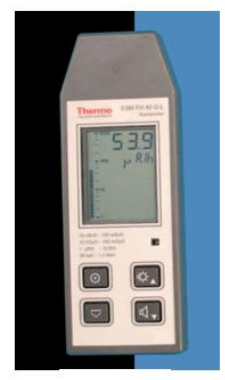

a)

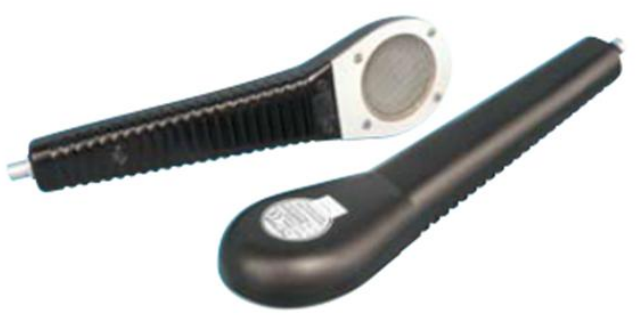

b)

Fonte: autor da tese.

Foram feitos dois gabaritos em papel com o objetivo de marcar as porções a serem medidas, conforme mostra a Figura 4. 
Figura 4 - a) Gabarito em papel para fonte $100 \mathrm{~mm} X 150 \mathrm{~mm}$ e b) Gabarito em papel para fonte de $100 \mathrm{~mm} \times 100 \mathrm{~mm}$.

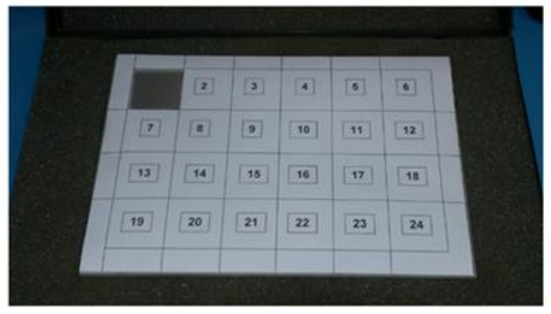

a)

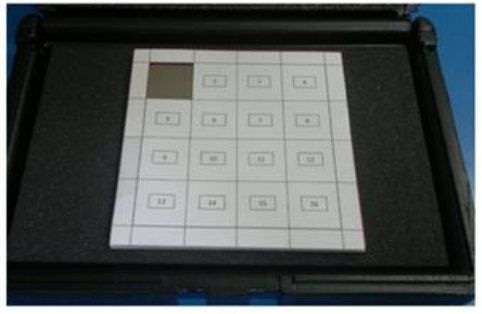

b)

Fonte: autor da tese.

Foi confeccionada uma máscara em alumínio conforme a Figura 5, com uma espessura de $2 \mathrm{~mm}$, tendo uma abertura quadrada em seu centro $(2,5 \mathrm{~cm} x$ $2,5 \mathrm{~cm}$ ) com uma área de $6,25 \mathrm{~cm}^{2}$.

Figura 5 - Máscara em alumínio com uma abertura em seu centro.

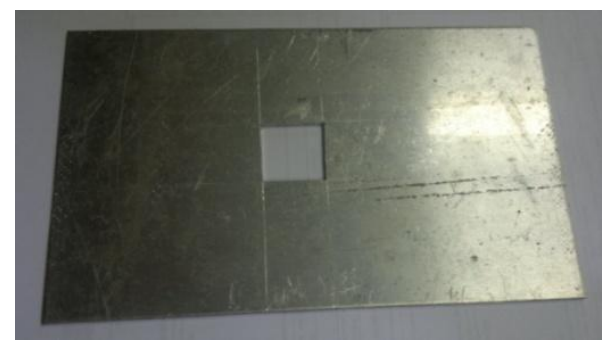

Fonte: autor da tese.

Foram realizadas as medições de uniformidade das fontes extensas de referência, sendo utilizada uma base em poliestireno (isopor) perfurado com as dimensões da fonte, com o objetivo de deixar a superfície da fonte rente ao poliestireno, para facilitar o posicionamento do gabarito em papel e a máscara em alumínio sobre essa fonte, também se utilizou uma placa de acrílico sobre o arranjo, como blindagem para a radiação, conforme Figura 6. 
Figura 6 - Arranjo experimental.

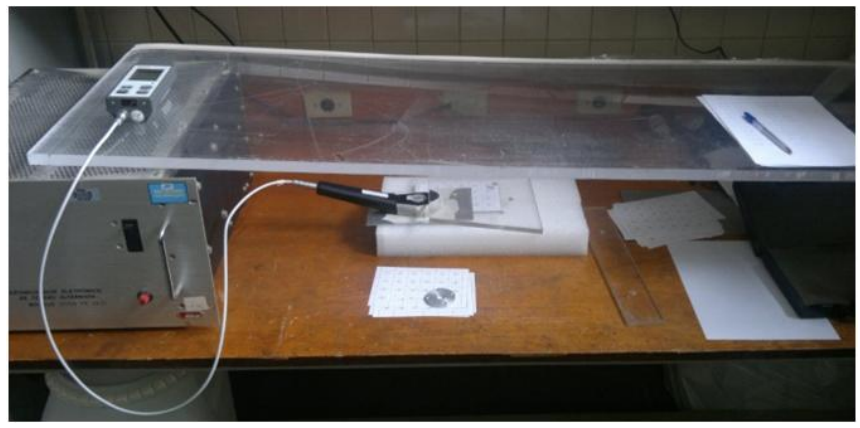

Fonte: autor da tese.

Foram realizadas medições da uniformidade com as fontes extensas de referência de $150 \mathrm{~cm}^{2}$ e $100 \mathrm{~cm}^{2}$ de área conforme Tabela 7.

Tabela 7 - Fontes extensas de referência do LCI-IPEN.

\begin{tabular}{|c|c|c|c|c|c|}
\hline \multicolumn{6}{|c|}{ Fontes Extensa de Referência } \\
\hline Nuclídeo & № Fonte & Área & Atividade & Uniformidade & Data Referência \\
\hline & & $\mathrm{cm}^{2}$ & $\mathrm{~Bq}$ & $\%$ & \\
\hline${ }^{241} \mathrm{Am}$ & FG497 & 150 & 933 & 5,7 & 26/11/1996 \\
\hline${ }^{14} \mathrm{C}$ & FG498 & 150 & 1070 & 50,3 & 26/11/1996 \\
\hline${ }^{90} \mathrm{Sr}+{ }^{90} \mathrm{Y}$ & FG499 & 150 & 1030 & 8,8 & 26/11/1996 \\
\hline${ }^{99} \mathrm{Tc}$ & FG773 & 150 & 1170 & 9,2 & $13 / 12 / 1996$ \\
\hline${ }^{137} \mathrm{Cs}$ & $\mathrm{FI} 214$ & 150 & 972 & 8,8 & 14/01/1997 \\
\hline${ }^{36} \mathrm{Cl}$ & $\mathrm{FI} 215$ & 150 & 1030 & 16,6 & 14/01/1997 \\
\hline${ }^{60} \mathrm{Co}$ & E7-012 & 100 & 3804 & 10,4 & $01 / 12 / 2007$ \\
\hline${ }^{137} \mathrm{Cs}$ & E7-013 & 100 & 3678 & 7,4 & $01 / 12 / 2007$ \\
\hline${ }^{14} \mathrm{C}$ & E7-014 & 100 & 5265 & 46,7 & $01 / 12 / 2007$ \\
\hline
\end{tabular}

Fonte: autor da tese.

$\mathrm{Na}$ Tabela 7 são apresentados em vermelho os valores de uniformidade que estão em desacordo com as recomendações da norma ISO 8769:2010 (INTERNATIONAL ORGANIZATION FOR STANDARDIZATION, 2010).

Os gráficos apresentados na Figura 7 ilustram os resultados apresentados na Tabela 7, referente às fontes extensas de referência de $150 \mathrm{~cm}^{2}$, facilitando a visualização das distribuições da intensidade dos fluxos de cada fonte.

${ }^{7}$ OBS: Nessa data a forma de expressar o valor de uniformidade era diferente do atual. 
Figura 7 - Gráficos de distribuição superficial das intensidades das taxas de contagens das fontes extensas de referência de $150 \mathrm{~cm}^{2}$ :
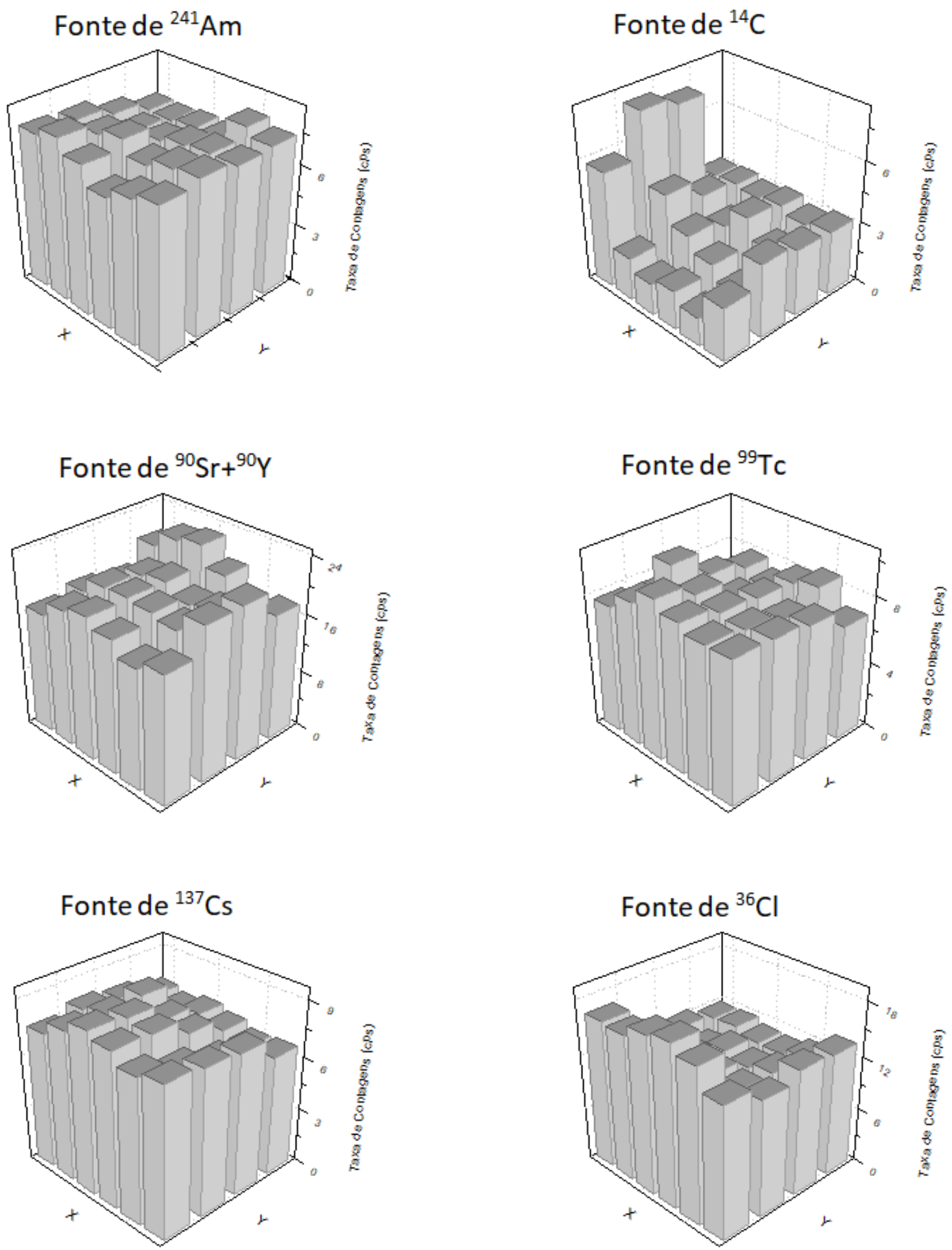

Fonte: autor da tese. 
Os gráficos apresentados na Figura 8 servem para ilustrar os resultados apresentados na tabela 7 , referente às fontes extensas de referência de $100 \mathrm{~cm}^{2}$, facilitando a visualização das distribuições da intensidade dos fluxos de cada fonte.

Figura 8 - Gráficos de distribuição superficial das intensidades das taxas de contagens das fontes extensas de referência de $100 \mathrm{~cm}^{2}$ :
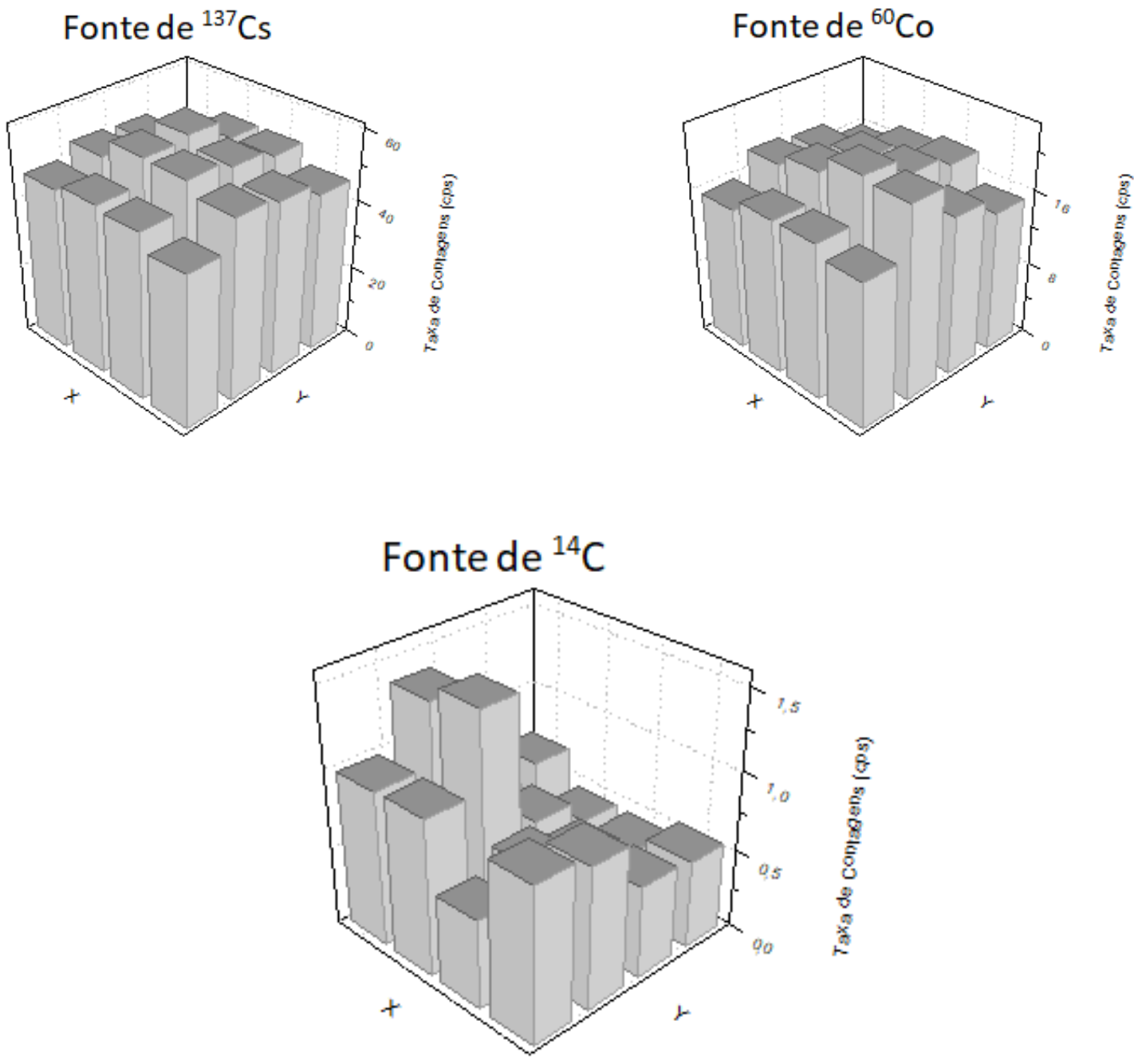

Fonte: autor da tese. 


\subsubsection{Estimativa de Incertezas}

Todas as medições realizadas neste trabalho tiveram suas incertezas obtidas de acordo com as recomendações da Associação Brasileira de Normas Técnicas e seguindo a ISO GUM (INSTITUTO NACIONAL DE METROLOGIA, QUALIDADE E TECNOLOGIA, 2008).

A Tabela 8 mostra como exemplo os dados da fonte extensa de referência de ${ }^{99} \mathrm{Tc}$ e todas as componentes de incertezas utilizadas no cálculo da uniformidade da fonte; o mesmo procedimento foi utilizado para todas as medições de mapeamento de uniformidade, foram utilizadas apenas as componentes do tipo A.

Fórmula para calcular a incerteza padrão relativa:

$$
\text { incerteza padrão relativa }=\frac{\sigma_{\sigma_{M_{L}}} \times \sigma_{M_{L}}}{M_{L}}
$$


Tabela 8 - Tabela das medições de mapeamento da uniformidade da fonte de ${ }^{99}$ Tc e suas respectivas componentes de incerteza.

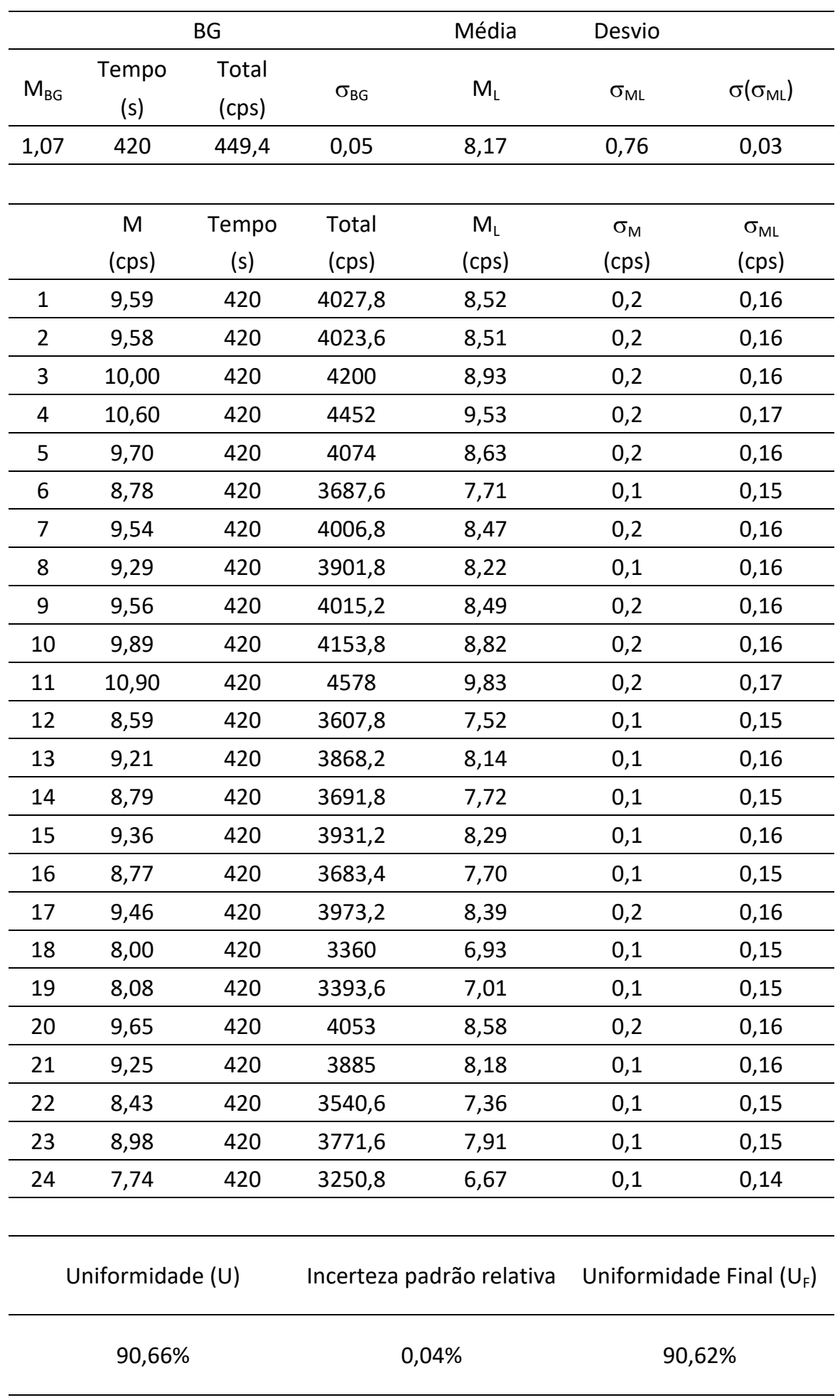

Fonte: autor da tese. 


\subsubsection{Conclusões Específicas}

Nesta etapa do trabalho foi possível quantificar a uniformidade das fontes extensas de referência de contaminação de superfície, utilizadas nas calibrações de monitores de radiação de contaminação de superfície e realizar uma comparação entre as fontes de ${ }^{241} \mathrm{Am},{ }^{14} \mathrm{C},{ }^{90} \mathrm{Sr}+{ }^{90} \mathrm{Y},{ }^{99} \mathrm{Tc},{ }^{137} \mathrm{Cs}$ e ${ }^{36} \mathrm{Cl}$ adquiridas entre 1996/1997 e as fontes de ${ }^{60} \mathrm{Co},{ }^{137} \mathrm{Cs}$ e ${ }^{14} \mathrm{C}$ adquiridas em 2007, possibilitando constatar que mesmo após 10 anos entre as aquisições, algumas fontes possuem problemas de baixa uniformidade, sendo o caso do ${ }^{14} \mathrm{C} O$ de maior relevância, uma vez que seus valores estão próximos de $50 \%$ em ambos os casos, demonstrando que pelo menos quatro fontes extensas de referência da tabela 7 não atendem as exigências de uniformidades recomendadas pela norma ISO 8769:2010 (INTERNATIONAL ORGANIZATION FOR STANDARDIZATION, 2010)(edição da norma vigente na época).

O draft: BSI ISO 8769:2014 (INTERNATIONAL ORGANIZATION FOR STANDARDIZATION, 2014) demonstra um recuo nas exigências em relação à uniformidade das fontes extensas de referência, para o caso de fontes Classe 1, embora tenha mantido o mesmo valor de exigência de uniformidade para as fontes Classe 2, sendo as fontes utilizadas pelo LCI-IPEN do tipo Classe 2.

A questão importante aqui é demonstrar a necessidade do desenvolvimento de uma nova metodologia de calibração que permita a utilização de fontes extensas de referência que estejam em desacordo com as recomendações de uniformidade especificadas pela norma ISO 8769 (ASSOCIAÇÃO BRASILEIRA DE NORMAS TÉCNICAS, 2016).

Os resultados desse mapeamento da uniformidade serviram de base para as simulações utilizando o código MCNP, que foram realizados em conjunto com - CEN-IPEN (Centro de Engenharia Nuclear do IPEN) com o objetivo de incorporar essas simulações a uma nova proposta de metodologia de calibração de monitores de radiação de contaminação de superfície, de modo a considerar o mapeamento da uniformidade como parte do processo de calibração (SILVA JR, XAVIER, et al., 2014). 


\subsection{Avaliação de Uniformidade de Fontes Extensas Circulares}

Durante o desenvolvimento desse trabalho foram realizadas medições de uniformidade de fontes de alguns laboratórios de calibração pelo Brasil, que prestam serviço de calibração de monitores de contaminação de superfície e fazem parte do Comitê de Avaliação de Serviços de Ensaio e Calibração (CASEC). Durante essas avaliações foi percebido que diversos laboratórios ainda utilizam em suas calibrações fontes extensas de referência circular. Tanto a norma ISO 8769, quanto o Guia de Boas Práticas №14 não tratam a questão do uso de fontes circulares, pois a norma ISO 8769 recomenda o uso de fontes extensas de referência retangulares com área sensível de no mínimo $100 \mathrm{~cm}^{2}$. Mas também não restringe o uso dessas fontes, desde que o laboratório garanta seu uso adequado; essa informação é dada pelo Guia de Boas Práticas №14 (LEE e BURGESS, 2014).

Devido ao uso dessas fontes circulares por alguns laboratórios, é que foi desenvolvida uma forma de medir sua uniformidade, tratando-as como fontes extensas de referência retangulares. Para isso foi realizada uma transposição da metodologia de mapeamento utilizada para fontes retangulares para as circulares, procurando ao máximo minimizar as incertezas causadas por tal aproximação. Mostrou-se muito útil e prática essa forma de medir e calcular a uniformidade desse tipo de fonte; outros métodos seriam possíveis, mas não seriam tão práticos.

\subsubsection{Mapeamento da Uniformidade}

No mapeamento das fontes extensas de referência circulares utilizadas, com diâmetro total de $10 \mathrm{~cm}$, foram utilizados os mesmos gabaritos de delimitação de células desenvolvidos para as fontes retangulares de $10 \mathrm{~cm} \times 10 \mathrm{~cm}\left(100 \mathrm{~cm}^{2}\right)$.

A Figura 9 mostra as células, numeradas de 1 a 16, com dimensões de $2,5 \mathrm{~cm} \times 2,5 \mathrm{~cm}\left(6,25 \mathrm{~cm}^{2}\right)$ e a distribuição de cada porção da fonte circular em relação à dimensão de cada célula. 
Figura 9 - Diagrama das divisões em células da fonte extensa de referência circular.

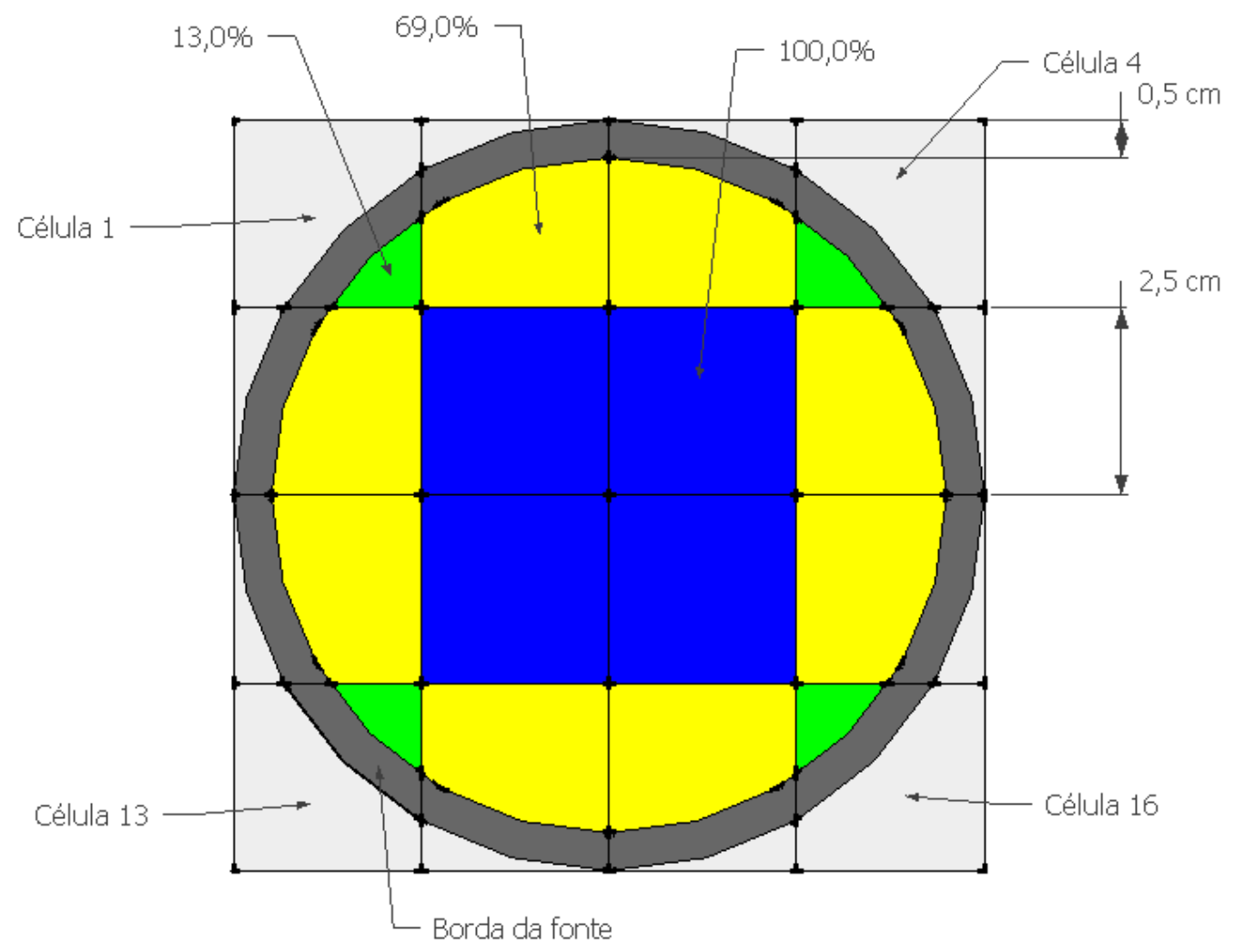

Fonte: autor da tese.

A partir da observação da Figura 9 evidencia-se a existência de três tipos de células a serem considerados na avaliação da uniformidade das fontes extensas de referência circular:

1. Aquelas que têm $100 \%$ de sua área $\left(6,25 \mathrm{~cm}^{2}\right)$ sobreposta à área ativa da fonte (azul);

2. Aquelas que têm $69 \%$ de sua área $\left(4,31 \mathrm{~cm}^{2}\right)$ sobrepondo-se à área ativa (amarela);

3. Aquelas que têm somente $13 \%$ de sua área $\left(0,81 \mathrm{~cm}^{2}\right)$ sobrepondose à área ativa da fonte (verde);

A Tabela 9 mostra a matriz das taxas de contagens de cada célula obtidas no mapeamento da fonte de ${ }^{14} \mathrm{C}$ (incertezas são inferiores a $5 \%$ ). 
Tabela 9 - Matriz com a distribuição dos valores de taxa de contagens (cps) obtidos no mapeamento da fonte de ${ }^{14} \mathrm{C}$.

\begin{tabular}{cccc}
\hline 8,92 & 51,32 & 52,32 & 11,02 \\
\hline 50,12 & 73,92 & 76,92 & 57,22 \\
\hline 52,22 & 75,22 & 73,52 & 56,92 \\
\hline 9,12 & 52,02 & 54,12 & 11,12 \\
\hline
\end{tabular}

Fonte: autor da tese.

Os valores mostrados na matriz da Tabela 9 foram recalculados, usando as áreas de cada região, conforme Tabela 10, obtendo a Tabela com as taxas de contagens por unidade de área ativa de cada região, conforme Tabela 11.

Tabela 10 - Matriz dos valores de área ativa da fonte extensa de referência $\left(\mathrm{cm}^{2}\right)$.

\begin{tabular}{llll}
\hline 0,81 & 4,31 & 4,31 & 0,81 \\
\hline 4,31 & 6,25 & 6,25 & 4,31 \\
\hline 4,31 & 6,25 & 6,25 & 4,31 \\
\hline 0,81 & 4,31 & 4,31 & 0,81 \\
\hline
\end{tabular}

Fonte: autor da tese.

Tabela 11 - Matriz dos valores de taxa de contagens por unidade de área ativa (cps.cm ${ }^{-2}$ )

\begin{tabular}{llll}
\hline 11,01 & 11,91 & 12,14 & 13,60 \\
\hline 11,63 & 11,83 & 12,31 & 13,28 \\
\hline 12,12 & 12,04 & 11,76 & 13,21 \\
\hline 11,26 & 12,07 & 12,56 & 13,73 \\
\hline
\end{tabular}

Fonte: autor da tese.

A Figura 10 apresenta os histogramas das distribuições de intensidades das taxas de contagens por unidade de área das fontes de ${ }^{14} \mathrm{C}(\mathrm{a}),{ }^{36} \mathrm{Cl}$ (b) e ${ }^{90} \mathrm{Sr}_{+}{ }^{90} \mathrm{Y}$ (c), com o objetivo de facilitar a visualização das regiões de maior uniformidade. 
Figura 10 - Distribuição das intensidades das taxas de contagens por unidade de área das fontes extensas de referência circulares.
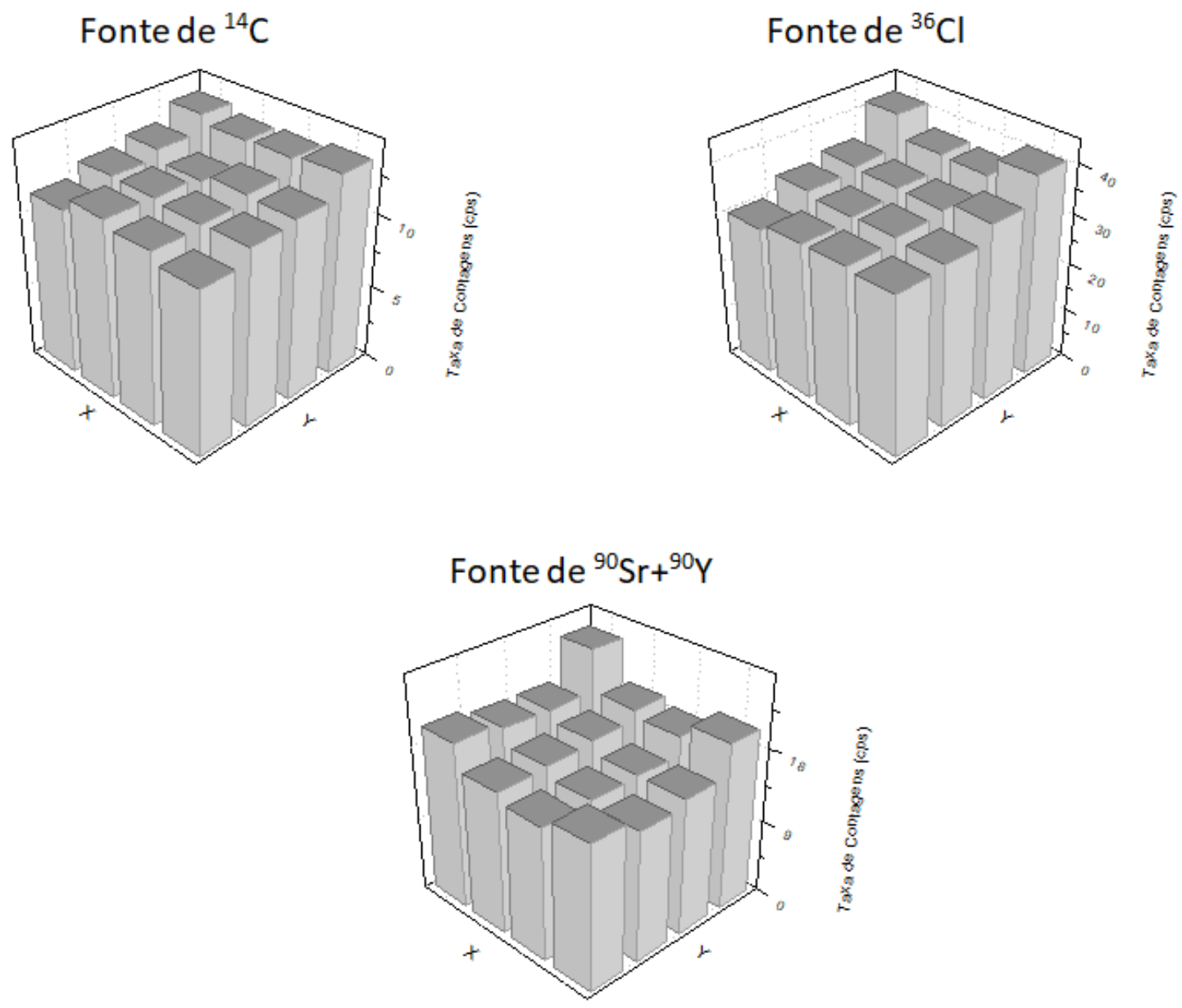

Fonte: autor da tese.

Com os valores de taxa de contagens por unidade de área para cada célula das fontes de ${ }^{14} \mathrm{C},{ }^{36} \mathrm{Cl}$ e ${ }^{90} \mathrm{Sr}+{ }^{90} \mathrm{Y}$, foram calculados os valores de suas uniformidades, esta avaliação foi realizada tanto para o total da fonte como para a região central. A Tabela 12 mostra os valores de uniformidade obtidos.

Tabela 12 - Valores de uniformidade total e parcial (região central) da fonte.

\begin{tabular}{ccc}
\hline \multirow{2}{*}{ Nuclídeo } & \multicolumn{2}{c}{ Uniformidade } \\
Total & Central \\
$\%$ & $\%$ \\
\hline${ }^{14} \mathrm{C}$ & 93,4 & 98,0 \\
\hline${ }^{36} \mathrm{Cl}$ & 91,0 & 97,8 \\
\hline${ }^{90} \mathrm{Sr}+{ }^{90} \mathrm{Y}$ & 88,2 & 95,0 \\
\hline
\end{tabular}

Fonte: autor da tese. 
A apresentação da uniformidade das regiões centrais das fontes extensas de referência busca ilustrar o quanto o procedimento adotado atende à recomendação do Guia de Boas Práticas №14 do NPL pela utilização das regiões mais uniformes das fontes extensas de referência.

\subsubsection{Eficiência do instrumento}

A Tabela 13 mostra os valores de taxa de contagens e a taxa de emissão superficial de cada uma das fontes, corrigidas para a data de medida, calculadas para uma área correspondente à da sonda, com incertezas de 5\%.

\begin{tabular}{|c|c|c|}
\hline Nuclídeo & $\begin{array}{c}\text { Taxa de } \\
\text { Contagens } \\
\text { cps }\end{array}$ & $\begin{array}{c}\text { Taxa de } \\
\text { Contagens } \\
\text { Superficial } \\
\mathrm{s}^{-1} \text { in } 2 \pi\end{array}$ \\
\hline${ }^{14} \mathrm{C}$ & 93,4 & 98,0 \\
\hline${ }^{36} \mathrm{Cl}$ & 91,0 & 97,8 \\
\hline${ }^{90} \mathrm{Sr}+{ }^{90} \mathrm{Y}$ & 88,2 & 95,0 \\
\hline
\end{tabular}

Fonte: autor da tese.

A Tabela 14 mostra os valores de eficiência do instrumento sem correção $(\varepsilon)$ e corrigidos pelos fatores de correção obtidos pelo método do NPL $\left(\varepsilon_{N P L}\right)$ além de suas respectivas diferenças.

Tabela 14 - Valores calculados de eficiência do instrumento e suas diferenças.

\begin{tabular}{ccccc}
\hline \multirow{2}{*}{ Nuclídeo } & $\varepsilon$ & $\begin{array}{c}\text { Fator de } \\
\text { Correção }\end{array}$ & $\begin{array}{c}\varepsilon_{\mathrm{NPL}} \\
\%\end{array}$ & $\begin{array}{c}\text { Diferença } \\
\%\end{array}$ \\
\hline${ }^{14} \mathrm{C}$ & 27,4 & 1,023 & 28,0 & $-2,2$ \\
\hline${ }^{36} \mathrm{Cl}$ & 70,7 & 1,029 & 72,7 & $-2,8$ \\
\hline${ }^{90} \mathrm{Sr}+{ }^{90} \mathrm{Y}$ & 72,5 & 1,070 & 77,6 & $-7,0$ \\
\hline
\end{tabular}

Fonte: autor da tese. 


\subsubsection{Conclusões Específicas}

Uma das dificuldades encontradas durante esse trabalho foi realizar o mapeamento da uniformidade de fontes extensas de referência circular, embora esse tipo de fonte não seja a recomendada pela norma ISO 8769 , alguns laboratórios ainda possuem esse tipo de fonte, devido às dificuldades em aquisição de fontes extensas de referência recomendadas.

Foi desenvolvida uma metodologia que permitiu a transposição do método de mapeamento da uniformidade da fonte extensa de referência retangular para a circular, possibilitando a aplicação direta do método de cálculo de fatores de correção de uniformidade proposto pelo NPL.

Os valores de eficiência do instrumento calculados e corrigidos com o uso de fatores de correção mostram que, para as fontes utilizadas neste trabalho, esses valores podem estar subestimados em até $7 \%$.

A transposição adotada neste trabalho busca validar a incorporação de fontes extensas de referência circular nos procedimentos de calibração, a despeito da sua não conformidade com as normas apresentadas pela ISO 8769 (ASSOCIAÇÃO BRASILEIRA DE NORMAS TÉCNICAS, 2016).

As exigências desta norma quanto ao formato da fonte extensa de referência ou com relação à sua uniformidade não parecem atender a qualquer necessidade procedimental que não possa ser corrigida. Nesse trabalho não houve uma preocupação com as incertezas, pois o objetivo foi apenas de verificar a viabilidade da transposição do método de mapeamento. (SILVA JR, XAVIER, et al., 2017). 


\section{DESENVOLVIMENTO EM MCNP}

Essa etapa foi desenvolvida através de uma cooperação com o Centro de Engenharia Nuclear do IPEN (CEN-IPEN/CNEN), realizada com o pesquisador Dr. Paulo de Tarso Dalledone Siqueira.

Inicialmente o desafio consistiu em definir a geometria que seria simulada e seus respectivos materiais, avançando depois para detalhes de espectros desses radionuclídeos.

Foi definido que seria utilizada a versão MCNP5, pois essa possibilita transporte de fótons e partículas beta, sendo simuladas as fontes extensas de referência beta $\left({ }^{14} \mathrm{C},{ }^{36} \mathrm{Cl},{ }^{99} \mathrm{Tc},{ }^{137} \mathrm{Cs} \mathrm{e}{ }^{90} \mathrm{Sr}+{ }^{90} \mathrm{Y}\right)$ com área ativa total de $150 \mathrm{~cm}^{2}$ $(10 \mathrm{~cm} \times 15 \mathrm{~cm})$.

As simulações foram desenvolvidas no CEN, porém acompanhadas de diversas discussões em conjunto, possibilitando um enorme aprendizado sobre as diversas questões relacionadas às fontes e ao trabalho como um todo.

\subsection{Descrição do Conjunto Sonda e Suporte Simulados}

$\mathrm{Na}$ descrição da geometria foi definida uma placa em alumínio de dimensões $10 \mathrm{~cm} \times 15 \mathrm{~cm} \times 3 \mathrm{~cm}$, para servir de substrato para a fonte e uma estrutura em alumínio utilizada como suporte para a sonda do monitor de radiação. Todos estes componentes foram considerados imersos em ar, conforme a geometria apresentada na Figura 11 e seus respectivos materiais são mostrados na Tabela 15.

Os espectros de energia beta foram obtidos do Radar (RADAR, 2017) e sua emissão foi isotrópica.

A fonte foi considerada como sendo formada pela deposição do radionuclídeo específico numa camada uniforme ao longo do perfil de profundidade, de $6 \times 10^{-4} \mathrm{~cm}$ do substrato 
Figura 11 - Representação geométrica do sistema simulado.

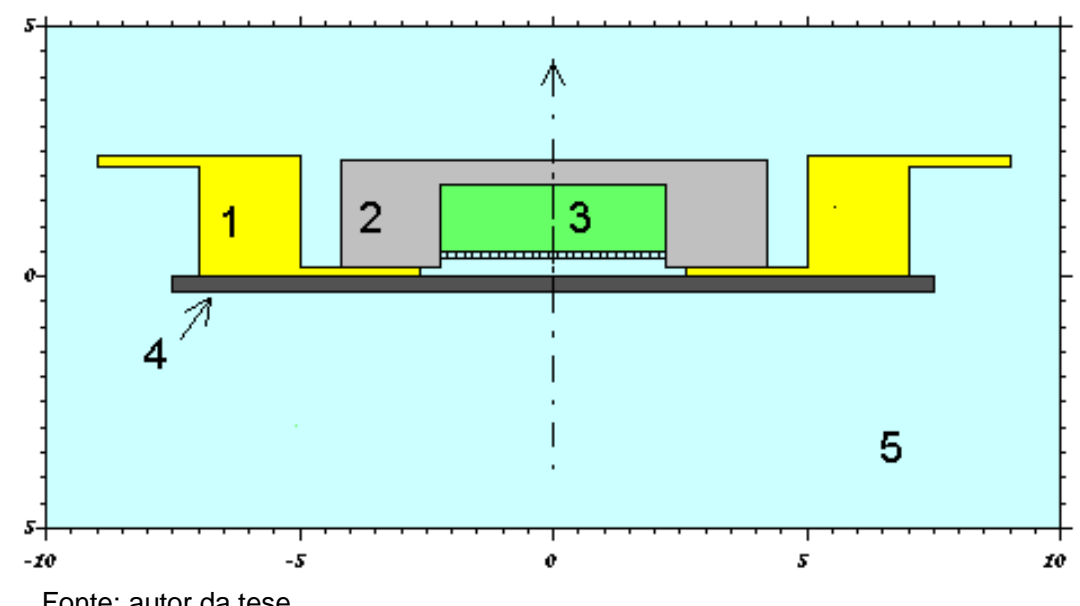

(1) Suporte de apoio do sistema de posicionamento da sonda do detector em alumínio (amarelo);

(2) Carcaça da sonda (panqueca) em aço inox (cinza);

(3) Área interna da sonda tipo panqueca, preenchido por gás e uma fina camada de mica com uma grade em aço inox (verde);

(4) Fonte extensa de referência, substrato mais fina camada de material ativo (marrom);

(5) Ar, onde o conjunto está imerso.

Tabela 15 - Especificação dos materiais utilizados na simulação.

$\left.\begin{array}{ccc}\hline \text { Material } & \begin{array}{c}\text { Densidade } \\ \mathrm{g} / \mathrm{cm}^{3}\end{array} & \begin{array}{c}\text { Composição } \\ \text { fração atômica }\end{array} \\ \text { Aço Inoxidável SS-446 } & 8,00 & \begin{array}{c}\mathrm{C}(0,89 \%) ; \mathrm{N}(0,95 \%) ; \mathrm{Si}(1,90 \%) ; \mathrm{P}(0,07 \%) ; \\ \mathrm{S}(0,05 \%) ; \mathrm{Cr}(27,74 \%) ; \mathrm{Mn}(1,46 \%) ; \\ \mathrm{Fe}(66,94 \%)\end{array} \\ \hline \mathrm{Ar} & 1,09 \mathrm{E}-03 & \begin{array}{c}\mathrm{H}(1,83 \%) ; \mathrm{C}(0,01 \%) ; \mathrm{N}(76,29 \%) ; \\ \mathrm{O}(21,41 \%) ; \mathrm{Ar}(0,45 \%)\end{array} \\ \hline \text { Mica (muscovita) } & 2,83 & \mathrm{H}(9,52 \%) ; \mathrm{O}(57,14 \%) ; \mathrm{Al}(14,29 \%) ; \\ \mathrm{Si}(14,29 \%) ; \mathrm{K}(4,76 \%)\end{array}\right)$

Fonte: autor da tese. 
A sonda tipo panqueca $\mathrm{FHZ} 732 \mathrm{GM}$ foi descrita como um cilindro de aço inox SS-446 de $8,4 \mathrm{~cm}$ de diâmetro por $2,1 \mathrm{~cm}$ de altura, formando o corpo da sonda do monitor de radiação (Geiger), com uma cavidade cilíndrica de $4,45 \mathrm{~cm}$ de diâmetro e $1,6172 \mathrm{~cm}$ de profundidade. Esta cavidade foi dividida em segmentos. No segmento superior com $1,8165 \mathrm{~cm}$ de espessura, representou-se 0 volume sensível do detector, composto por gás Ne e Halógenos. Logo abaixo desta seção, representou-se a janela do detector, composta por uma lâmina de mica com $7,067 \mathrm{~cm} \times 10^{-4} \mathrm{~cm}$ de espessura. Uma grade de aço formada por uma malha quadrada de fios de $0,017 \mathrm{~cm}$ de diâmetro com um espaçamento centro a centro ("pitch") de $0,167 \mathrm{~cm}$, foi representada logo abaixo da janela. O segmento da extremidade inferior correspondeu ao anel de guarda do detector; no Apêndice A é possível visualizar um dos "input" do MCNP desenvolvido pelo CEN.

A Figura 12 apresenta detalhes da representação do sistema simulado, sendo que na parte (a) da figura é possível ter uma visão geral do sistema, enquanto na parte (b) é possível visualizar as grades em mais detalhes.

Amarelo: alumínio;

Lilás: aço inoxidável;

Verde: gás do detector;

Azul escuro: mica;

Azul claro: ar.

Figura 12 - Detalhes da representação do detector, (a) visão geral e (b) detalhes da grade.

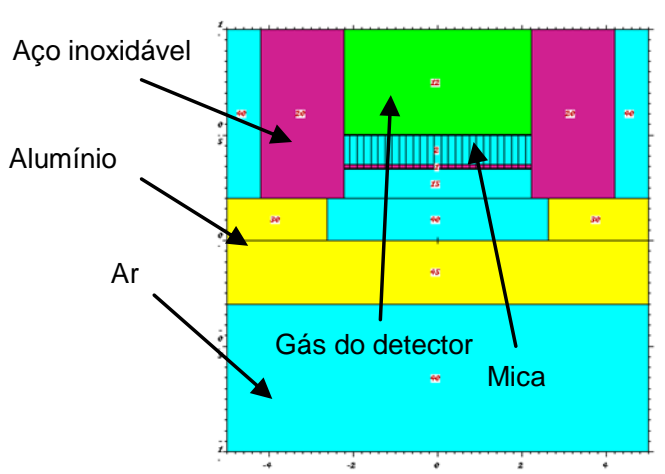

(a)

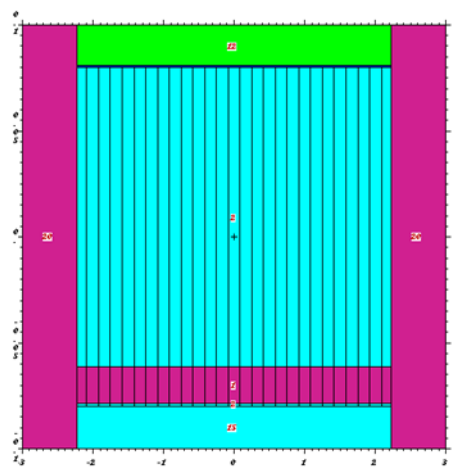

(b)

Fonte: autor da tese. 


\subsection{Simulações}

Foram realizadas simulações considerando as distribuições de intensidade das fontes extensas de referência como $100 \%$ uniformes e depois não uniformes, sendo que para o segundo caso, foram utilizados os dados experimentais do mapeamento da uniformidade das fontes obtidos na primeira etapa do trabalho, para atribuir pesos às 24 porções individuais de $2,5 \mathrm{~cm} \times 2,5 \mathrm{~cm}\left(6,25 \mathrm{~cm}^{2}\right)$ das fontes extensas de referência, conforme Figura 13, obtendo assim as mesmas distribuições de intensidade das fontes reais, pois foram usados os valores de ponderação obtidos experimentalmente a partir dos valores de contagens de cada segmento, descontando-se as contribuições da radiação de fundo.

A Tabela 16 apresenta os dados utilizados na ponderação da representação da distribuição geométrica das fontes não uniformes, onde em vermelho temos a numeração da seção, em preto os dados experimentais (descontando-se a radiação de fundo) e em azul a intensidade de cada porção.

As taxas de contagem foram estimadas através da contagem das histórias que depositaram qualquer quantidade de energia no volume sensível da sonda simulada e foi utilizado o cartão F8 do MCNP5.

Figura 13 - Diagrama esquemático da representação da fonte extensa de referência.

\begin{tabular}{|c|c|c|c|c|c|}
\hline 1 & 2 & 3 & 4 & 5 & 6 \\
\hline 7 & 8 & 9 & 10 & 11 & 12 \\
\hline 13 & 14 & 15 & 16 & 17 & 18 \\
\hline 19 & 20 & 21 & 22 & 23 & 24 \\
\hline
\end{tabular}

Fonte: autor da tese. 
Tabela 16 - Dados da distribuição geométrica das fontes não uniformes, onde em vermelho temos a numeração da seção, em preto os dados experimentais e em azul a intensidade de cada porção.

\begin{tabular}{|c|c|c|c|c|c|c|c|c|}
\hline \multirow[b]{2}{*}{ Células } & \multicolumn{2}{|c|}{${ }^{14} \mathrm{C}$} & \multicolumn{2}{|c|}{${ }^{99} \mathrm{Tc}$} & \multicolumn{2}{|c|}{${ }^{36} \mathrm{Cl}$} & \multicolumn{2}{|c|}{${ }^{90} \mathrm{Sr}+{ }^{90} \mathrm{Y}$} \\
\hline & $\begin{array}{c}\text { Taxa de } \\
\text { Contagens } \\
\text { (cps) }\end{array}$ & $\begin{array}{c}\text { Intensidade } \\
\text { de cada } \\
\text { célula }\end{array}$ & $\begin{array}{c}\text { Taxa de } \\
\text { Contagens } \\
\text { (cps) }\end{array}$ & $\begin{array}{c}\text { Intensidade } \\
\text { de cada } \\
\text { célula }\end{array}$ & $\begin{array}{c}\text { Taxa de } \\
\text { Contagens } \\
\text { (cps) }\end{array}$ & $\begin{array}{c}\text { Intensidade } \\
\text { de cada } \\
\text { célula }\end{array}$ & $\begin{array}{c}\text { Taxa de } \\
\text { Contagens } \\
\text { (cps) }\end{array}$ & $\begin{array}{c}\text { Intensidade } \\
\text { de cada } \\
\text { célula }\end{array}$ \\
\hline 1 & 2,65 & $3,3481 \mathrm{E}-2$ & 8,52 & $4,3456 \mathrm{E}-2$ & 14,59 & $4,5457 \mathrm{E}-2$ & 17,89 & $3,8895 \mathrm{E}-2$ \\
\hline 2 & 1,36 & $1,7183 \mathrm{E}-2$ & 8,51 & $4,3405 \mathrm{E}-2$ & 16,99 & $5,2935 \mathrm{E}-2$ & 16,69 & $3,6286 \mathrm{E}-2$ \\
\hline 3 & 1,88 & $2,3752 \mathrm{E}-2$ & 8,93 & $4,5547 \mathrm{E}-2$ & 17,89 & $5,5739 \mathrm{E}-2$ & 18,59 & $4,0417 \mathrm{E}-2$ \\
\hline 4 & 1,54 & $1,9457 \mathrm{E}-2$ & 9,53 & $4,8608 \mathrm{E}-2$ & 17,39 & $5,4181 \mathrm{E}-2$ & 19,79 & $4,3025 \mathrm{E}-2$ \\
\hline 5 & 2,14 & $2,7037 \mathrm{E}-2$ & 8,63 & $4,4017 \mathrm{E}-2$ & 16,19 & $5,0442 \mathrm{E}-2$ & 18,89 & $4,1069 \mathrm{E}-2$ \\
\hline 6 & 5,71 & $7,2142 \mathrm{E}-2$ & 7,71 & $3,9325 \mathrm{E}-2$ & 16,39 & $5,1066 \mathrm{Z}-2$ & 16,89 & $3,6721 \mathrm{E}-2$ \\
\hline 7 & 3,61 & $4,5610 \mathrm{E}-2$ & 8,47 & $4,3201 \mathrm{E}-2$ & 12,89 & $4,0161 \mathrm{E}-2$ & 21,39 & $4,6504 \mathrm{E}-2$ \\
\hline 8 & 1,44 & $1,8193 \mathrm{E}-2$ & 8,22 & $4,1926 \mathrm{E}-2$ & 12,39 & $3,8603 \mathrm{E}-2$ & 18,99 & $4,1286 \mathrm{E}-2$ \\
\hline 9 & 2,19 & $2,7669 \mathrm{E}-2$ & 8,49 & $4,3303 \mathrm{E}-2$ & 12,79 & $3,9849 \mathrm{E}-2$ & 19,69 & $4,2808 \mathrm{E}-2$ \\
\hline 10 & 2,96 & $3,7397 \mathrm{E}-2$ & 8,82 & $4,4986 \mathrm{E}-2$ & 13,29 & $4,1407 \mathrm{E}-2$ & 19,99 & $4,3460 \mathrm{E}-2$ \\
\hline 11 & 4,36 & $5,5085 \mathrm{E}-2$ & 9,83 & $5,0138 \mathrm{E}-2$ & 12,69 & $3,9538 \mathrm{E}-2$ & 19,79 & $4,3025 \mathrm{E}-2$ \\
\hline 12 & 7,84 & $9,9052 \mathrm{E}-2$ & 7,52 & $3,8356 \mathrm{E}-2$ & 12,19 & $3,7980 \mathrm{E}-2$ & 17,69 & $3,8460 \mathrm{E}-2$ \\
\hline 13 & 3,29 & $4,1567 \mathrm{E}-2$ & 8,14 & $4,1518 \mathrm{E}-2$ & 13,99 & $4,3588 \mathrm{E}-2$ & 21,39 & $4,6504 \mathrm{E}-2$ \\
\hline 14 & 2,55 & $3,2217 \mathrm{E}-2$ & 7,72 & $3,9376 \mathrm{E}-2$ & 12,29 & $3,8291 \mathrm{E}-2$ & 18,79 & $4,0851 E-2$ \\
\hline 15 & 3,55 & $4,4852 \mathrm{E}-2$ & 8,29 & $4,2283 \mathrm{E}-2$ & 11,59 & $3,6110 \mathrm{E}-2$ & 18,29 & $3,9764 \mathrm{E}-2$ \\
\hline 16 & 2,50 & $3,1586 \mathrm{E}-2$ & 7,70 & $3,9274 \mathrm{E}-2$ & 12,19 & $3,7980 \mathrm{E}-2$ & 19,89 & $4,3243 E-2$ \\
\hline 17 & 3,49 & $4,4093 \mathrm{E}-2$ & 8,39 & $4,2793 \mathrm{E}-2$ & 11,29 & $3,5176 \mathrm{E}-2$ & 19,29 & $4,1938 \mathrm{E}-2$ \\
\hline 18 & 7,45 & $9,4125 \mathrm{E}-2$ & 6,93 & $3,5346 \mathrm{E}-2$ & 12,29 & $3,8291 \mathrm{E}-2$ & 16,99 & $3,6938 \mathrm{E}-2$ \\
\hline 19 & 3,15 & $3,9798 \mathrm{E}-2$ & 7,01 & $3,5754 \mathrm{Z}-2$ & 13,69 & $4,2653 \mathrm{E}-2$ & 17,69 & $3,8460 \mathrm{E}-2$ \\
\hline 20 & 2,90 & $3,6639 \mathrm{E}-2$ & 8,58 & $4,3762 \mathrm{E}-2$ & 11,89 & $3,7045 \mathrm{E}-2$ & 16,49 & $3,5851 z-2$ \\
\hline 21 & 3,25 & $4,1061 \mathrm{E}-2$ & 8,18 & $4,1722 \mathrm{E}-2$ & 11,19 & $3,4864 \mathrm{E}-2$ & 19,99 & $4,3460 \mathrm{E}-2$ \\
\hline 22 & 3,06 & $3,8661 \mathrm{E}-2$ & 7,36 & $3,7540 \mathrm{E}-2$ & 11,29 & $3,5176 \mathrm{E}-2$ & 22,79 & $4,9548 \mathrm{E}-2$ \\
\hline 23 & 3,18 & $4,0177 \mathrm{E}-2$ & 7,91 & $4,0345 \mathrm{E}-2$ & 11,89 & $3,7045 \mathrm{E}-2$ & 22,09 & $4,8026 \mathrm{~B}-2$ \\
\hline \multirow[t]{8}{*}{24} & 3,10 & $3,9166 \mathrm{E}-2$ & 6,67 & $3,4020 \mathrm{E}-2$ & 11,69 & $3,6422 \mathrm{E}-2$ & 19,99 & $4,3460 \mathrm{E}-2$ \\
\hline & Média & $\begin{array}{c}\text { Intensidade } \\
\text { Total }\end{array}$ & Média & $\begin{array}{c}\text { Intensidade } \\
\text { Total }\end{array}$ & Média & $\begin{array}{c}\text { Intensidade } \\
\text { Total }\end{array}$ & Média & $\begin{array}{c}\text { Intensidade } \\
\text { Total }\end{array}$ \\
\hline & 3,30 & 1,00 & 8,17 & 1,00 & 13,37 & 1,00 & 19,17 & 1,00 \\
\hline & Desvio & Incerteza & Desvio & Incerteza & Desvio & Incerteza & Desvio & Incerteza \\
\hline & Padrão & Relativa & Padrão & Relativa & Padrão & Relativa & Padrão & Relativa \\
\hline & 1,64 & 0,021 & 0,76 & 0,004 & 2,08 & 0,006 & 1,69 & 0,004 \\
\hline & Uniformidade & $\begin{array}{c}\text { Incerteza } \\
\text { Relativa }\end{array}$ & Uniformidade & $\begin{array}{c}\text { Incerteza } \\
\text { Relativa }\end{array}$ & Uniformidade & $\begin{array}{c}\text { Incerteza } \\
\text { Relativa }\end{array}$ & Uniformidade & $\begin{array}{l}\text { Incerteza } \\
\text { Relativa }\end{array}$ \\
\hline & $50,3 \%$ & 2,18 & $90,7 \%$ & 0,48 & $84,4 \%$ & 0,68 & $91,2 \%$ & 0,48 \\
\hline
\end{tabular}

Fonte: autor da tese.

Os valores presentes na parte inferior de cada coluna de dados experimentais da Tabela 16 (valores em preto) são respectivamente na ordem descendente de apresentação, o valor médio, $\boldsymbol{x}_{\boldsymbol{m}}$; o desvio-padrão (incerteza), $\boldsymbol{\sigma}$; e a incerteza relativa, $\sigma \cdot x_{m}{ }^{-1}$.

A Tabela 17 mostra os valores de intensidade obtidos nas simulações, para os dois casos, uniforme e não uniforme, com incertezas de $0,1 \%$. 
Tabela 17 - Diferenças entre os valores de intensidade obtidos nas simulações.

\begin{tabular}{|c|c|c|c|c|}
\hline \multirow{3}{*}{ Nuclídeo } & \multirow{3}{*}{$\begin{array}{c}\text { Energia } \\
\text { Máxima } \\
\text { keV }\end{array}$} & \multicolumn{2}{|c|}{ Distribuição das Intensidades } & \multirow{3}{*}{$\begin{array}{c}\text { Diferença } \\
\%\end{array}$} \\
\hline & & Uniforme & Não-Uniforme & \\
\hline & & cps & cps & \\
\hline${ }^{14} \mathrm{C}$ & 156,5 & $9,66 \mathrm{E}-03$ & $8,21 \mathrm{E}-03$ & $-17,7$ \\
\hline${ }^{99} \mathrm{Tc}$ & 293,8 & $2,19 \mathrm{E}-02$ & $2,23 \mathrm{E}-02$ & 1,8 \\
\hline${ }^{36} \mathrm{Cl}$ & 709,5 & $3,62 \mathrm{E}-02$ & $3,38 \mathrm{E}-02$ & $-7,1$ \\
\hline${ }^{90} \mathrm{Sr}+{ }^{90} \mathrm{Y}$ & $545,9 / 2279,8$ & $3,94 \mathrm{E}-02$ & $4,00 \mathrm{E}-02$ & 1,5 \\
\hline
\end{tabular}

Fonte: autor da tese.

Com base nessas simulações é possível concluir que a utilização destas fontes extensas de referência beta em procedimentos de calibração pode fornecer valores incorretos, subestimando ou superestimando a resposta.

\subsection{Validação da Simulação}

A validação da simulação foi realizada com base na avaliação da variação das taxas de contagens na sonda do instrumento em função da distância fontesonda com as fontes de área de $150 \mathrm{~cm}^{2}$.

Esta avaliação foi realizada para as fontes de ${ }^{14} \mathrm{C},{ }^{36} \mathrm{Cl},{ }^{99} \mathrm{Tc},{ }^{137} \mathrm{Cs}$, ${ }^{90} \mathrm{Sr}+{ }^{90} \mathrm{Y}$ e ${ }^{241} \mathrm{Am}$, ou seja, para todas as fontes utilizadas pelo LCI-IPEN. As distâncias do detector em relação à fonte variaram em intervalos de $1 \mathrm{~mm}$ (limite de aproximação da sonda frente à geometria considerada) a 15mm.

Nas simulações, as distâncias variaram em intervalos de $5 \mathrm{~mm}$ para o mesmo intervalo considerado. A Figura 14 ilustra a geometria do sistema simulado para a distância de $15 \mathrm{~mm}$.

A base da estrutura de suporte da sonda foi utilizada como referência para as distâncias, sendo utilizado um relógio comparador para controlar as variações de distância fonte-sonda. 
Figura 14 - Representação geométrica do sistema simulado para o conjunto detector 15mm afastado da fonte.

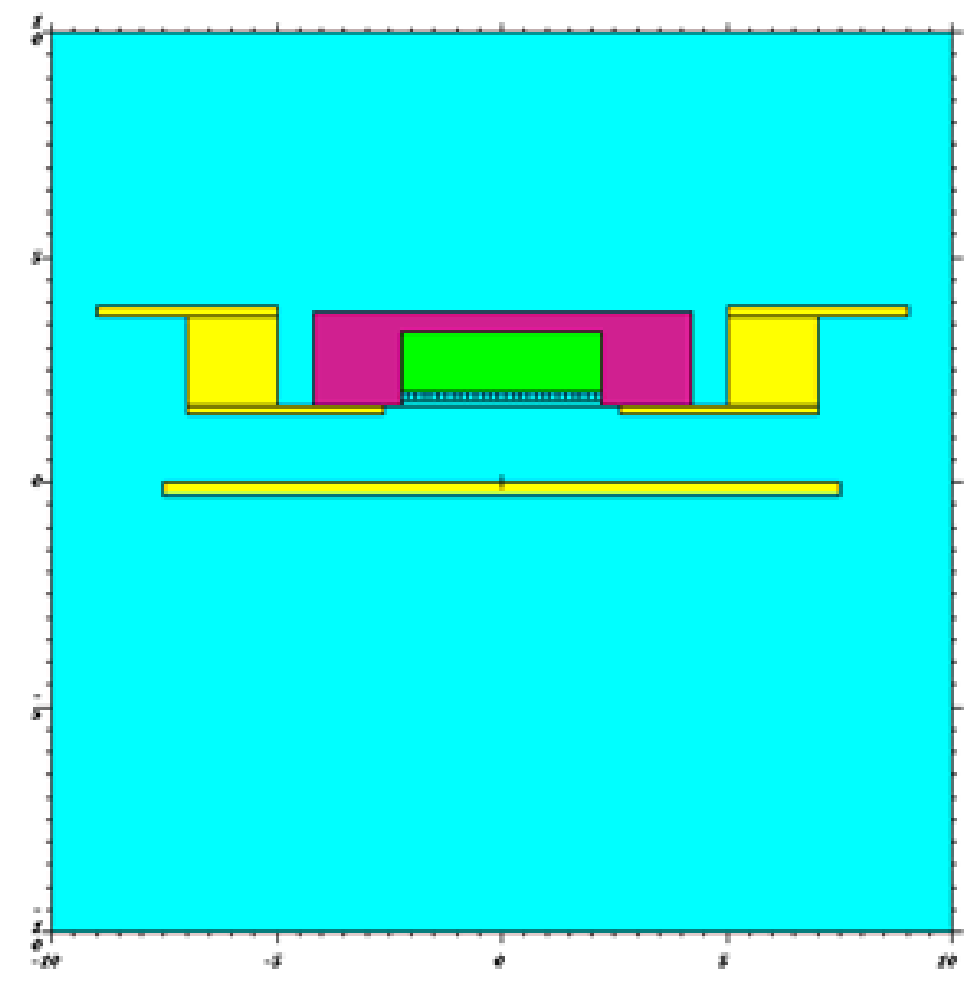

Fonte: autor da tese.

As simulações foram validadas por comparação entre os resultados experimentais e os simulados, utilizando os valores das taxas de contagens normalizadas, com incertezas de $5 \%$ para as experimentais e $0,15 \%$ para as simuladas. A Figura 15 apresenta os gráficos das quatro fontes extensas de referência $\left({ }^{14} \mathrm{C},{ }^{36} \mathrm{Cl},{ }^{99} \mathrm{Tc}\right.$ e $\left.{ }^{90} \mathrm{Sr}+{ }^{90} \mathrm{Y}\right)$ com os dados experimentais e simulados para cada caso (a linha tracejada ligando os pontos é apresentada para facilitar a visualização dos dados, onde se observa o decréscimo das taxas de contagens com o aumento da distância entre o sistema de detecção e a fonte. Os dados obtidos a partir das simulações tiveram um comportamento semelhante ao experimental, dentro das incertezas de medição. 
Figura 15 - Comparação entre as taxas de contagens normalizadas em função da distância obtidas experimentalmente e por simulação com MCNP.
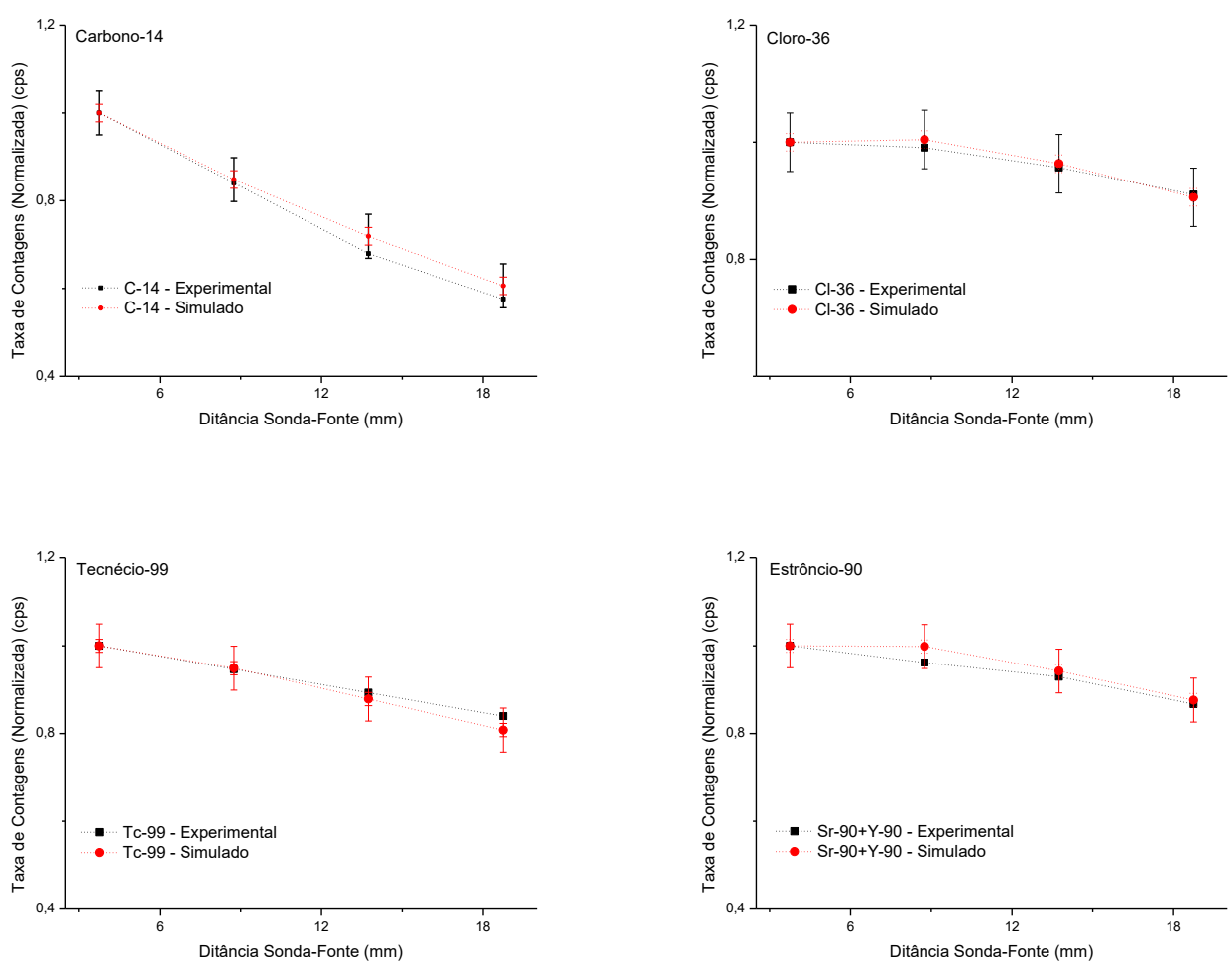

Fonte: autor da tese

\subsection{Conclusões Específicas}

As simulações tiveram uma grande importância no desenvolvimento desse trabalho, pois apenas com as simulações é possível ter-se os valores de taxa de contagens para uma fonte extensa de referência com 100\% de uniformidade.

Com as simulações realizadas com o código MCNP foi possível quantificar as diferenças entre taxa de contagens das fontes estudadas, tanto em condições de 100\% uniforme (condição ideal), como não uniforme (condição real).

Para o caso das fontes de ${ }^{14} \mathrm{C} \mathrm{e}{ }^{36} \mathrm{Cl}$ como sendo uniformes, hipótese adotada nos procedimentos de calibração de monitores de radiação de contaminação de superfície, os valores de eficiência da sonda são subestimadas em $15,1 \%$ e $6,6 \%$ respectivamente. 
Para as fontes de ${ }^{99} \mathrm{Tc},{ }^{137} \mathrm{Cs}$ e ${ }^{90} \mathrm{Sr}+{ }^{90} \mathrm{Y}$, os valores da resposta da sonda estariam superestimadas em 1,8\%; 5,0\% e 1,5\% respectivamente (SILVA JR, SIQUEIRA, et al., 2015).

No ANEXO A - Script do MCNP, é apresentado o imput do MCNP de forma simplificada, com o objetivo de facilitar eventuais simulações. 


\section{COMPARAÇÃO ENTRE DOIS TIPOS DE CORREÇÃO}

Foi realizada uma comparação entre o método numérico apresentado no Guia de Boas Práticas №14 e o método com MCNP desenvolvido nesse trabalho, usando como parâmetro de comparação o valor calculado da eficiência do instrumento.

\subsection{Método Numérico}

Seguindo as orientações apresentada no Apêndice 5 do Guia de Boas Práticas №14 do NPL (LEE e BURGESS, 2014), foram obtidos os valores de taxa de contagens (cps) para cada uma das 24 regiões (células) das fontes extensas de referência, sendo que serão apresentados apenas os cálculos para a fonte de ${ }^{14} \mathrm{C}$, como forma de ilustrar os cálculos, sendo que para as demais fontes tratadas neste trabalho foi seguido o mesmo procedimento de cálculo. Na Tabela 18 é apresentado uma matriz dos valores das taxas de contagens líquidas das 24 regiões em que foi dividida a fonte extensa de referência de ${ }^{14} \mathrm{C}$, obtidos na avaliação de sua uniformidade, com incertezas de $5 \%$.

Tabela 18 - Matriz da distribuição das taxas de contagem da fonte extensa de referência de ${ }^{14} \mathrm{C}$.

\begin{tabular}{llllll}
\hline 2,65 & 1,36 & 1,88 & 1,54 & 2,14 & 5,71 \\
\hline 3,61 & 1,44 & 2,19 & 2,96 & 4,36 & 7,84 \\
\hline 3,29 & 2,55 & 3,55 & 2,50 & 3,49 & 7,45 \\
\hline 3,15 & 2,90 & 3,25 & 3,06 & 3,16 & 3,10 \\
\hline
\end{tabular}

Fonte: autor da tese.

A Tabela 19 apresenta a matriz dos valores das taxas de contagens, apresentados na Tabela 18, normalizados pela média das taxas de contagens.

Tabela 19 - Matriz da distribuição das taxas de contagem da fonte extensa de referência de ${ }^{14} \mathrm{C}$.

\begin{tabular}{llllll}
\hline 0,80 & 0,41 & 0,57 & 0,47 & 0,65 & 1,73 \\
\hline 1,09 & 0,44 & 0,66 & 0,90 & 1,32 & 2,38 \\
\hline 1,00 & 0,77 & 1,08 & 0,76 & 1,06 & 2,26 \\
\hline 0,96 & 0,88 & 0,99 & 0,93 & 0,96 & 0,94 \\
\hline
\end{tabular}

Fonte: autor da tese. 
Para simplificação adotou-se neste trabalho a mesma nomenclatura utilizada pelo NPL.

Embora o Guia de Boas Práticas № 14 do NPL (LEE e BURGESS, 2014) recomende o uso da parte mais uniforme da fonte extensa de referência, optouse, neste trabalho, pela utilização da parte central das fontes, pois essa é a região comumente utilizada no processo de calibração. A sonda panqueca tem uma área sensível de $15,5 \mathrm{~cm}^{2}$, abrangendo parcialmente as quatro regiões centrais, que formam um quadrado de $5 \mathrm{~cm} \times 5 \mathrm{~cm}\left(25 \mathrm{~cm}^{2}\right)$. A fonte extensa de referência de ${ }^{14} \mathrm{C}$ utilizada está em desacordo com as exigências da norma ISO 8769:2016 (ASSOCIAÇÃO BRASILEIRA DE NORMAS TÉCNICAS, 2016), pois apresenta um valor de uniformidade de $50,3 \%$.

A Figura 16 apresenta um esquema com as 24 regiões na qual foi segmentada a fonte extensa de referência e a indicação da área sensível do detector sobreposta às quatro regiões centrais.

Figura 16 - Desenho esquemático da sobreposição da área sensível do detector à fonte extensa de referência segmentada em 24 regiões.

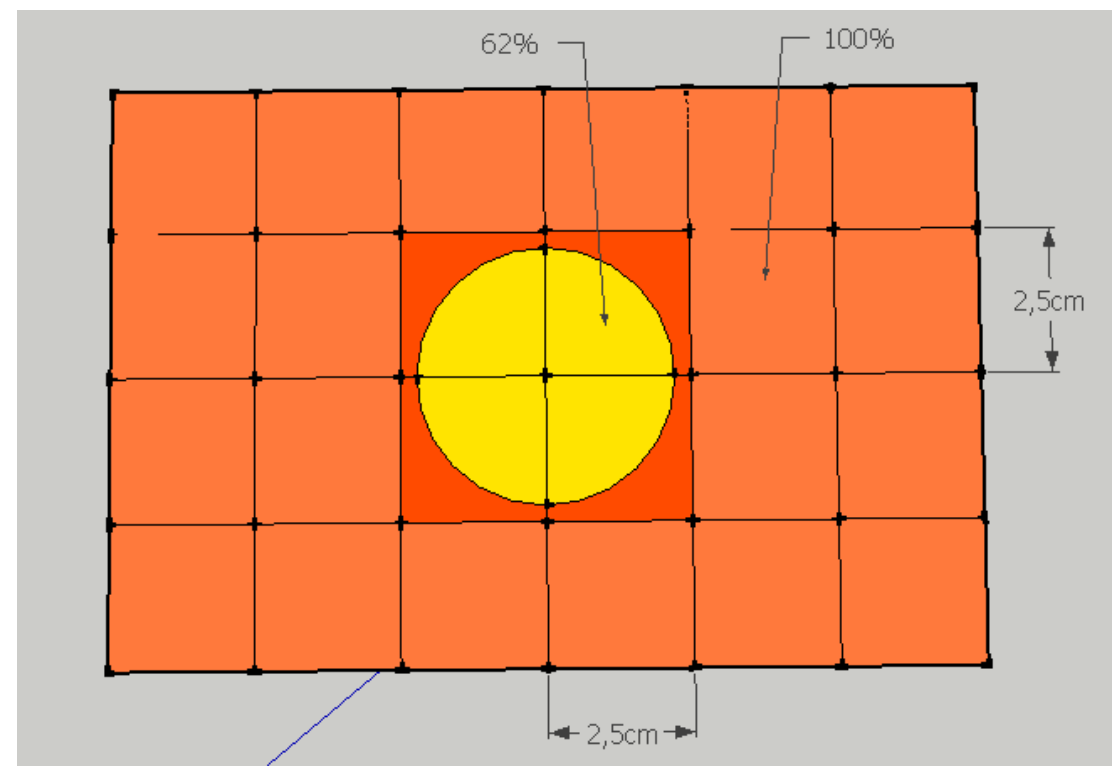

Fonte: autor da tese.

Conforme indicado na Figura 16, a região sensível do detector sobrepõe-se a $62 \%$ da área ativa de cada uma das quatro porções centrais (células). 
São apresentados a seguir os cálculos para obtenção do fluxo efetivo para a região abaixo da área sensível da sonda panqueca, conforme procedimentos apresentados no Guia de Boas Práticas № 14 do NPL.

Utilizando-se a Equação 6, obtém-se o valor do fluxo efetivo ( $S E R_{\text {eff) }}$.

$$
S E R_{e f f}=\frac{\sum_{i}\left(E_{N} \times f_{i}\right)}{\sum_{i} f_{i}} \times S E R
$$

Onde :

SER: valor do fluxo da fonte fornecido pelo certificado da fonte;

$E_{N}$ : leitura do instrumento para cada célula;

$f_{i}$ : é a fração de sobreposição da área ativa do detector sobre a região $i$.

Apresenta-se a seguir como forma ilustrativa, a aplicação da metodologia de cálculo para os dados referentes à fonte extensa de referência de ${ }^{14} \mathrm{C}$.

Utilizando-se a Equação 1 para calcular o fluxo efetivo da fonte extensa de referência de ${ }^{14} \mathrm{C}$ tem-se:

$$
\begin{gathered}
S E R_{e f f\left({ }^{14} C\right)}=\frac{(0,66+0,90+1,08+0,76) \times 0,62}{(0,62+0,62+0,62+0,62)} \times S E R_{\left({ }^{14} C\right)} \\
S E R_{e f f\left({ }^{4} C\right)}=0,849 \times S E R_{\left(^{*} C\right)}
\end{gathered}
$$

O valor do fluxo para a data das medições:

$$
\begin{gathered}
S E R_{\left({ }^{4} C\right)}=41,865 \mathrm{cps} \\
S E R_{e f f\left({ }^{\left({ }^{\circ} C\right)}\right)}=0,849 \times 41,865 \\
S E R_{e f f\left({ }^{14} \mathrm{C}\right)}=35,544 \mathrm{cps}
\end{gathered}
$$


A Equação 7 é utilizada para calcular a eficiência do instrumento em porcentagem $(\varepsilon)$ :

$$
\varepsilon=\frac{(R-B)}{S E R_{e f f}} \times 100
$$

onde $(R-B)$ é o valor obtido a partir da subtração das contagens de fundo das do valor medido (taxa de contagem líquida). Para o caso do ${ }^{14} \mathrm{C}$, tem-se:

$$
\begin{gathered}
\varepsilon_{\left({ }^{\wedge} C\right)}=\frac{(9,81-1,35)}{35,544} \times 100 \\
\varepsilon_{\left({ }^{\star} C\right)}=23,8 \%
\end{gathered}
$$

$\mathrm{Na}$ Tabela 20 são apresentados os valores calculados para todas as fontes extensas de referência avaliadas neste trabalho.

Tabela 20 - Valores de eficiência do instrumento calculados para cada uma das fontes avaliadas.

\begin{tabular}{cccccc}
\hline Nuclídeo & SER & SER eff & $\begin{array}{c}\text { R-B } \\
\text { cps }\end{array}$ & $\begin{array}{c}\varepsilon \\
\%\end{array}$ & $\begin{array}{c}\varepsilon_{\mathrm{NPL}} \\
\%\end{array}$ \\
\hline${ }^{14} \mathrm{C}$ & 41,865 & 35,544 & 8,46 & 20,2 & 23,8 \\
\hline${ }^{99} \mathrm{Tc}$ & 59,103 & 60,230 & 22,43 & 38,0 & 37,2 \\
\hline${ }^{36} \mathrm{Cl}$ & 66,441 & 61,928 & 32,35 & 48,7 & 52,2 \\
\hline${ }^{90} \mathrm{Sr}+{ }^{90} \mathrm{Y}$ & 87,645 & 89,017 & 49,53 & 56,5 & 55,6 \\
\hline
\end{tabular}

Fonte: autor da tese.

onde:

ع: Eficiência do instrumento sem a correção.

$\varepsilon_{\mathrm{NPL}}:$ Eficiência do instrumento com a correção numérica do NPL.

\subsection{Método com MCNP}

O MCNP (TEAM, 2003) é um código de transporte de radiação baseado no método de Monte Carlo. Este código permite a simulação dos principais 
componentes do sistema de calibração (fonte extensa de referência e detector), reproduzindo-se as condições em que a calibração é realizada, i.e., obtendo-se como resultado a estimativa de taxa de contagens no detector. Neste trabalho o MCNP5 foi utilizado para calcular a diferença de valores esperados na taxa de contagens do detector para duas condições de fonte distintas:

- Uniforme, em que a fonte apresenta um valor de uniformidade de $100 \%$ e

- Não uniforme, em que a especificação da fonte no código é dada pelo mapeamento de sua intensidade.

A simulação destas duas condições resulta em estimativas distintas de reposta do sistema, permitindo avaliar e quantificar a interferência da falta de uniformidade da fonte no procedimento de calibração.

Obtém-se o fator de correção devido à uniformidade da fonte extensa de referência a partir da razão entre o valor obtido pelas simulações para a fonte extensa de referência uniforme e não uniforme, proporcionando uma estimativa mais acurada para a eficiência do detector.

A Tabela 21 apresenta os valores obtidos para a taxa de contagem por simulações para as duas representações da fonte extensa de referência: uniforme e não uniforme, cujas incertezas relativas são de $0,15 \%$. Apresentam-se também as diferenças percentuais entre as estimativas de eficiência atribuídas e seus respectivos fatores de correção com suas incertezas.

Tabela 21 - Valores de taxa de contagens obtidos com as simulações e seus respectivos fatores de correção, calculados a partir da diferença.

\begin{tabular}{ccccc}
\hline \multirow{2}{*}{ Nuclídeo } & \multicolumn{2}{c}{ Distribuição das Intensidades } & Diferença & Fator de Correção \\
\cline { 2 - 4 } & $\begin{array}{c}\text { Uniforme } \\
\text { cps }\end{array}$ & $\begin{array}{c}\text { Não-Uniforme } \\
\text { cps }\end{array}$ & $\%$ & \\
\hline${ }^{14} \mathrm{C}$ & 9,61 & 8,15 & $-17,9$ & $1,179 \pm 0,003$ \\
\hline${ }^{99} \mathrm{Tc}$ & 22,73 & 23,19 & 2,0 & $0,980 \pm 0,002$ \\
\hline${ }^{36} \mathrm{Cl}$ & 34,45 & 32,07 & $-7,4$ & $1,074 \pm 0,002$ \\
\hline${ }^{90} \mathrm{Sr}+{ }^{90} \mathrm{Y}$ & 49,79 & 50,44 & 1,3 & $0,987 \pm 0,002$ \\
\hline
\end{tabular}

Fonte: autor da tese. 
$\mathrm{Na}$ Tabela 22 são apresentados os valores de eficiência do instrumento com base nas medidas obtidas com a sonda tipo panqueca, para os três casos:

Cálculo sem correção $(\varepsilon)$, com correção numérica proposta pelo NPL no Guia de Boas Práticas № 14 (LEE e BURGESS, 2014) $\left(\varepsilon_{\mathrm{NPL}}\right)$ e com o código MCNP5 (TEAM, 2003) ( $\left.\varepsilon_{\text {MCNP5 }}\right)$. São apresentadas as incertezas de um desviopadrão nos valores da eficiência do instrumento para os três casos, sem a aplicação de correção, corrigida pelo MCNP5 e NPL.

Tabela 22 - Valores de eficiência do instrumento, sem correção, com correção pelo método do NPL e pelo MCNP5.

\begin{tabular}{cccc}
\hline \multirow{2}{*}{ Nuclídeos } & $\varepsilon$ & $\varepsilon_{\mathrm{NPL}}$ & $\varepsilon_{\mathrm{MCNP5}}$ \\
& $\%$ & $\%$ & $\%$ \\
\hline${ }^{14} \mathrm{C}$ & $20,2 \pm 0,5$ & $23,8 \pm 0,6$ & $23,8 \pm 0,6$ \\
\hline${ }^{99} \mathrm{TC}$ & $38,0 \pm 0,8$ & $37,2 \pm 0,8$ & $37,2 \pm 0,8$ \\
\hline${ }^{36} \mathrm{Cl}$ & $48,7 \pm 0,9$ & $52,2 \pm 1,1$ & $52,3 \pm 1,0$ \\
\hline${ }^{90} \mathrm{Sr}+{ }^{90} \mathrm{Y}$ & $56,5 \pm 1,0$ & $55,6 \pm 1,1$ & $55,8 \pm 1,0$ \\
\hline
\end{tabular}

Fonte: autor da tese.

Observa-se, a partir dos dados apresentados na Tabela 22 que os valores de eficiência do instrumento obtidos pelas três metodologias $(\varepsilon$ - sem correção; $\varepsilon_{N P L}$ - com correção numérica de uniformidade e $\varepsilon_{M C N P}$ - com correção de uniformidade via simulação) apresentam uma concordância qualitativa, i.e., a estimativa de eficiência do instrumento aumenta com o aumento da energia máxima das partículas betas da fonte. Observa-se que os valores de eficiência estimados pelas duas metodologias de correção apresentadas neste trabalho são muito próximos entre si, mostrando uma equivalência nas correções propostas. Contudo, ao se comparar aos valores de eficiência, sem correção e com correção, chega-se à proposição de valores estatisticamente distintos e eventualmente incompatíveis (casos do ${ }^{14} \mathrm{C} \mathrm{e}{ }^{36} \mathrm{Cl}$ ). 


\subsection{Conclusões Específicas}

As avaliações de eficiência do instrumento em procedimentos de calibração podem ser significativamente afetadas pela falta de uniformidade da fonte extensa de referência usada no procedimento. Obtiveram-se valores de eficiência do instrumento que diferiram em até 15\% (3 em 20) em relação aos valores corrigidos para a fonte de ${ }^{14} \mathrm{C}$, que é, entre as fontes estudadas, aquela com menor valor de uniformidade, o que evidencia a importância da adoção do uso de fatores de correção devido à uniformidade, para fontes extensas de referência que não atendam às recomendações de uniformidade da norma ISO 8769:2016.

As metodologias de correção adotadas apresentaram estimativas de eficiência do instrumento estatisticamente iguais para todos os valores, demonstrando concordância entre ambas as correções da eficiência do instrumento (SILVA JR, SIQUEIRA, et al., 2016). 


\section{NOVA METODOLOGIA DE CALIBRAÇÃO}

Para auxiliar na aplicação da nova metodologia de calibração, foram desenvolvidos um sistema automatizado de posicionamento das fontes extensas de referência e um software para calcular os fatores de correção.

\subsection{Sistema Automatizado de Calibração}

\subsubsection{Sistema de Calibração do LCI-IPEN}

$\mathrm{O}$ arranjo atual de calibração dos monitores de radiação adotado no LCl consiste no posicionamento do monitor de radiação em aferição sobre uma plataforma de alumínio, com uma abertura circular central. A fonte extensa de referência utilizada na calibração é posicionada manualmente em um suporte abaixo desta plataforma de tal modo que o centro da abertura da plataforma se sobreponha ao centro da fonte. A plataforma é acoplada a um sistema de controle de movimentação ao longo do eixo vertical, permitindo a alteração da distância, fonte-sonda, caso necessário, conforme Figura 17.

Figura 17 - Sistema de calibração do LCI-IPEN.

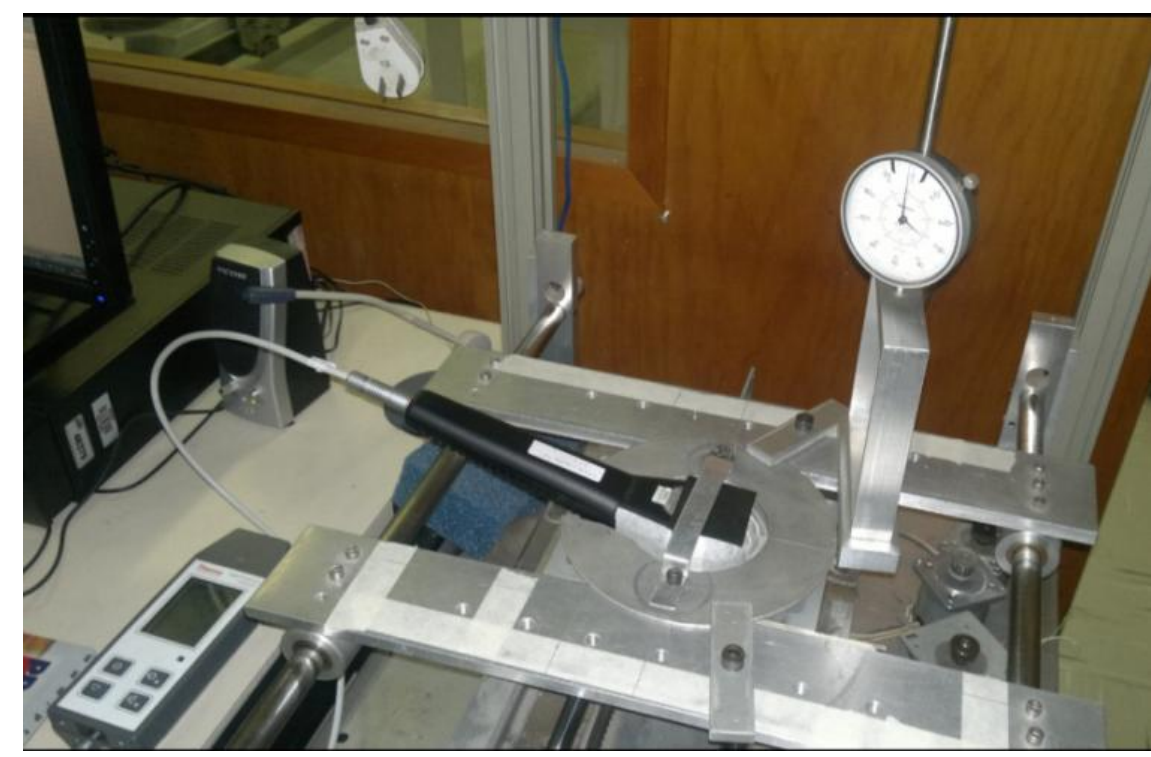

Fonte: autor da tese. 


\subsubsection{Protótipo do Sistema Automatizado de Calibração}

Foi desenvolvido um protótipo do sistema automatizado de posicionamento das fontes extensas de referência, para ser utilizado no processo de calibração dos monitores de contaminação de superfície.

Os principais itens utilizados nesse protótipo foram:

Uma placa Arduino Mega 2560;

Driver Motor de Passo L293D;

Display 16X2;

Módulo Serial I2C para Display LCD Arduino;

Motor de Passo;

A Figura 18 mostra os itens listados.

Figura 18 - Itens utilizados no protótipo.

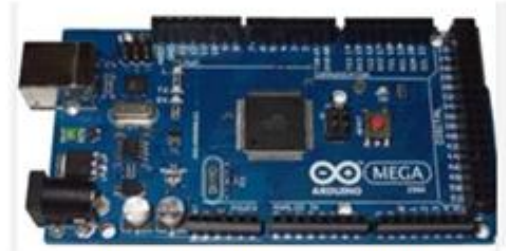

Placa Arduino Mega 2560

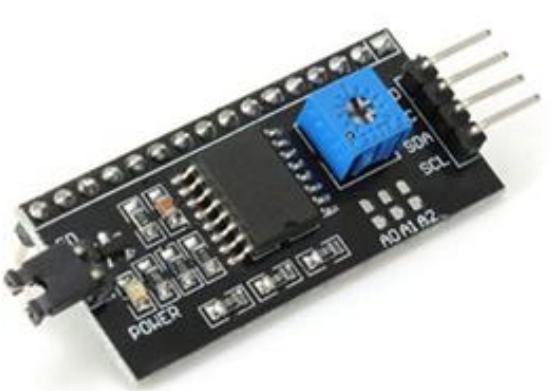

Módulo I2C para display

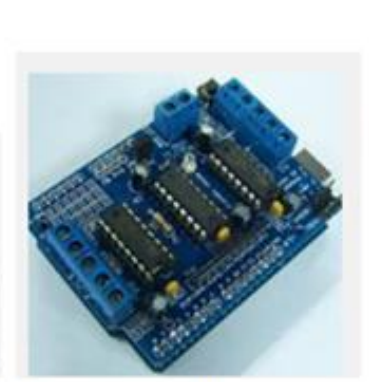

Driver motor de passo

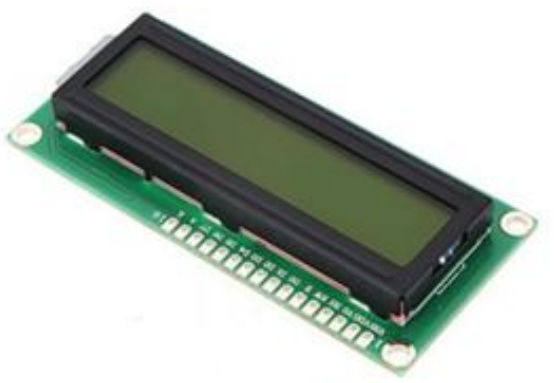

Display $16 \times 20$

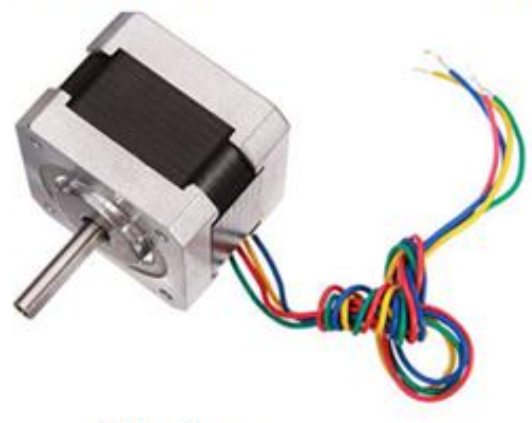

Motor de passo

Fonte: autor da tese.

A Figura 19 mostra o protótipo montado e funcional, assim como uma roda de posicionamento das fontes confeccionado em madeira, para os testes iniciais. 
Figura 19 - (a) Protótipo do sistema automatizado e (b) roda de posicionamento das fontes extensas de referência.

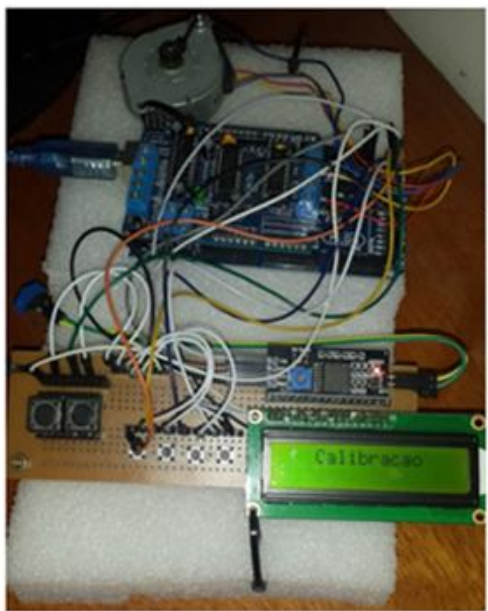

(a)

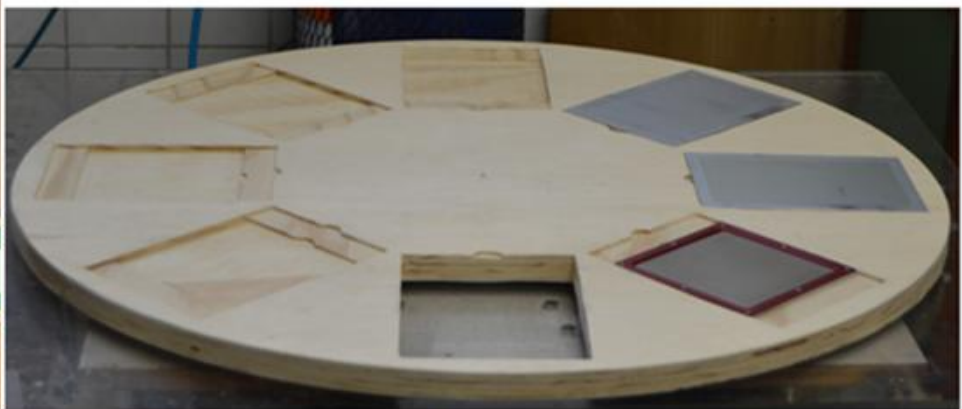

(b)

Fonte: autor da tese.

\subsubsection{Sistema Automatizado de Calibração}

O projeto do protótipo desenvolvido foi enviado para confecção por uma empresa ${ }^{8}$ contratada para este serviço. O sistema foi confeccionado em acrílico e metal e está demonstrado na Figura 20.

Figura 20 - (a) Projeto do sistema automatizado de calibração e (b) equipamento produzido.

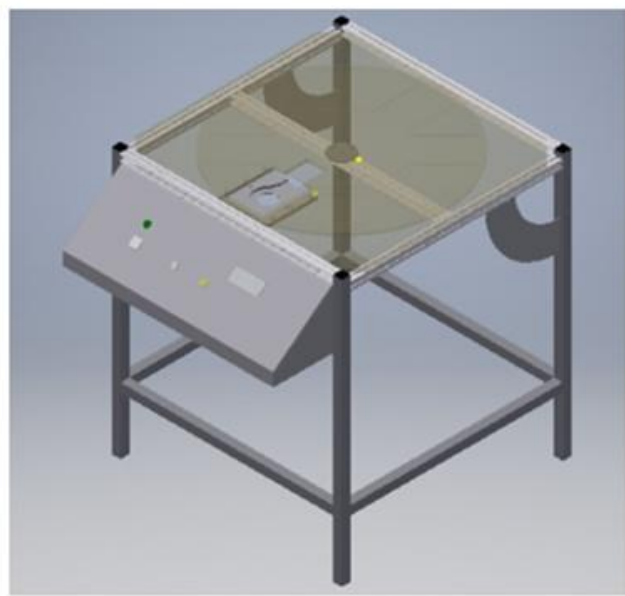

(a)

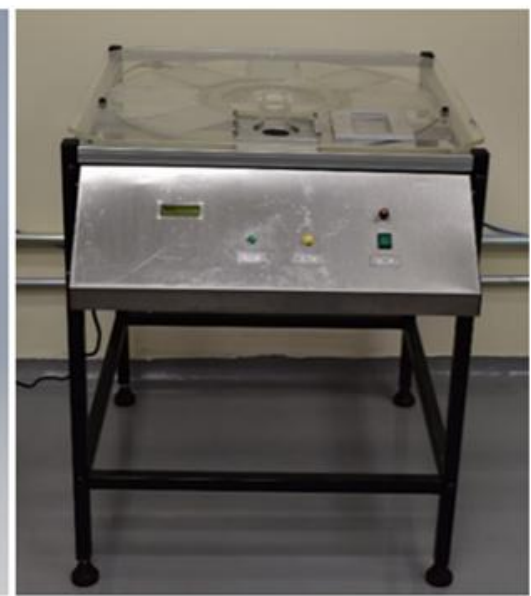

(b)

Fonte: autor da tese.

\footnotetext{
${ }^{8}$ Promec - Fabiana Dias Coqueiro ME.
} 
A Figura 21 mostra detalhes do sistema automatizado de calibração.

Figura 21 - (a) Visão da parte superior do equipamento e (b) detalhe do local de posicionamento da sonda.

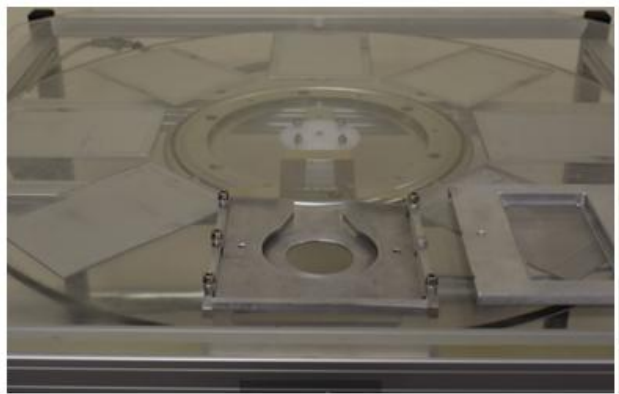

(a)

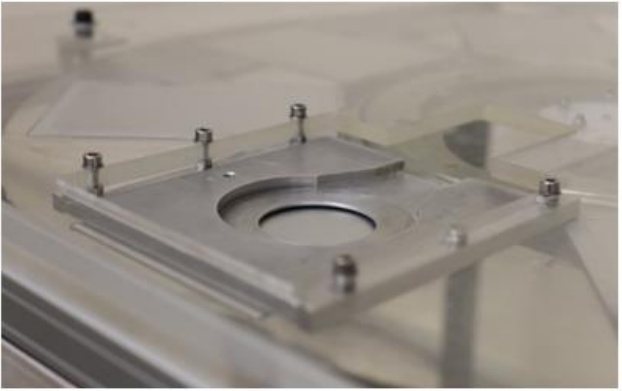

(b)

Fonte: autor da tese.

\subsubsection{Conclusões Específicas}

O desenvolvimento do sistema automatizado de calibração de monitores de radiação de contaminação de superfície trouxe diversas vantagens, como:

Evitar o manuseio das fontes extensas de referência pelo técnico responsável pelas calibrações, uma vez que as fontes ficam confinadas na parte interna do equipamento, ficando assim blindadas pelo acrílico, que serve como blindagem e proteção física, promovendo uma redução na dose.

Garantir a reprodutibilidade das calibrações por qualquer técnico, uma vez que o posicionamento das fontes é automatizado, bastando selecionar a fonte que será utilizada, sendo a distância fonte-sonda fixa em $3 \mathrm{~mm}$ e o posicionamento da fonte é realizado por um motor de passo, que garante sempre a mesma posição.

\subsection{Software de Cálculo dos Fatores de Correção}

Com o objetivo de facilitar o cálculo dos fatores de correção para cada fonte extensa de referência utilizada pelo laboratório, foi desenvolvido um software em linguagem Pascal no software Livre Lazarus.

Esse software será utilizado com as medidas das taxas de contagens do mapeamento da fonte. Foi desenvolvido para calcular os fatores de correção para 
as fontes extensas de referência de dimensões quadrada de $100 \mathrm{~cm}^{2}$, retangular de $150 \mathrm{~cm}^{2}$ e circular de $63,62 \mathrm{~cm}^{2}$ de áreas ativas.

A Figura 22 mostra a tela inicial do software, com as três opções de fontes que podem ser selecionadas.

Figura 22 - Tela inicial do software para calcular os fatores de correção.

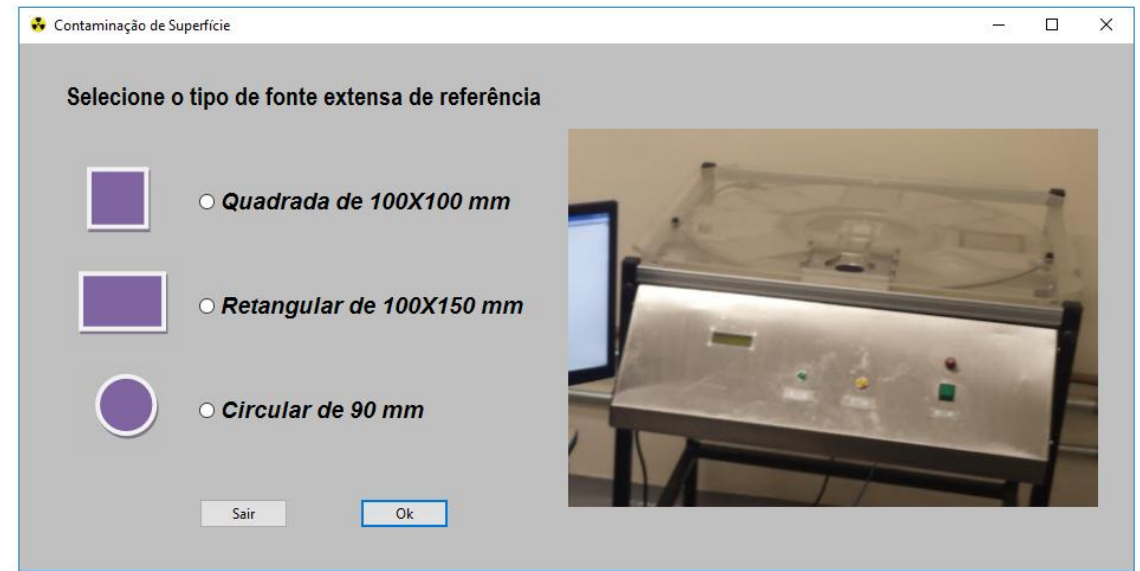

Fonte: autor da tese.

Ao selecionar a primeira opção (Quadrada de $100 \mathrm{~mm} \times 100 \mathrm{~mm}$ ), temos a tela apresentada na Figura 23.

Basta digitar os valores correspondentes a cada posição de célula realizada no mapeamento da fonte. Esse procedimento só precisa ser feito uma vez após o mapeamento, depois esse valor do fator de correção deve ser anotado e usado sempre para corrigir o valor da eficiência do instrumento, gerando assim um valor de eficiência do instrumento corrigido. Será gerado um fator de correção para cada fonte, além de fornecer o valor de uniformidade central e total da fonte extensa de referência. 
Figura 23 - Tela da opção: Quadrada de 100mm x 100 mm.

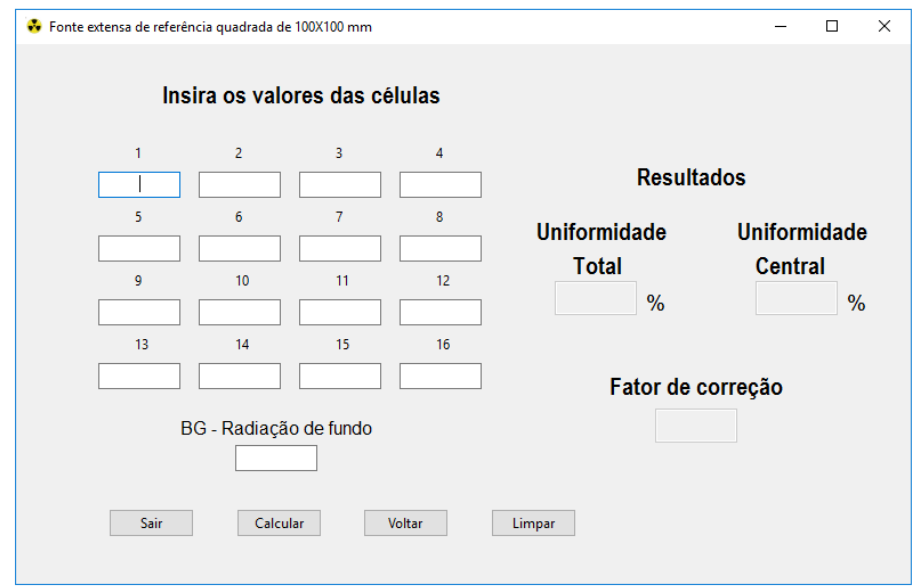

Fonte: autor da tese.

Uma observação importante é que o fator de correção gerado é para a sonda do tipo panqueca, mas tanto o sistema automatizado de calibração, quanto o software foram projetados para realizar calibrações e gerar fatores de correção para monitores de radiação do tipo MIP10, que possuem duas sondas GeigerMüller e por isso só sendo possível sua calibração em fontes extensas de referência de $100 \mathrm{~mm} \times 150 \mathrm{~mm}\left(150 \mathrm{~cm}^{2}\right)$, por esse motivo, na escolha da segunda opção (Retangular de $100 \mathrm{~mm} \times 150 \mathrm{~mm}$ ) irá aparecer na tela uma opção adicional, que será o fator de correção para instrumento do tipo MIP10, conforme mostra a Figura 24.

Figura 24 - Tela da opção: Retangular de 100mm x 150mm.

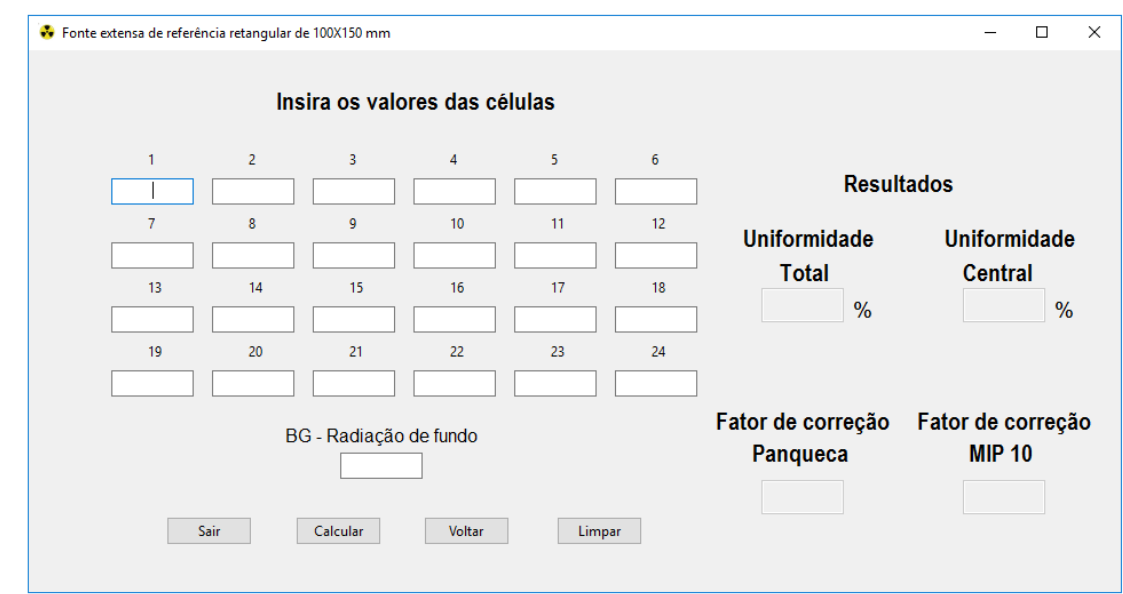

Fonte: autor da tese. 
$\mathrm{Na}$ escolha da terceira opção (Circular de $90 \mathrm{~mm}$ ), a tela é igual a tela da primeira opção, porem a forma de calcular é diferente, pois leva em consideração que a fonte é circular, embora se digite os valores de medidas da uniformidade como sendo uma fonte quadrada, a Figura 25 mostra a última tela, no Apêndice B é possível visualizar a forma como os cálculos foram escritos em linguagem de programação Pascal.

Figura 25 - Tela da opção: Circular de $90 \mathrm{~mm}$.

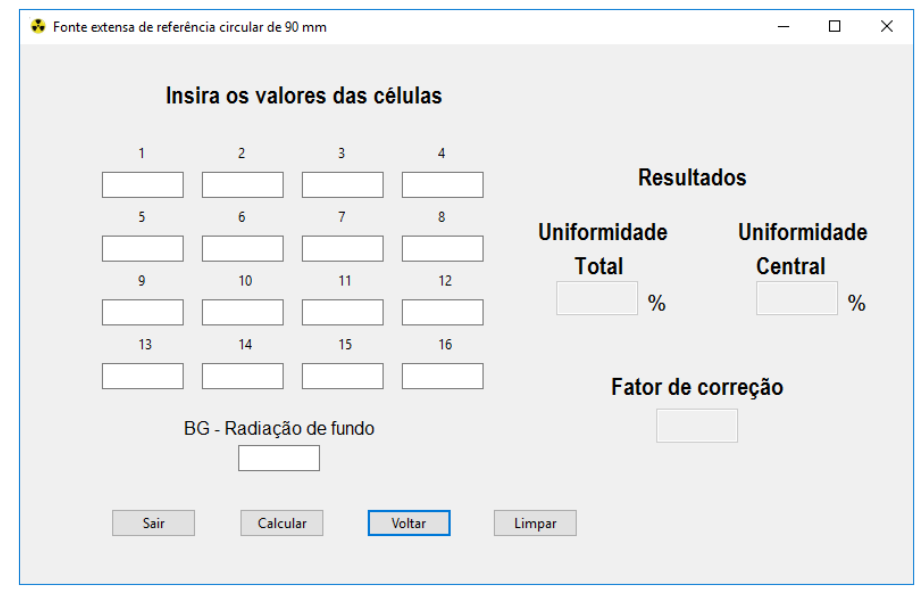

Fonte: autor da tese.

\subsubsection{Conclusões Específicas}

Esse software facilitou o cálculo dos fatores de correção utilizando a metodologia disponibilizada pelo NPL no Guia de Boas Práticas №14. Foi escolhida essa metodologia como forma de simplificar o uso por qualquer laboratório de calibração, uma vez que seriam necessários conhecimentos de simulação com o código MCNP para obter esses fatores de correção pelo método desenvolvido nesse trabalho.

Foi escolhido o software de código aberto Lazarus para desenvolver o programa de cálculo dos fatores de correção, por ser um software de código aberto e por tanto de uso livre, podendo ser disponibilizado o software desenvolvido nesse trabalho aos laboratórios que tenham interesse em usar, no final é apresentado o código fonte nos anexos (ANEXO B - Script do software). 


\subsection{Fatores de Correção}

Os fatores de correção podem ser obtidos por dois métodos já discutidos nesse trabalho, na seção 7 (Comparação entre dois tipos de correção):

Por meio do método numérico foi obtido o fator de correção $\left(\mathrm{FC}_{\mathrm{npl}}\right)$ após realizar a correção do fluxo sob a área a ser utilizada, bastando calcular a razão entre o valor do fluxo sem correção (SER) e o corrigido (SER eff $_{\text {), conforme }}$ Equação 8:

$$
F C_{n p l}=\frac{S E R}{S E R_{e f f}}
$$

Também é possível obter o fator de correção $\left(\mathrm{FC}_{\mathrm{mcnp}}\right)$ pelo método desenvolvido nesse trabalho, bastando calcular a razão entre as taxas de contagens líquidas na sonda, obtidas por simulação para o caso 100\% uniforme $\left(\rho_{u}\right)$ e o não uniforme $\left(\rho_{\text {nu }}\right)$, simulado com os pesos obtidos no mapeamento da uniformidade, conforme Equação 9:

$$
F C_{m c n p}=\frac{\rho_{u}}{\rho_{n u}}
$$

Ambos os métodos fornecem fatores de correção que são numericamente idênticos, mas com diferenças em suas incertezas.

O objetivo final é usar esses fatores de correção para corrigir o valor da eficiência do instrumento, pois esse é 0 item presente em todas as fórmulas fornecidas na norma ISO 7503-3:2016 (BRITISH STANDARD INTERNATIONAL, 2016), para obter grandezas que descrevem o instrumento, como:

Eficiência do instrumento;

Resposta do instrumento (em termos de emissões ou atividade);

Fator de calibração (em termos de emissões ou atividade). 


\subsection{Variabilidade}

A variabilidade é aqui definida como um parâmetro associado à distribuição superficial ao longo da fonte extensa de referência.

Esse parâmetro foi utilizado com o objetivo de verificar se a uniformidade da fonte é adequada para restringir seu uso no procedimento de calibração. Em caso afirmativo, os valores de eficiência do instrumento atribuídos aos monitores de radiação seriam dependentes da energia média da fonte de radiação, mas não de sua distribuição ao longo da superfície da fonte extensa de referência, isto é, da variabilidade, desde que atendido o critério de uniformidade.

Como os valores de eficiência do instrumento $(\varepsilon)$ dependem da taxa de contagens líquida $\left(\rho_{c}\right)$, foram avaliados unicamente os fatores de correção fornecidos pelas duas metodologias empregadas neste trabalho. $O$ valor dos fatores de correção $\left(\mathrm{FC}_{\mathrm{npl}}\right)$ e $\left(\mathrm{FC}_{\mathrm{mcnp}}\right)$ foram utilizados para avaliar quanto à eficiência do instrumento $(\varepsilon)$ depende da variabilidade, ou seja, da distribuição da fonte para um mesmo valor de uniformidade.

Avaliou-se o comportamento de fontes extensas de referência que atendiam às exigências da norma ISO 8769:2016 (ASSOCIAÇÃO BRASILEIRA DE NORMAS TÉCNICAS, 2016) quanto ao valor de uniformidade (maior que $90 \%$ ), mas em condições de distribuição de intensidade diferentes. A partir dos valores de intensidade de emissão de radiação das células, obtidos experimentalmente no procedimento de mapeamento das fontes de ${ }^{99} \mathrm{Tc} e$ ${ }^{90} \mathrm{Sr}^{9}{ }^{90} \mathrm{Y}$, rearranjaram-se os valores de intensidades de emissão de radiação de cada uma destas fontes em outras três distribuições, obtendo um conjunto de quatro representações para cada fonte, sendo uma distribuição real e as outras três hipotéticas, com o mesmo valor de uniformidade para cada fonte, porque o cálculo da uniformidade só depende da média dos valores das células e do desvio padrão das medidas.

As Figuras 26 e 27 apresentam, respectivamente, os histogramas das distribuições de intensidades das taxas de emissão de radiação das fontes de ${ }^{99} \mathrm{Tc} \mathrm{e}{ }^{90} \mathrm{Sr}+{ }^{90} \mathrm{Y}$ para quatro distribuições de fonte: 
(a) distribuição experimental original, onde se manteve a distribuição de intensidades das células obtidas experimentalmente pelo mapeamento das fontes;

(b) distribuição em rampa, onde a distribuição de intensidades foi ordenada de forma decrescente;

(c) distribuição central, onde as maiores intensidades foram atribuídas às células de posição central;

(d) distribuição marginal, onde as maiores intensidades foram atribuídas às células das extremidades, ficando a parte central, correspondente à parte sobre a qual o monitor foi posicionado com as células de menores intensidades.

Figura 26 - Distribuições de intensidade de emissão da fonte de ${ }^{99} \mathrm{Tc}$ : a) experimental, b) rampa, c) central e d) marginal.
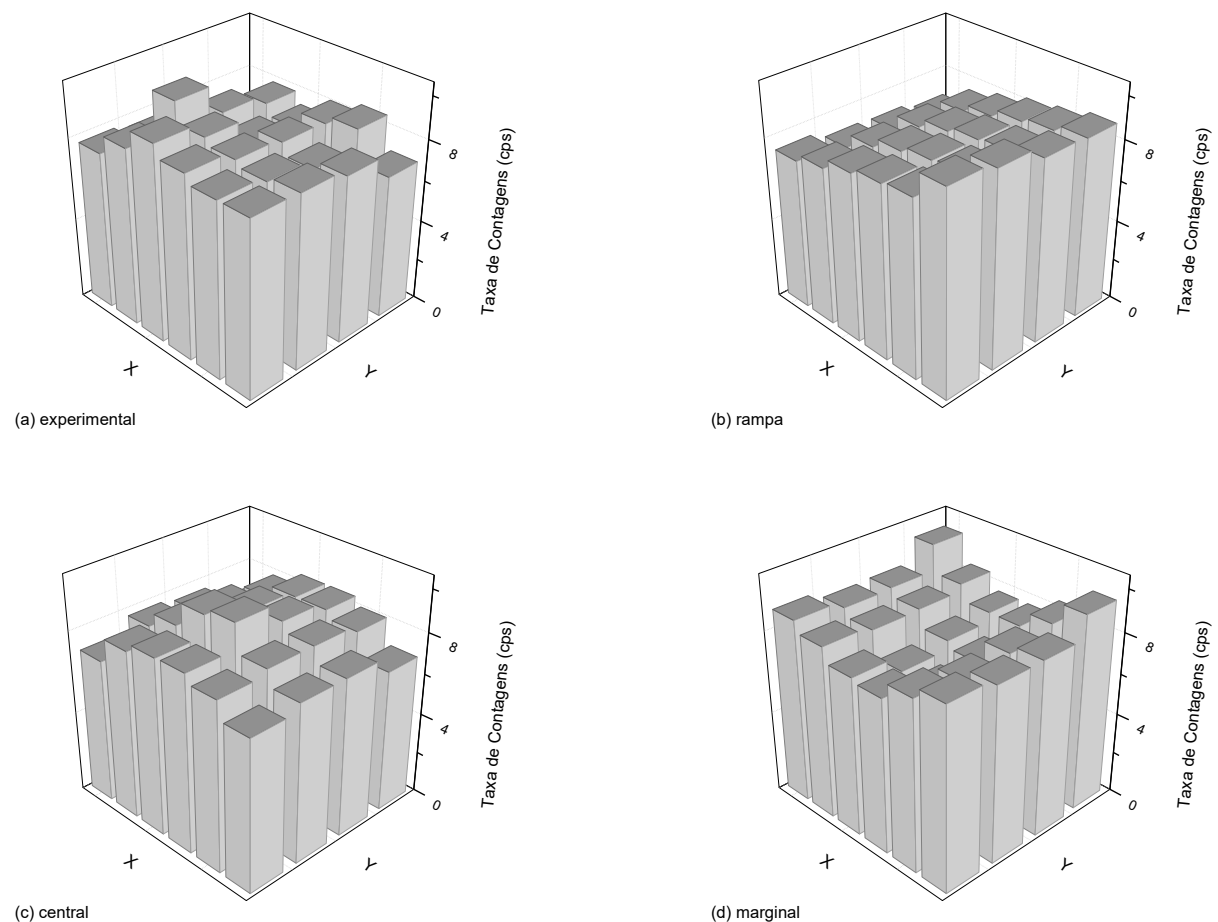

Fonte: autor da tese. 
Figura 27 - Distribuições de intensidade de emissão da fonte de ${ }^{90} \mathrm{Sr}+{ }^{90} \mathrm{Y}$ : a) experimental, b) rampa, c) central e d) marginal.

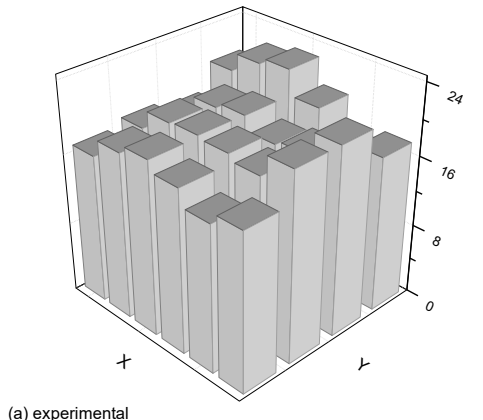

(a) experimental

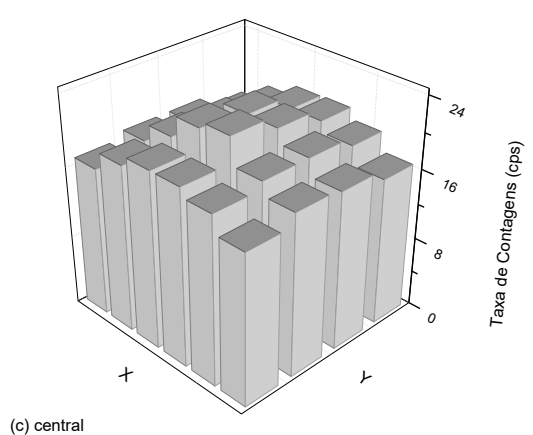

(c) central

Fonte: autor da tese.
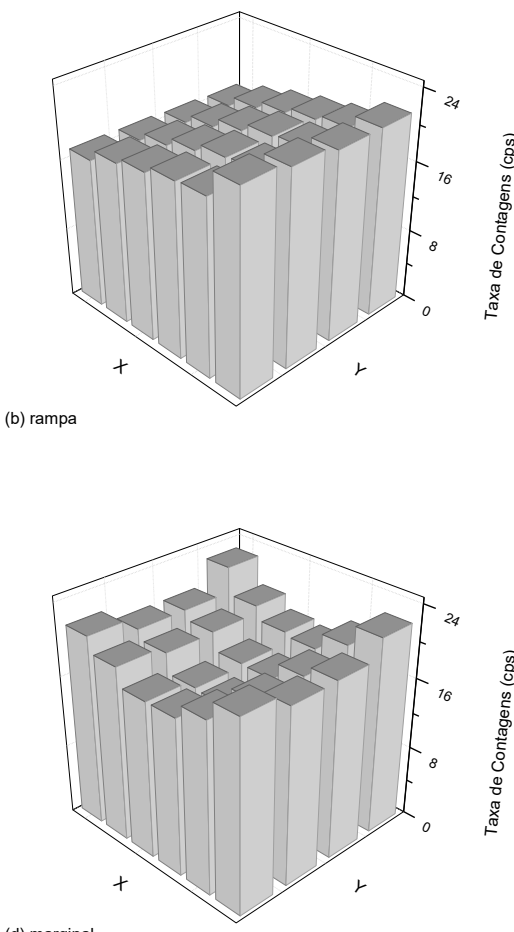

(d) marginal

A Tabela 23 mostra os valores dos fatores de correção, obtidos pela metodologia de correção apresentada neste trabalho para cada uma das quatro distribuições de emissões das fontes de ${ }^{99} \mathrm{Tc} \mathrm{e}{ }^{90} \mathrm{Sr}+{ }^{90} \mathrm{Y}$ apresentadas nas Figuras 27 e 28. Apresentam-se também os valores estimados para as eficiências $(\varepsilon)$ que seriam obtidos caso não se aplicassem os fatores de correção ( $F C_{m c n p}$ ) e as diferenças percentuais $(\Delta \varepsilon)$ em relação aos valores de eficiência corrigidos $\left(\varepsilon_{\mathrm{mcnp}}\right)$.

Tabela 23 - Efeito da variabilidade das fontes de ${ }^{99} \mathrm{Tc} \mathrm{e}^{90} \mathrm{Sr}+{ }^{90} \mathrm{Y}$ usando o método MCNP.

\begin{tabular}{c|c|c|c|c|c|c}
\hline \multirow{2}{*}{ Distribuição } & \multicolumn{3}{|c|}{${ }^{99} \mathrm{Tc}$} & \multicolumn{3}{c}{${ }^{90} \mathrm{Sr}+{ }^{90} \mathrm{Y}$} \\
\cline { 2 - 7 } & \multicolumn{3}{|c|}{$\varepsilon_{\mathrm{mcnp}}=37,2 \%$} & \multicolumn{3}{c}{$\varepsilon_{\mathrm{mcnp}}=55,8 \%$} \\
\cline { 2 - 7 } & $\varepsilon$ & $\Delta \varepsilon$ & \multirow{2}{*}{$\% C_{\mathrm{mcnp}}$} & $\begin{array}{c}\varepsilon \\
\%\end{array}$ & $\begin{array}{c}\Delta \varepsilon \\
\%\end{array}$ & $\mathrm{FC}_{\mathrm{mcnp}}$ \\
\hline Experimental & 38,0 & 2,0 & 0,980 & 56,5 & 1,3 & 0,987 \\
\hline Rampa & 38,6 & 3,7 & 0,963 & 57,9 & 3,7 & 0,963 \\
\hline Central & 44,0 & 15,5 & 0,845 & 66,1 & 15,6 & 0,844 \\
\hline Marginal & 33,2 & $-12,0$ & 1,120 & 50,8 & $-9,9$ & 1,099 \\
\hline
\end{tabular}

Fonte: autor da tese. 
Pode-se observar pela Tabela 23 que uma fonte de um radionuclídeo específico, à qual é associada uma energia de calibração, e que têm o mesmo valor de uniformidade, teria valor de eficiência diferente se não fosse aplicado fator de correção.

As expectativas de eficiência do instrumento atribuídas aos monitores de contaminação de superfície, adotando-se fontes com as distribuições estudadas e sem a adoção da metodologia de correção, variariam entre 33,2\% e 44,0\% para o ${ }^{99} \mathrm{Tc}$ e entre $50,8 \%$ e $66,1 \%$ para ${ }^{90} \mathrm{Sr}+{ }^{90} \mathrm{Y}$.

As eficiências podem ser superestimadas (distribuição central) ou subestimadas (distribuição marginal) e apresentar uma variação na eficiência do instrumento $(\Delta \varepsilon)$ de até $15 \%$ em relação à distribuição experimental para a mesma fonte extensa de referência, mesmo para fontes que tenham valores de uniformidade melhor que $90 \%$.

Os fatores de correção obtidos pela metodologia usando o código MCNP apresentam uma correlação mais pronunciada com as distribuições de intensidades do que com a uniformidade da fonte extensa de referência.

A Tabela 24 mostra a mesma informação tratada na Tabela 23, mas calculada pela metodologia desenvolvida a partir do método de correção proposto pela NPL e mostra os fatores de correção $\left(F_{n p l}\right)$ que seriam obtidos pela aplicação dessa metodologia para as distribuições de fontes consideradas.

Tabela 24 - Efeito da variabilidade das fontes de ${ }^{99} \mathrm{Tc}{ }^{90} \mathrm{Sr}+{ }^{90} \mathrm{Y}$ usando o método do NPL.

\begin{tabular}{|c|c|c|c|c|c|c|c|c|}
\hline \multirow{3}{*}{ Distribuição } & \multicolumn{4}{|c|}{${ }^{99} \mathrm{Tc}$} & \multicolumn{4}{|c|}{${ }^{90} \mathrm{Sr}+{ }^{90} \mathrm{Y}$} \\
\hline & \multicolumn{4}{|c|}{$\varepsilon_{\mathrm{npl}}=37,2 \%$} & \multicolumn{4}{|c|}{$\varepsilon_{\mathrm{npl}}=55,6 \%$} \\
\hline & $\mathrm{FC}_{\mathrm{npl}}$ & $\begin{array}{c}\varepsilon \\
\%\end{array}$ & $\begin{array}{c}\Delta \varepsilon \\
\%\end{array}$ & $\begin{array}{c}\Delta \mathrm{FC} \\
\%\end{array}$ & $\mathrm{FC}_{\mathrm{npl}}$ & $\begin{array}{c}\varepsilon \\
\%\end{array}$ & $\begin{array}{c}\Delta \varepsilon \\
\%\end{array}$ & $\begin{array}{c}\Delta \mathrm{FC} \\
\%\end{array}$ \\
\hline Experimental & 0,981 & 37,9 & 1,9 & 0,1 & 0,985 & 56,4 & 1,5 & 0,2 \\
\hline Rampa & 0,985 & 37,8 & 1,5 & 2,2 & 0,994 & 55,9 & 0,6 & 3,1 \\
\hline Central & 0,881 & 42,2 & 11,9 & 4,1 & 0,875 & 63,5 & 12,5 & 3,5 \\
\hline Marginal & 1,168 & 31,8 & $-16,8$ & 4,1 & 1,143 & 48,6 & $-14,3$ & 3,8 \\
\hline
\end{tabular}

Fonte: autor da tese. 
Os valores de eficiência do instrumento e fatores de correção obtidos por ambas as metodologias são muito próximos; as diferenças entre os fatores de correção não superam $4,1 \%(\Delta \mathrm{FC})$.

As eficiências do instrumento não corrigidas $(\varepsilon)$ são obtidas pela razão entre o valor de eficiência do instrumento corrigido $\left(\varepsilon_{n p l}\right)$ e seu respectivo fator de correção $\left(\mathrm{FC}_{\mathrm{npl}}\right)$. Estas eficiências são mostradas para enfatizar os efeitos de tais distribuições.

Observa-se também que os valores do fator de correção obtidos pelas duas metodologias utilizadas são ligeiramente diferentes entre $\mathrm{si}$, as colunas da $(\triangle \mathrm{FC})$ na Tabela 24 apresentam percentual diferenças entre os fatores de correção obtidos pelas duas metodologias, evidenciando a equivalência de seu uso mesmo para situações muito diferentes (central x marginal).

Os dados apresentados na Tabela 24 reiteram as informações e análises apresentadas na Tabela 23. Portanto, pode-se afirmar que a uniformidade não é um parâmetro suficiente para caracterizar fontes extensas de referência.

A variação nos valores de eficiência do instrumento que seriam atribuídos aos monitores de radiação, sugere que o mapeamento e aplicação de fatores de correção são etapas necessárias em procedimentos de calibração de monitores de radiação de contaminação de superfície.

\subsection{Método de Calibração Direto}

A calibração de monitores de contaminação de superfície pelo método direto consiste em se posicionar a sonda a uma distância de $3 \mathrm{~mm}$ da superfície da fonte extensa de referência e se realizar uma série de medidas. Estas são normalizadas, considerando-se a relação entre as áreas da fonte e da sonda, introduzidas numa equação que subtrai a leitura da radiação de fundo (BG) e relaciona este valor ao fluxo de emissão da fonte extensa de referência (INSTITUTO DE PESQUISAS ENERGÉTICAS E NUCLEARES, 1996). 


\subsection{Cálculo do Fator de Calibração}

A norma ISO 7503-3 apresenta uma tabela com fórmulas de grandezas que descrevem o instrumento. Todas essas fórmulas estão relacionadas à eficiência do instrumento, sendo o fator de calibração um dos mais utilizados dessa tabela pelos laboratórios de calibração; essa tabela ajuda a mostrar a importância de usar um valor de eficiência do instrumento corrigido para um valor o mais próximo possível do valor verdadeiro convencional (BRITISH STANDARD INTERNATIONAL, 2016).

\subsection{Proposta de Nova Metodologia de Calibração}

A nova metodologia de calibração de monitores de radiação de contaminação de superfície possibilita o emprego de fontes extensas de referência que normalmente não poderiam ser utilizadas, por conta das exigências de uniformidade da norma ISO 8769:2016 (ASSOCIAÇÃO BRASILEIRA DE NORMAS TÉCNICAS, 2016), que recomenda o uso de fontes com uniformidade melhor que $90 \%$.

Nessa nova metodologia de calibração é necessário realizar o mapeamento da uniformidade das fontes extensas de referência que serão utilizadas. Com esses valores são calculados os fatores de correção devido à falta de uniformidade para cada fonte extensa de referência, não sendo mais o valor de uniformidade uma característica importante para avaliar se uma fonte deve ou não ser utilizada, desde que se utilize o fator de correção calculado.

Esse fator de correção deve ser calculado para cada fonte, podendo ser calculado com o emprego do código de transporte de radiação MCNP, como foi realizado nesse trabalho e apresentado no item 6 (DESENVOLVIMENTO EM MCNP5) ou pelo método apresentado no apêndice 5 do Guia de Boas Práticas №14 do NPL (LEE e BURGESS, 2014) e também apresentado aqui no item 7.1 (Método Numérico), uma vez que ambos os métodos se mostraram praticamente iguais em seus resultados.

O método desenvolvido nesse trabalho com o uso de simulações em código MCNP, tem a vantagem de obter valores extremamente baixos de 
incertezas, mas com a desvantagem de exigir domínio de técnicas de simulação de transporte de radiação, enquanto o método numérico do NPL tem a desvantagem de trazer valores de incertezas mais altos, mas com a vantagem de ser extremamente simples de ser utilizado.

Uma grande vantagem ao se usar fatores de correção devido à falta de uniformidade das fontes extensas de referência é a possibilidade de utilizar fontes que antes estariam com restrição de uso por conta de apresentarem valores de uniformidade inferior aos recomendados pela norma ISO 8769 (ASSOCIAÇÃO BRASILEIRA DE NORMAS TÉCNICAS, 2016).

\subsection{Conclusões Específicas}

Os resultados apresentados nas simulações mostram diferenças nos valores de eficiência do instrumento atribuídos aos monitores de contaminação de superfície, na adoção de fontes extensas de referência uniformes, i.e., com uniformidade igual a 100\%, e não uniformes (uniformidade inferior a 100\%).

Apesar da diferença metodológica na proposição de fatores de correção para corrigir o valor da eficiência do instrumento, atribuída aos monitores de radiação de contaminação de superfície, o método do NPL corrige a taxa de contagem superficial e o método desenvolvido neste trabalho, corrige a taxa de contagem na sonda. Ambos fornecem resultados estatisticamente equivalentes, evidenciando a concordância entre os métodos.

A avaliação dos fatores de correção para diferentes distribuições de fonte com o mesmo valor de uniformidade, que concorrem para estimativas de eficiência de deteç̧ão que variam em até $15 \%$ do valor atribuído, evidencia a importância do mapeamento da distribuição espacial da fonte extensa de referência de calibração e a avaliação da aplicação dos fatores de correção independentemente da adesão ou não ao parâmetro de uniformidade da fonte extensa de referência proposto pela Norma ISO 8769:2016 (ASSOCIAÇÃO BRASILEIRA DE NORMAS TÉCNICAS, 2016). 


\section{CONCLUSÕES FINAIS}

Após todos os experimentos realizados e diversas simulações com o código MCNP, foi possível confirmar a possibilidade de uso de fontes de baixa uniformidade, desde que o mapeamento desta seja feito e utilizado para gerar um fator de correção. Neste trabalho o fator de correção serviu para corrigir o valor de eficiência do instrumento, sendo utilizado nas quatro equações apresentadas pela norma ISO 7503-3 (na Tabela 1 da página 5 da norma) para descrever a resposta do instrumento.

A importância de corrigir a eficiência do instrumento se dá principalmente pelo motivo dessas equações serem utilizadas considerando a fonte extensa de referência com $100 \%$ de uniformidade, condição essa que não é possível com uma fonte real.

Os resultados das simulações mostraram que o método proposto pelo Guia de Boas Práticas №14 do NPL para corrigir o fluxo de emissão superficial pode ser utilizado sem prejuízos ao resultado, pois fornece resultados estatisticamente iguais aos obtidos por simulação computacional, tendo a vantagem da simplicidade de uso, pois as simulações exigem o conhecimento de técnicas de simulação computacional para o transporte de radiação.

Uma das equações fornecidas pela norma ISO 7503-3 possibilita calcular o fator de calibração em função da emissão, sendo esse fator normalmente utilizado pelos laboratórios de calibração de instrumentos em atividades de intercomparação, para corrigir a eficiência do instrumento e poder calcular um fator de calibração de forma mais precisa e possibilita a melhora da qualidade nessas atividades.

Um item importante desenvolvido nesse trabalho foi o sistema automatizado de calibração de monitores de contaminação de superfície, pois ajuda a preservar a integridade das fontes extensas de referência, porque colocam fim ao seu manuseio e ainda ajudam para a redução da dose aos operadores dessas fontes, contribuindo com a proteção radiológica do laboratório. Também foi iniciado o desenvolvimento de contador proporcional sem janela e com fluxo de gás controla, conforme recomendação da norma ISO 8769 (ASSOCIAÇÃO BRASILEIRA DE NORMAS TÉCNICAS, 2016) para ser um 
instrumento de transferência, com o objetivo de realizar as calibrações das fontes extensas de referência, que não foi concluído por conta das dificuldades em realizar sua calibração, por conta de dificuldades técnicas, que podem ser resolvidas em um trabalho futuro, os detalhes do instrumento está no ANEXO C Contador Proporcional.

O objetivo principal foi atingido, que era possibilitar o uso de fontes extensas de referência independentemente de seus valores de uniformidade. Recomenda-se o mapeamento das fontes extensas de referência utilizadas e a aplicação da correção dos valores de eficiência do instrumento, por meio do uso de fatores de correção.

O resultado desse trabalho permite afirmar que os laboratórios de calibração de instrumentos, que executam a calibração de monitores de contaminação de superfície possam utilizar fontes extensas de referência com qualquer valor de uniformidade, desde que seja realizado o mapeamento da uniformidade e utilizado fator de correção.

Os laboratórios de calibração de instrumentos terão um enorme ganho, porque podem utilizar as fontes extensas de referência por um tempo bem mais amplo, principalmente para as fontes que degradam mais rapidamente, como é o caso da fonte de ${ }^{14} \mathrm{C}$, devido à possível troca isotópica com o carbono da atmosfera.

Esta remoção asseguraria aos serviços de calibração de monitores de radiação de contaminação de superfície, e particularmente no Brasil, a prestação de serviços qualificados e com resultados mais exatos e precisos. 


\section{REFERÊNCIAS BIBLIOGRÁFICAS}

AMBROSI, P.; BUCHHOLZ, G.; HELMSTADTER, K. The PTB Beta Secondary Standard BSS 2 for radiation protection. Iopscience, 2014. Disponivel em: <http://iopscience.iop.org/1748-0221/2/11/P11002/pdf/1748-0221_2_11_P110 02.pdf>. Acesso em: 10 Agosto 2014.

ASSOCIAÇÃO BRASILEIRA DE NORMAS TÉCNICAS. Requisitos Gerais para a Competência de Laboratórios de Calibração e de Ensaios. Rio de Janeiro: ABNT, 2005. (ABNT NBR ISO/IEC 17025).

ASSOCIAÇÃO BRASILEIRA DE NORMAS TÉCNICAS. Calibration of surface contamination monitors - Alpha-, beta- and photon emitters. Rio de Janeiro: ABNT, 2016. (ABNT NBR ISO 8769).

ATOMTEX. UDG-AT110 Gamma Beam Irradiator with Calibration Bench. Atomtex, 2014. Disponivel em: <http://www.atomtex.com/en/products/gammabeam-irradiators-and-calibration-benchs/udg-at110-gamma-beam-irradiatorcalibration-b>. Acesso em: 10 Agosto 2014.

BEDOGNI, R. e MONTEVENTI, F. Development of automatic systems for the ionising radiation metrology at the ENEA-IRP secondary standard laboratory. Radiation Protection Dosimetry, 2005. v. 115, p. 612-615.

BERGER, M. J. A method for determining the $2 \pi$-counting efficiency of beta-particle sources. Nuclear Instruments and Methods in Physics Research, 1998. v. B 134, p. 276-286.

BETTI, F. Desenvolvimento e Implantação de um Programa de Controle e Aquisição de Dados na Calibração de Instrumentos em Radiodiagnóstico. 2007. 89 p. Dissertação (Mestrado em Tecnologia Nuclear) Instituto de Pesquisas Energéticas e Nucleares, São Paulo.

BRITISH STANDARD INTERNATIONAL. Radiation protection instrumentation - Alpha, beta and alpha/beta (beta energy > $60 \mathrm{keV}$ ) contamination meters and monitors. Geneva: BSI, 2002. (BS IEC 60325).

BRITISH STANDARD INTERNATIONAL. Radiation protection instrumentation - Portable photon contamination meters and monitors. Geneva: BSI, 2011. (BS IEC 62363). 
BRITISH STANDARD INTERNATIONAL. MEASUREMENT OF RADIOACTIVITY - Measurement and evaluation of surface contamination Part 3: Apparatus calibration. Geneva: BSI, 2016. (BS ISO 7503-3).

CALDAS, L. V. E. e POTIENS, M. D. P. A. Calibration of parallel plate ionization chambers in different kinds of radiation. 8 th World Congress of the International Radiation Protection Association (IRPA8). Montreal: 1992. p. 144147.

CAVALIERI, T. A. Emprego do MCNP no estudo dos TLDs 600 e 700 visando a implementação da caracterização do feixe de irradiação na instalação de BNCT do IEA-R1. 2013. 140 p. Dissertação (Mestrado em Tecnologia Nuclear) Instituto de Pesquisas Energéticas e Nucleares, São Paulo.

COMISSÃO NACIONAL DE ENERGIA NUCLEAR. Requisitos técnicos para certificação de laboratório de calibração de instrumentos de medição para radiação ionizante usados em radioproteção. Rio de Janeiro: CNEN, 2011. (CASEC/IRD/CNEN).

COMISSÃO NACIONAL DE ENERGIA NUCLEAR. Requisitos de Segurança e Proteção Radiológica para Serviços de Medicine Nuclear. Rio de Janeiro: CNEN, 2013. (CNEN-NN 3.05).

DIAS, S. K.; CALDAS, L. V. E. Desenvolvimento de um sistema de controle de fontes radioativas alfa e beta. Revista Brasileira de Engenharia Biomédica, 1990. v. 115 , p. 612-615.

DUARTE, D. D. et al. Estudo da eficiência de deteção de um monitor portátil de contaminação de superfícies em função da distância e do débito de emissão da fonte. Saúde \& Tecnologia, 2012. v. 8, p. 18-23.

DUNSCORNBE, P. B.; BHATTACHARYYA, A. K.; DUNN, M. J. The calibration of surface contamination monitors for use in a hospital environment. Phys. Med. Biol, 1980. v. 25, n. 1, p. 143-149.

GARCIA-HERNANDEZ, J. M. et al. An Automatic Calibration System for Portable Radiation Monitors. IEEE transactions on nuclear science, 2009. v. 56, p. $1537-1543$. 
GRIGORESCU, E. L. et al. Standardization of large area alpha and beta sources with a window-less multi-wire proportional counter. Romanian Reports in Physics, 2008. v. 60, p. 909-916.

INSTITUTO DE PESQUISAS ENERGÉTICAS E NUCLEARES. Procedimento de Calibração de Monitores de Contaminação Radioativa de Superfície. São Paulo: IPEN/CNEN, 1996. (IPEN/ND-063/CNEN).

INSTITUTO NACIONAL DE METROLOGIA, QUALIDADE E TECNOLOGIA. Avaliação de dados de medição - Guia para a expressão de incerteza de medição - GUM. Duque de Caxias: INMETRO, 2008. (INMETRO/CICMA/SEPIN).

INTERNATIONAL ATOMIC ENERGY AGENCY. Calibration of radiation protection monitoring instruments. Vienna: IAEA, 2000. (Safety reports series, ISSN 1020-6450 ; no. 16).

INTERNATIONAL COMMISSION ON RADIATION PROTECTION. Recommendation of the international commission on radiological protection. Vienna: ICRP, 2007. (ICRP Report 103).

INTERNATIONAL ORGANIZATION FOR STANDARDIZATION. Evaluation of surface contamination - Part 1: Beta-emitters (maximum beta energy greater than 0,15 MeV) and alpha-emitters. Geneva: ISO, 1988. (ISO 7503-1).

INTERNATIONAL ORGANIZATION FOR STANDARDIZATION. Evaluation of surface contamination - Part 2: Tritium surface contamination. Geneva: ISO, 1988. (ISO 7503-2).

INTERNATIONAL ORGANIZATION FOR STANDARDIZATION. Reference sources for the calibration of surface contamination monitors - Beta-emitters (maximum beta energy greater than 0,15 MeV) and alpha-emitters. Geneva: ISO, 1988. (ISO 8769).

INTERNATIONAL ORGANIZATION FOR STANDARDIZATION. Evaluation of surface contamination - Part 3: Isomeric transition and electron capture emitters, low energy beta-emitters $(E<0,15$ MeV). Geneva: ISO, 1996. (ISO 7503-3). 
INTERNATIONAL ORGANIZATION FOR STANDARDIZATION. Reference sources for calibration of surface contamination monitors. Electrons of energy less than 0.15 MeV and photons of energy less than 1.5 MeV. Geneva: ISO, 1996. (ISO 8769-2).

INTERNATIONAL ORGANIZATION FOR STANDARDIZATION. $\boldsymbol{X}$ and gamma reference radiations for calibrating dose meters and dose rate meters and for determining their response as a function of photon energy. PART 1: Characteristics of the radiation and their methods of production. Geneva: ISO, 1996. (ISO 4037-1).

INTERNATIONAL ORGANIZATION FOR STANDARDIZATION. References sources - Calibration of surface contamination monitors - Alpha, beta and photon emitters. Geneva: ISO, 2010. (BS ISO 8769).

INTERNATIONAL ORGANIZATION FOR STANDARDIZATION. Draft BS ISO 7503-1 Measurement of radioactivity - Measurement and evaluation of surface contamination - Part 1: General Principles. Geneva: ISO, 2014.

INTERNATIONAL ORGANIZATION FOR STANDARDIZATION. Draft BS ISO 7503-2 Measurement of radioactivity -Measurement and e evaluation of surface contamination - Part 2: Test method using wipe-test samples. Geneva: ISO, 2014.

INTERNATIONAL ORGANIZATION FOR STANDARDIZATION. Draft BS ISO 7503-3 Measurement of radioactivity - Measurement and evaluation of surface contamination - Part 3: Apparatus calibration. Geneva: ISO, 2014.

INTERNATIONAL ORGANIZATION FOR STANDARDIZATION. Draft BS ISO 8769 Reference sources - Calibration of surface contamination monitors - Alpha-, beta- and photon emitters. Geneva: ISO, 2014.

INTERNATIONAL ORGANIZATION FOR STANDARDIZATION. MEASUREMENT OF RADIOACTIVITY - Measurement and evaluation of surface contamination - Part 1: General principles. Geneva: ISO, 2016. (BS ISO 7503-1). 
JANSSEN, H.; KLEIN, R. Characterization of large-area reference sources for the calibration of alpha contamination monitors. Nuclear Instruments and Methods in Physics Research, v. 339, p. 318-321, 1994.

JANSSEN, H.; KLEIN, R. Characterization of large-area reference sources for the calibration of beta-contamination monitors. Nuclear Instruments and Methods in Physics Research, v. 369, p. 552-556, 1996.

JANSSEN, H.; THIEME, K. On the determination of activity profiles in widearea reference sources. Applied Radiation and Isotopes, v. 52, p. 533-537, 2000.

JAVORNIK, A.; SVEC, A. An advanced method of activity determination of large area beta emitting sources. Applied Radiation and Isotopes, v. 87, p. 216219, 2014.

KUMAR, M. et al. A novel method for the preparation of large-area 90Sr/90Y sources for the calibration of hand contamination monitors. Applied Radiation and Isotopes, v. 79, p. 5-11, 2013.

LEE, C.; BURGESS, P. Good Practice Guide No. 14 - The Examination, Testing and Calibration of Portable Radiation Protection Instruments. National Physical Laboratory. Teddington. 2014.

MOSTERT, J. C. A primary standard for the measurement of alpha and beta particle surface emission rate at the National Metrology Institute of South Africa. Applied Radiation and Isotopes, v. 66, p. 925-928, 2008.

NAHLE, O.; KOSSERT, K. Characterization of photon-emitting wide area reference sources. Applied Radiation and Isotopes, v. 70, p. 2018-2024, 2012.

PTW. Calibration facility for radiological calibration with isotope sources or x-ray tubes, $2014 . \quad$ Disponivel em: <http://www.ptw.de/radiological_calibration .html>. Acesso em: 10 Agosto 2014.

RADAR. RADAR - The Decay Data, 18 Julho 2017. Disponivel em: <http://www.doseinfo-radar.com/RADARDecay.html>. Acesso em: 18 Julho 2017.

RAMOS, C. D. Medicina Nuclear: avanços e desafios de uma especialidade promissora. Conselho Federal de Medicina, 10 Novembro 2014. 
Disponivel em: <http://www.portal.cfm.org.br/index.php?option=com_content\&vie $\mathrm{W}=$ article\&id=25204:medicina-nuclear-avancos-e-desafios-de-uma-especialidadepromissora\&cati $d=46>$. Acesso em: 22 Junho 2017.

SARTORI, G.; MOLINA, L. A.; LIMA, W. C. G. D. Desenvolvimento de um sistema microcontrolado de baixo custo utilizando smartphone para aplicações de automação residencial. Trabalho de Conclusão de Curso (TCC) Universidade Tecnológica Federal do Paraná. Curitiba, 2015.

SATO, Y. et al. The new fabrication method of standard surface sources. Applied Radiation and Isotopes, v. 60, p. 543-546, 2004.

SCOTT, C.; BURGESS, P.; WOODS, M. Measurement Good Practice Guide No. 14 - The Examination, Testing and Calibration of Portable Radiation Protection Instruments. National Physical Laboratory. Teddington. 1999.

SILVA JR, I. A. D. Desenvolvimento e Implantação de um Sistema Automatizado para Adequação do Processo de Calibração de Monitores de Radiação Gama. 2012. 92 p. Dissertação (Mestrado em Tecnologia Nuclear) Instituto de Pesquisas Energéticas e Nucleares, São Paulo.

SILVA JR, I. A. D. et al. Avaliação da homogeneidade das fontes planas de referência utilizadas na calibração de monitores de contaminação de superfície. INTERNATIONAL JOINT CONFERENCE - RADIO 2014, August 26 29, 2014. Rio Grande do Sul.

SILVA JR, I. A. D. et al. Overcoming the reference large-area sources non-uniformity in surface area monitor calibration. INTERNATIONAL NUCLEAR ATLANTIC CONFERENCE - INAC 2015, Octuber 4-9, 2015. São Paulo.

SILVA JR, I. A. D. et al. Comparação entre duas metodologias para correção da uniformidade de fontes extensas de referência. CONGRESSO BRASILEIRO DE METROLOGIA DAS RADIAÇÕES IONIZANTES - CBMRI 2016, 21-24 Novembro, 2016. Rio de Janeiro.

SILVA JR, I. A. D. et al. Avaliação da uniformidade de fonte extensa de referência circular e aplicação de fatores de correção. CONGRESSO 
BRASILEIRO DE METROLOGIA DAS RADIAÇÕES IONIZANTES. CBMRI 2017, 26-29 Novembro, 2017. Fortaleza.

SILVA JR, I. A. D.; SANTOS, G. P. D.; POTIENS, M. D. P. A. Adequação e ajuste dos elementos eletromecânicos de um gerador de radiação $X$ para automação do sistema de filtração adicional. INTERNATIONAL JOINT CONFERENCE RADIO 2011, 17-20 maio, 2011. Recife.

STANGA, D. Numerical modeling of large-area beta sources constructed from anodized-aluminum foils. Applied Radiation and Isotopes, v. 70, p. 19551958, 2012.

STANGA, D. A simple method for determining the activity of large-area beta sources constructed from anodized aluminum foils. Applied Radiation and Isotopes, v. 87, p. 211-215, 2014.

STANGA, D. P. . F. Accurate measurements of surface emission rate for large-area alpha and beta reference sources. HIPAN - INTERNATIONAL CONFERENCE ON APPLICATIONS OF HIGH PRECISION ATOMIC AND NUCLEAR METHODS, 2002. Romania.

STANGA, D.; DE FELICE, P. Improvements in the absolute standardization of large-area reference sources. Applied Radiation and Isotopes, v. 67, p. 17161720, 2009.

STANGA, D.; MARINGER, F. J.; IONESCU, E. A new method for determining the efficiency of large-area beta sources constructed from anodized aluminum foils. Applied Radiation and Isotopes, v. 69, p. 227-230, 2011.

SVEC, A. et al. A modified method for the characterisation and activity determination of large area sources. Applied Radiation and Isotopes, v. 64, p. 1207-1210, 2006.

TEAM, M. X-5 Monte Carlo Team. 2003.

TSOUPKO-SITNIKOV, V. et al. A novel method for large-area sources preparation for the calibration of alfa- and beta- contamination monitors. Applied Radiation and Isotopes, v. 56, p. 21-29, 2002. 
VIVOLO, V. Aplicação de metodologia de testes de desempenho para monitores portáteis de radiação. 2000. 89 p. Dissertação (Mestrado em Tecnologia Nuclear) Instituto de Pesquisas Energéticas e Nucleares, São Paulo.

VIVOLO, V. et al. Determinação dos parâmetros dos campos de radiação gama do Laboratório de Calibração do IPEN. INTERNATIONAL CONGRESS, INDUSTRIAL BUSINESS FORUM AND MEASUREMENT INSTRUMENTS EXHIBITION IN ADVANCED METROLOGY, 2000. São Paulo.

VIVOLO, V.; POTIENS, M. D. P. A. Evaluation of the planar sources surface homogeneity used to instruments calibration. Applied Radiation and Isotopes, v. 68, p. 605-606, 2010.

YEUNG, K.; HUANG, J. Development of a remote-access laboratory: a dc motor control experiment. Computers in Industry, v. 52, n. 3, p. 305-311, 2003.

YUNOKI, A.; HINO, Y. APMP comparison of measurement of surface emission rate of $36 \mathrm{Cl}$ large area source. Applied Radiation and Isotopes, v. 70, p. 1831-1835, 2012. 


\section{ANEXO A - Script do MCNP}

\subsection{Input do MCNP}

Aval.Efic.Geom.-Espec. B 99Tc RADAR Fonte Heterog.- d=00 mm - E14e C

c grade de aco (pitch $0.167 \mathrm{~cm}$ ) e fios de $0.017 \mathrm{~cm}$
$11-8.00-1:-2$
$u=1 \quad$ imp: $p=1$ imp:e=1 $\$$ fios
$25-1.2013 E-3 \quad 12$
$\mathrm{u}=1 \quad$ imp: $p=1$ imp:e=1 $\$$ ar

C

$50-56-78$ lat=1 fill=1 $u=2 \quad$ imp:p=1 imp:e=1 $\$$ grid

C

c grade

100

-10 11 -12 fill=2 $u=3 \quad$ imp:p=1 imp:e=1

C janela de mica
$112-2.83$
$-1012-13$
$u=3 \quad$ imp:p=1 imp:e=1

C

C volume util do detector com ar

$124-1.09134 E-3 \quad-10 \quad 13-14 \quad u=3 \quad$ imp: $p=1$ imp:e=1

C

C ar abaixo da grade encapsulamento

155 -1.09134E-3 -10 $21-11 \quad u=3 \quad$ imp:p=1 imp:e=1

c

c detector

$201-8.00 \quad-2021-22(10: 14) \quad u=3 \quad$ imp:p=1 imp:e=1

C

c base

$303-2.7 \quad 31-3335-36 \quad u=3 \quad$ imp:p=1 imp:e=1

$313-2.7 \quad 32-3336-37 \quad u=3 \quad$ imp:p=1 imp:e=1

$323-2.7 \quad 32-3437-38 \quad u=3 \quad$ imp:p=1 imp:e=1

C

405 -1.09134E-3 (20:-21:22) \#30 \#31 \#32 u=3 imp:p=1 imp:e=1

$410-40 \quad$ fill=3 trcl=(l0 00.0001$) \quad u=4 \quad$ imp:p=1 imp:e=1

C

$\begin{array}{lllll}42 & 0 & -50 & 45 \quad \text { fill }=4 \quad \text { imp:p=1 imp:e }=1\end{array}$ 
C

c substrato de $3 \mathrm{~mm}$ Al para fonte

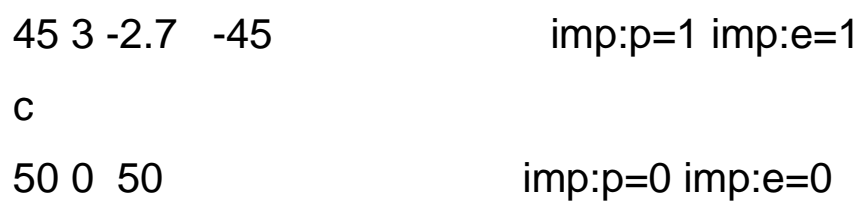

c fios

C raio dos fios aumentados de 0.0085 p 0.01 e centro afastado de 0.4 para 0.42 $1 \mathrm{c} / \mathrm{x} \quad 00.420 .01$ 


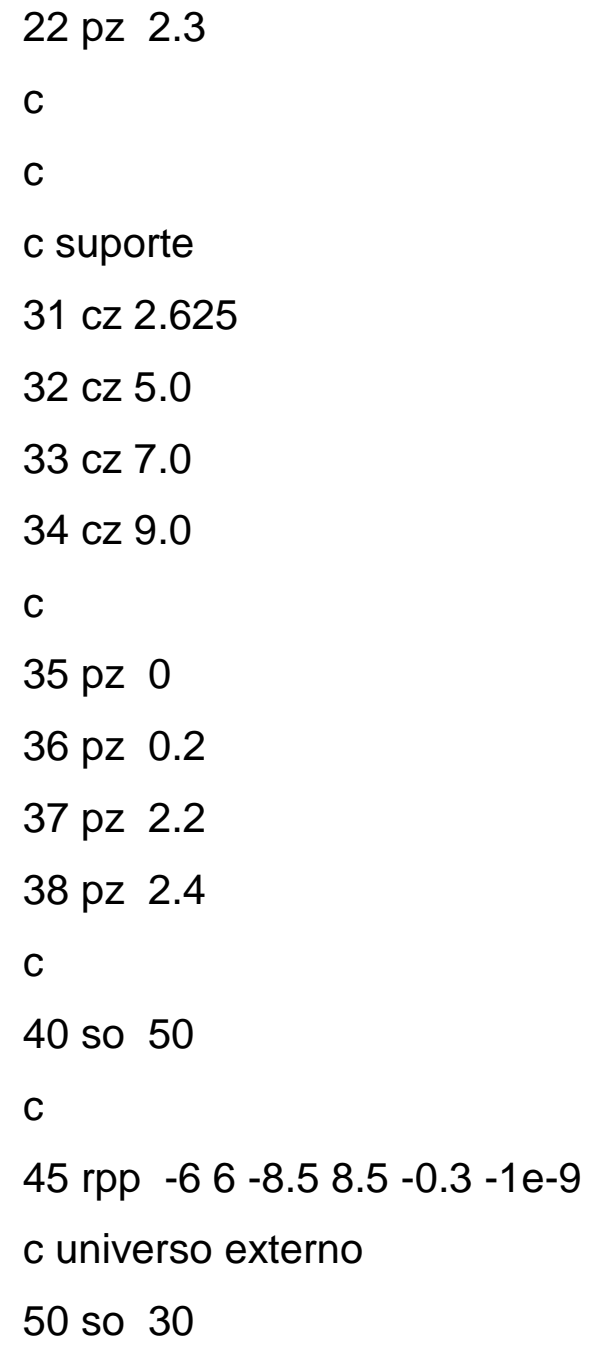




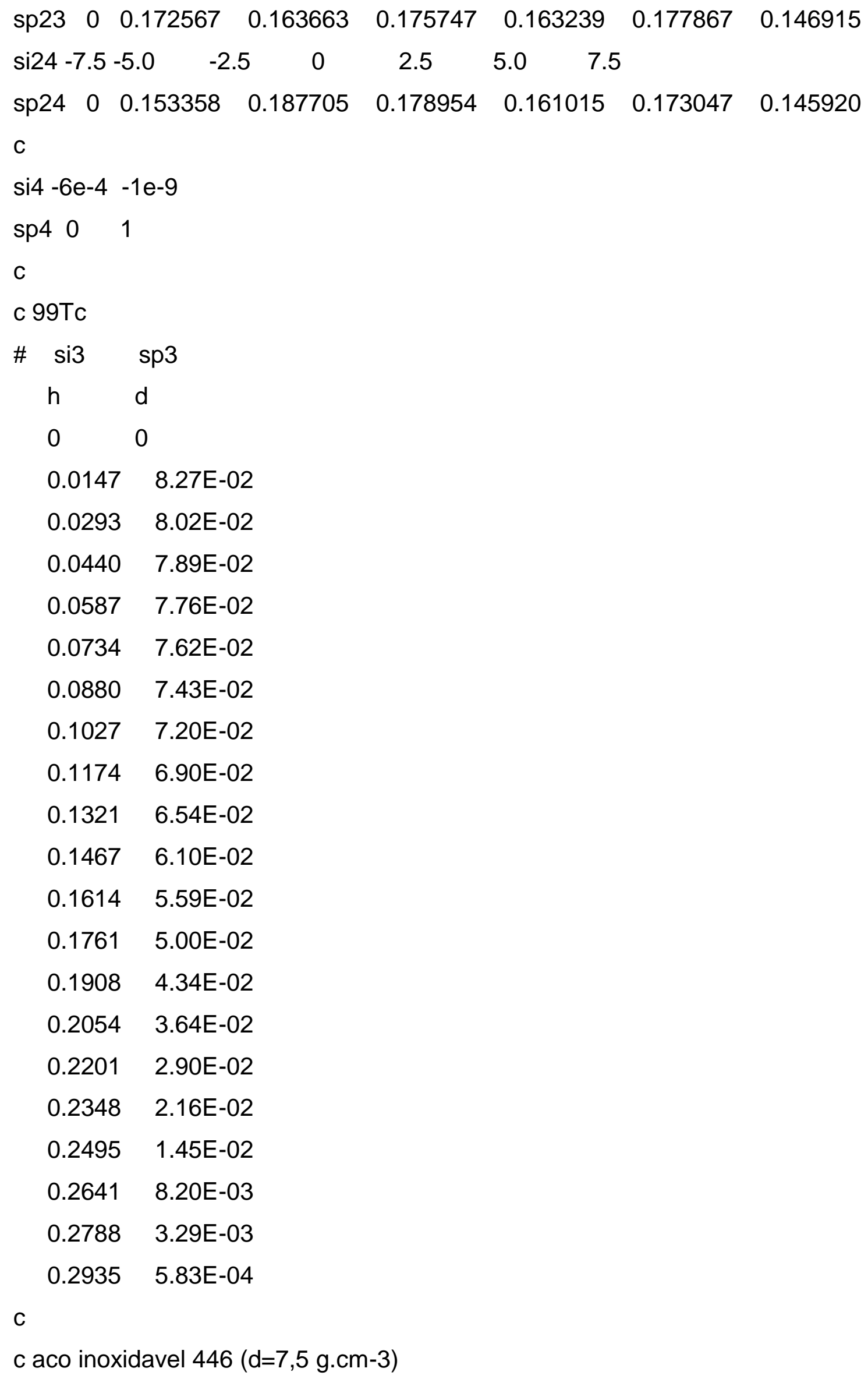




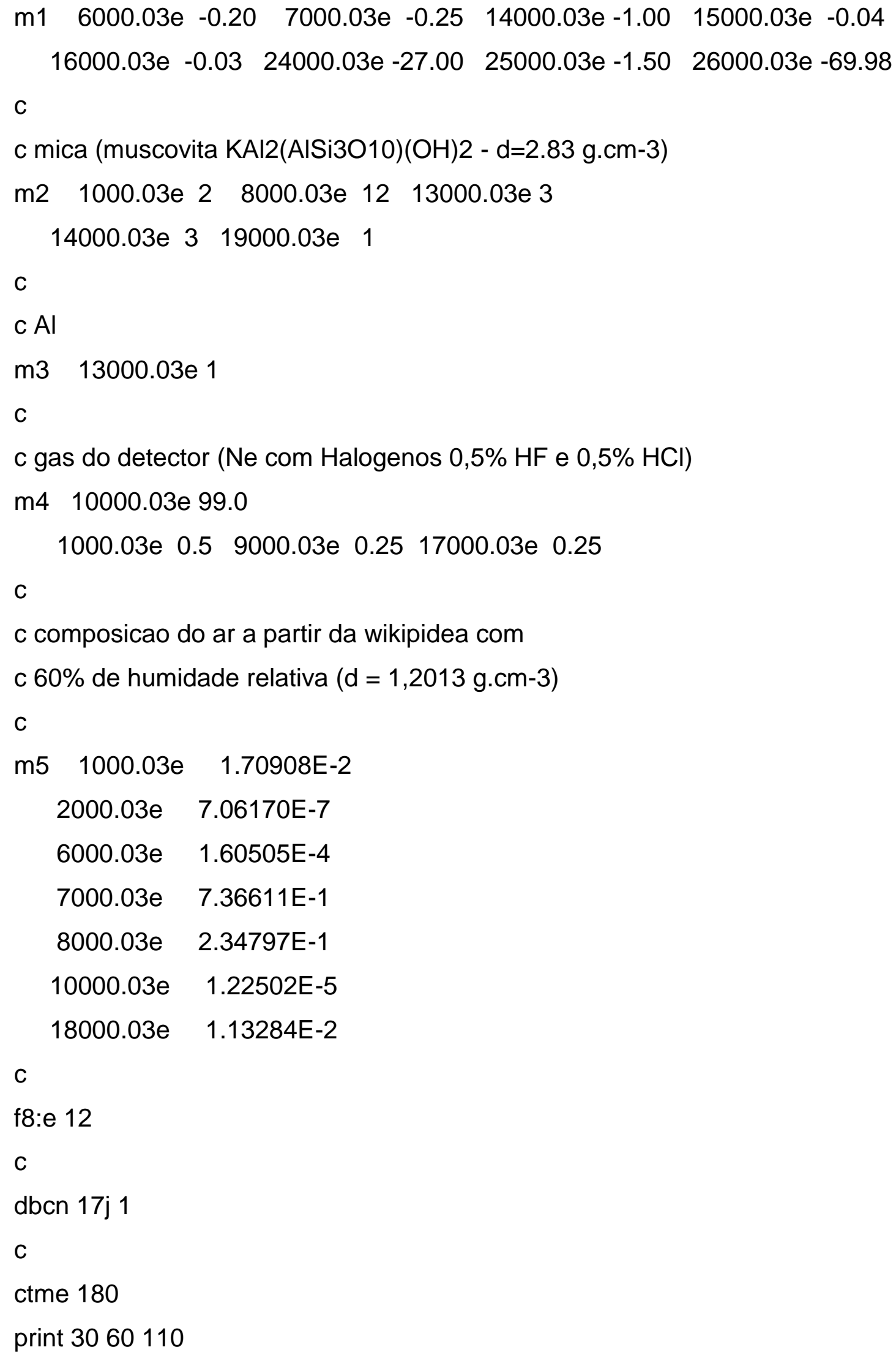




\section{ANEXO B - Script do software}

Serão apresentadas aqui apenas as partes do código que descrevem os cálculos contidos no programa desenvolvido nesse trabalho.

\subsection{Cálculo para fonte extensa de referência $100 \times 100 \mathrm{~mm}$.}

begin

bg:=StrToFloat(Edit19.Text);

cel1:=StrToFloat(Edit1.Text) - bg;

cel2:=StrToFloat(Edit2.Text) - bg;

cel3:=StrToFloat(Edit3.Text) - bg;

cel4:=StrToFloat(Edit4.Text) - bg;

cel5:=StrToFloat(Edit5.Text) - bg;

cel6:=StrToFloat(Edit6.Text) - bg;

cel7:=StrToFloat(Edit7.Text) - bg;

cel8:=StrToFloat(Edit8.Text) - bg;

cel9:=StrToFloat(Edit9.Text) - bg;

cel10:=StrToFloat(Edit10.Text) - bg;

cel11:=StrToFloat(Edit11.Text) - bg;

cel12:=StrToFloat(Edit12.Text) - bg;

cel13:=StrToFloat(Edit13.Text) - bg;

cel14:=StrToFloat(Edit14.Text) - bg;

cel15:=StrToFloat(Edit15.Text) - bg;

cel16:=StrToFloat(Edit16.Text) - bg;

media: $=($ cel1+cel2+cel3+cel4+cel5+cel6+cel7+cel8+cel9+cel10+cel11+cel12+cel1 $3+$ cel14+cel15+cel16)/16;

media_central:=(cel6+cel7+cel10+cel11)/4; 
soma_norm: $=\left((\text { cel6 } / \text { media })^{\star} 0.62\right)+\left((\text { cel7/media })^{\star} 0.62\right)+(($ cel10 $/$ media $) \star 0.62)$ $+\left((\text { cel11/media })^{\star} 0.62\right)$;

fator:=1/(soma_norm/2.48);

dif1:=(cel1-media $)^{\star}($ cel1-media);

dif2:=(cel2-media)* (cel2-media);

dif3:=(cel3-media)*(cel3-media);

dif4:=(cel4-media)*(cel4-media);

dif5:=(cel5-media)* (cel5-media);

dif6:=(cel6-media)* (cel6-media);

dif7:=(cel7-media) ${ }^{\star}($ cel7-media);

dif8:=(cel8-media) ${ }^{\star}($ cel8-media $)$;

dif9:=(cel9-media) ${ }^{*}($ cel9-media $)$;

$\operatorname{dif10}:=(\text { cel10-media })^{\star}($ cel10-media $)$;

dif11:=(cel11-media) ${ }^{\star}($ cel11-media);

dif12:=(cel12-media) ${ }^{\star}($ cel12-media);

dif13:=(cel13-media) ${ }^{\star}($ cel13-media $)$;

dif14:=(cel14-media) ${ }^{\star}($ cel14-media);

dif15:=(cel15-media) ${ }^{\star}($ cel15-media $)$;

dif16:=(cel16-media) ${ }^{\star}($ cel16-media $)$;

dif_c6:=(cel6-media_central $)^{\star}($ cel6-media_central);

dif_c7:=(cel7-media_central) ${ }^{\star}($ cel7-media_central);

dif_c10:=(cel10-media_central)* ${ }^{\star}($ cel10-media_central);

dif_c11:=(cel11-media_central)*(cel11-media_central); 
divisa:= (dif1+dif2+dif3+dif4+dif5+dif6+dif7+dif8+dif9+dif10+dif11+dif12+dif13+dif14+dif15 + dif16)/15;

desvio:= sqrt(divisa);

uniformidade_total:=(1-(desvio/media) $))^{*} 100$;

Edit17.Text:= FloatToStrf(uniformidade_total,ffnumber,12,1);

divisa_central:=(dif_c6+dif_c7+dif_c10+dif_c11)/3;

desvio_central:=sqrt(divisa_central);

uniformidade_central:=(1-(desvio_central $/$ media_central $)) * 100$;

Edit18.Text:= FloatToStrf(uniformidade_central,ffnumber,12,1);

Edit20.Text:= FloatToStrf(fator,ffnumber,12,3);

end;

\subsection{Cálculo para fonte extensa de referência 100X150 mm.}

begin

bg:=StrToFloat(Edit27.Text);

cel1:=StrToFloat(Edit1.Text) - bg;

cel2:=StrToFloat(Edit2.Text) - bg;

cel3:=StrToFloat(Edit3.Text) - bg;

cel4:=StrToFloat(Edit4.Text) - bg;

cel5:=StrToFloat(Edit5.Text) - bg;

cel6:=StrToFloat(Edit6.Text) - bg; 
cel7:=StrToFloat(Edit7.Text) - bg;

cel8:=StrToFloat(Edit8.Text) - bg;

cel9:=StrToFloat(Edit9.Text) - bg;

cel10:=StrToFloat(Edit10.Text) - bg;

cel11:=StrToFloat(Edit11.Text) - bg;

cel12:=StrToFloat(Edit12.Text) - bg;

cel13:=StrToFloat(Edit13.Text) - bg;

cel14:=StrToFloat(Edit14.Text) - bg;

cel15:=StrToFloat(Edit15.Text) - bg;

cel16:=StrToFloat(Edit16.Text) - bg;

cel17:=StrToFloat(Edit17.Text) - bg;

cel18:=StrToFloat(Edit18.Text) - bg;

cel19:=StrToFloat(Edit19.Text) - bg;

cel20:=StrToFloat(Edit20.Text) - bg;

cel21:=StrToFloat(Edit21.Text) - bg;

cel22:=StrToFloat(Edit22.Text) - bg;

cel23:=StrToFloat(Edit23.Text) - bg;

cel24:=StrToFloat(Edit24.Text) - bg;

media: $=($ cel $1+$ cel2+cel3+cel4+cel5+cel6+cel7+cel8+cel9+cel10+cel11+cel 1 $2+$ cel13+cel14+cel15+cel16+cel17+cel18+cel19+cel20+cel21+cel22+cel23 + cel24)/24;

media_central:=(cel9+cel10+cel15+cel16)/4;

soma_norm: $=\left((\text { cel9 } / \text { media })^{\star} 0.62\right)+\left((\text { cel10/media })^{\star} 0.62\right)+\left((\text { cel15 } / \text { media })^{\star} 0.62\right.$ )$+\left((\text { cel16/media })^{\star} 0.62\right)$; 
fator:=1/(soma_norm/2.48);

soma_norm_mip: $=\left((\text { cel } 7 / \text { media })^{*} 0.024\right)+\left((\text { cel } 8 / \text { media })^{*} 0.752\right)+(($ cel9/media $)$ $\left.{ }^{*} 0.424\right)+\left((\right.$ cel10/media $\left.){ }^{*} 0.424\right)+\left((\right.$ cel11 $/$ media $\left.){ }^{*} 0.752\right)+\left((\right.$ cel12/media $){ }^{*} 0.024$ )$+\left((\text { cel13/media })^{*} 0.024\right)+\left((\text { cel14/media })^{*} 0.752\right)+\left((\text { cel15/media })^{*} 0.424\right)+(($ cel $16 /$ media $\left.)^{*} 0.424\right)+\left((\text { cel17/media })^{*} 0.752\right)+\left((\text { cel18/media })^{*} 0.024\right)$;

fator_mip:=1/(soma_norm_mip/4.8);

dif1:=(cel1-media $)^{*}($ cel1-media);

dif2:=(cel2-media) ${ }^{\star}($ cel2-media);

dif3:=(cel3-media) ${ }^{\star}($ cel3-media);

dif4:=(cel4-media) ${ }^{\star}($ cel4-media);

dif5:=(cel5-media) ${ }^{\star}($ cel5-media);

dif6:=(cel6-media) ${ }^{\star}($ cel6-media);

dif7:=(cel7-media) ${ }^{\star}($ cel7-media);

dif8:=(cel8-media) ${ }^{*}($ cel8-media);

dif9:=(cel9-media) ${ }^{\star}($ cel9-media);

dif10:=(cel10-media) ${ }^{*}($ cel10-media);

dif11:=(cel11-media) ${ }^{*}($ cel11-media);

dif12:=(cel12-media) ${ }^{*}($ cel12-media);

dif13:=(cel13-media) ${ }^{\star}($ cel13-media);

$\operatorname{dif14}:=\left(\right.$ cel14-media) ${ }^{*}($ cel14-media);

dif15:=(cel15-media $)^{\star}($ cel15-media);

dif16:=(cel16-media)*(cel16-media);

dif17:=(cel17-media)*(cel17-media);

dif18:=(cel18-media)*(cel18-media);

dif19:=(cel19-media)*(cel19-media); 
dif20:=(cel20-media) ${ }^{*}($ cel20-media);

dif21:=(cel21-media) ${ }^{\star}($ cel21-media);

dif22:=(cel22-media) ${ }^{*}($ cel22-media);

dif23:=(cel23-media) $)^{\star}($ cel23-media);

dif24:=(cel24-media) ${ }^{*}($ cel24-media);

dif_c9:=(cel9-media_central) ${ }^{*}($ cel9-media_central);

dif_c10:=(cel10-media_central)*(cel10-media_central);

dif_c15:=(cel15-media_central $)^{\star}($ cel15-media_central);

dif_c16:=(cel16-media_central)*(cel16-media_central);

divisa:=

(dif1+dif2+dif3+dif4+dif5+dif6+dif7+dif8+dif9+dif10+dif11+dif12+dif13+dif14 +dif15+dif16+dif17+dif18+dif19+dif20+dif21+dif22+dif23+dif24)/23;

desvio:= sqrt(divisa);

uniformidade_total:= $(1-(\text { desvio/media }))^{*} 100$;

Edit25.Text:= FloatToStrf(uniformidade_total,ffnumber,12,1);

divisa_central:=(dif_c9+dif_c10+dif_c15+dif_c16)/3;

desvio_central:=sqrt(divisa_central);

uniformidade_central:= $(1-(\text { desvio_central } / \text { media_central }))^{*} 100$;

Edit26.Text:=FloatToStrf(uniformidade_central,ffnumber,12,1);

Edit28.Text:= FloatToStrf(fator,ffnumber,12,3); 
Edit29.Text:= FloatToStrf(fator_mip,ffnumber,12,3);

end;

\subsection{Cálculo para fonte extensa de referência $90 \mathrm{~mm}$.}

begin

bg:=StrToFloat(Edit19.Text);

cel1 :=(StrToFloat(Edit1.Text) - bg)/0.81;

cel2:=(StrToFloat(Edit2.Text) - bg)/4.31;

cel3:=(StrToFloat(Edit3.Text) - bg)/4.31;

cel4:=(StrToFloat(Edit4.Text) - bg)/0.81;

cel5:=(StrToFloat(Edit5.Text) - bg)/4.31;

cel6:=(StrToFloat(Edit6.Text) - bg)/6.25;

cel7:=(StrToFloat(Edit7.Text) - bg)/6.25;

cel8:=(StrToFloat(Edit8.Text) - bg)/4.31;

cel9:=(StrToFloat(Edit9.Text) - bg)/4.31;

cel10:=(StrToFloat(Edit10.Text) - bg)/6.25;

cel11:=(StrToFloat(Edit11.Text) - bg)/6.25;

cel12:=(StrToFloat(Edit12.Text) - bg)/4.31;

cel13:=(StrToFloat(Edit13.Text) - bg)/0.81;

cel14:=(StrToFloat(Edit14.Text) - bg)/4.31;

cel15:=(StrToFloat(Edit15.Text) - bg)/4.31;

cel16:=(StrToFloat(Edit16.Text) - bg)/0.81;

media: $=($ cel1+cel2+cel3+cel4+cel5+cel6+cel7+cel8+cel9+cel10+cel11+cel1 $2+$ cel13+cel14+cel15+cel16)/16; 
media_central:=(cel6+cel7+cel10+cel11)/4;

soma_norm: $=\left((\text { cel6/media })^{\star} 0.62\right)+\left((\text { cel7 } / \text { media })^{\star} 0.62\right)+\left((\text { cel } 10 / \text { media })^{\star} 0.62\right)$ $+\left((\text { cel11/media })^{\star} 0.62\right)$;

fator:=1/(soma_norm/2.48);

dif1:=(cel1-media)* ${ }^{\star}$ cel1-media);

dif2:=(cel2-media)*(cel2-media);

dif3:=(cel3-media)*(cel3-media);

dif4:=(cel4-media) ${ }^{\star}($ cel4-media $)$;

dif5:=(cel5-media) ${ }^{\star}($ cel5-media $)$;

dif6:=(cel6-media $)^{\star}($ cel6-media $)$;

dif7:=(cel7-media) ${ }^{\star}($ cel7-media);

dif8:=(cel8-media) ${ }^{\star}($ cel8-media);

dif9:=(cel9-media)* ${ }^{\star}$ cel9-media);

dif10:=(cel10-media $)^{\star}($ cel10-media $)$;

dif11:=(cel11-media) ${ }^{\star}($ cel11-media $)$;

dif12:=(cel12-media) ${ }^{\star}($ cel12-media);

dif13:=(cel13-media) ${ }^{\star}($ cel13-media $)$;

dif14:=(cel14-media) ${ }^{\star}($ cel14-media);

dif15:=(cel15-media) ${ }^{\star}($ cel15-media $)$;

dif16:=(cel16-media $)^{\star}($ cel16-media $)$;

dif_c6:=(cel6-media_central $)^{*}($ cel6-media_central $)$;

dif_c7:=(cel7-media_central) ${ }^{\star}($ cel7-media_central); 
dif_c10:=(cel10-media_central) $)^{*}($ cel10-media_central);

dif_c11:=(cel11-media_central $)^{*}($ cel11-media_central);

divisa:=

(dif1+dif2+dif3+dif4+dif5+dif6+dif7+dif8+dif9+dif10+dif11+dif12+dif13+dif14 + dif15+dif16)/15;

desvio:= sqrt(divisa);

uniformidade_total: $=(1-(\text { desvio/media }))^{*} 100$;

Edit17.Text:= FloatToStrf(uniformidade_total,ffnumber,12,1);

divisa_central:=(dif_c6+dif_c7+dif_c10+dif_c11)/3;

desvio_central:=sqrt(divisa_central);

uniformidade_central:=(1-(desvio_central $/$ media_central $))^{*} 100$;

Edit18.Text:= FloatToStrf(uniformidade_central,ffnumber,12,1);

Edit20.Text:= FloatToStrf(fator,ffnumber,12,3);

end; 


\section{ANEXO C - Contador Proporcional}

Com objetivo de desenvolver um contador proporcional sem janela e com fluxo de gás controlado, para ser utilizado como instrumento de transferência de referência, conforme indicado pela norma ABNT ISO 8769 (ASSOCIAÇÃO BRASILEIRA DE NORMAS TÉCNICAS, 2016), foi projetado e construído o instrumento, faltando os testes finais, que não foram realizados, porque não se mostrou uma boa solução.

\subsection{Contador Proporcional Comercial}

$\mathrm{Na}$ primeira fase do desenvolvimento do contador proporcional sem janela e com fluxo de gás, foi testada a parte eletrônica que seria utilizada.

Foi definido que seria utilizado um contador proporcional sem janela e com fluxo de gás controlado, de pequenas proporções físicas, que seria utilizado para os testes de toda instrumentação eletrônica, esse equipamento é da marca W.R.W. ENGINEERING CO. LTD. - PROPORTIONAL COUNTER TYPE C1364A - COUNTING HEAD ALPHA - BETA, conforme Figura 28.

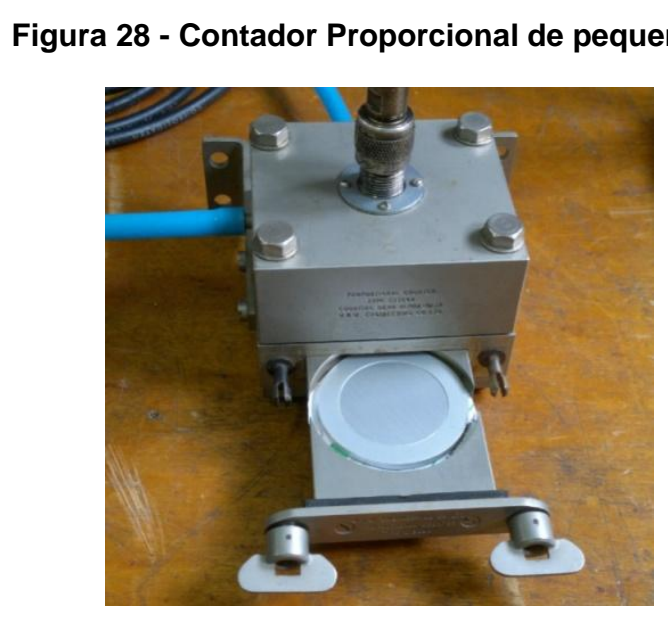

Fonte: autor da tese.

Esse contador proporcional foi escolhido devido às suas semelhanças de funcionamento com o contador proporcional em desenvolvimento, possibilitando testar toda eletrônica em um equipamento de uso comercial e que já estava em funcionamento. 


\subsection{Instrumentação Eletrônica}

Foi definida uma fonte de alta tensão da marca Canberra.

Um multicanal Ortec.

Um amplificador Canberra.

Um pré-amplificador Ortec, modelo 142, indicado para uso em contador proporcional.

Um BIN onde seriam instalados esses dispositivos.

Um cabo conversor USB para o multicanal.

Um notebook para aquisição dos sinais.

Um osciloscópio para visualização dos pulsos nucleares.

\subsection{Desenvolvimento do Contador Proporcional}

Foi escolhido um contador proporcional a gás e com janela de uso comercial para ser utilizado, devido ao fato de possuir toda uma geometria de construção já bem definida, facilitando sua transformação em um contador proporcional sem janela e com fluxo de gás controlado.

Na Figura 29 é apresentado o contador proporcional utilizado nesse projeto.

Figura 29 - (a) Janela do contador proporcional a gás e com janela e (b) parte interna.

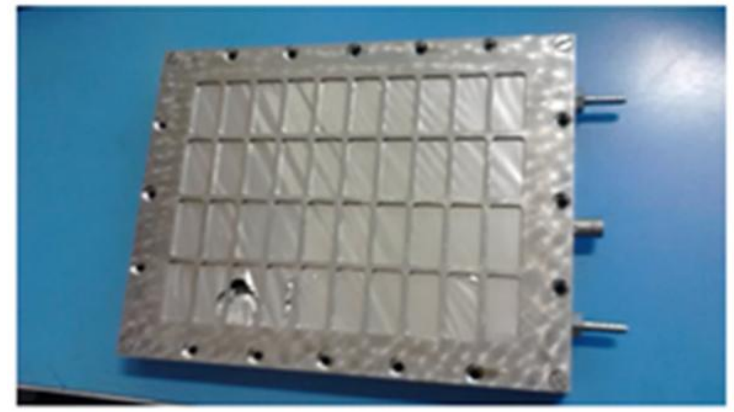

(a)

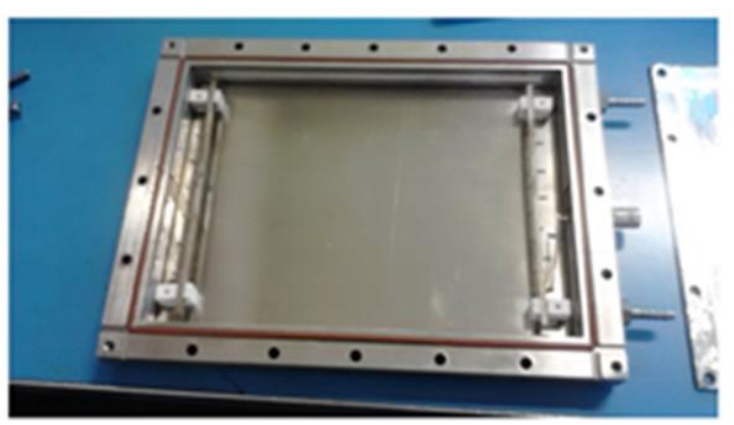

(b)

Fonte: autor da tese. 
Esse contador proporcional foi desmontado e verificou-se que sua parte interna estava danificada, o fio interno estava partido (ânodo), sendo necessária sua substituição.

Com a ajuda dos pesquisadores do Reator do IPEN, foi conseguido um fio de ouro de $25 \mu$ (mícrons), que é o indicado para esse tipo de contador proporcional.

Foi consertada essa parte do multi-fio da parte interna, conforme Figura 30.

Figura 30 - Fios que foram substituídos.

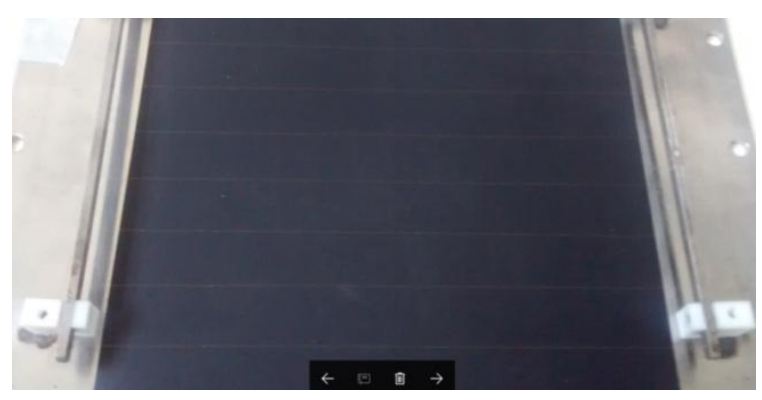

Fonte: autor da tese.

Foi estabelecida uma parceria com o setor de projetos do IPEN, onde foram desenvolvidas em Solid Edge as partes moveis que seriam adicionadas ao proporcional existente, a Figura 31 apresenta o projeto completo.

Figura 31 - Projeto em Solid Edge.

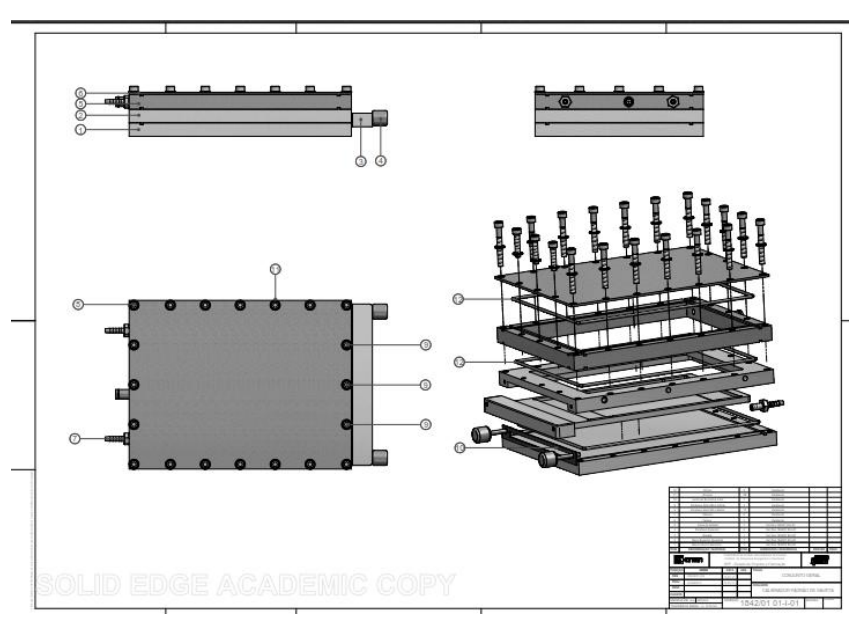

Fonte: autor da tese. 
O setor de mecânica do IPEN foi responsável pela usinagem das peças projetadas. A Figura 32 apresenta as partes do contador proporcional após a usinagem.

Figura 32 - (a) Partes do contador proporcional usinadas e (b) Peças montadas encaixadas.

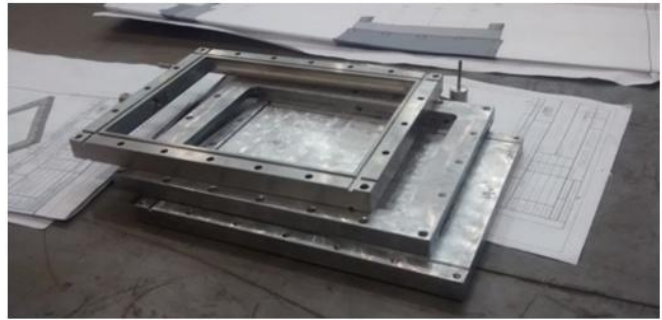

(a)

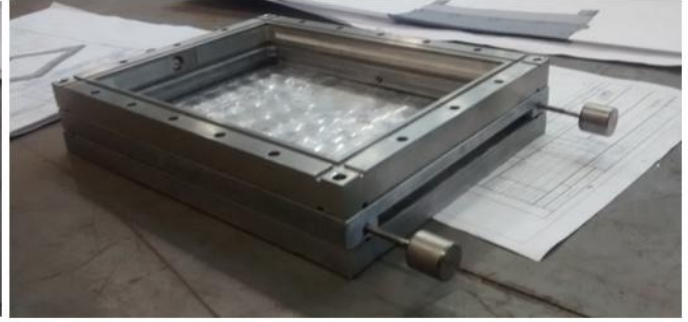

(b)

Fonte: autor da tese.

A Figura 33 mostra o contador proporcional desenvolvido neste trabalho já montado.

Figura 33 - Contador proporcional com fluxo de gás e sem janela montado.

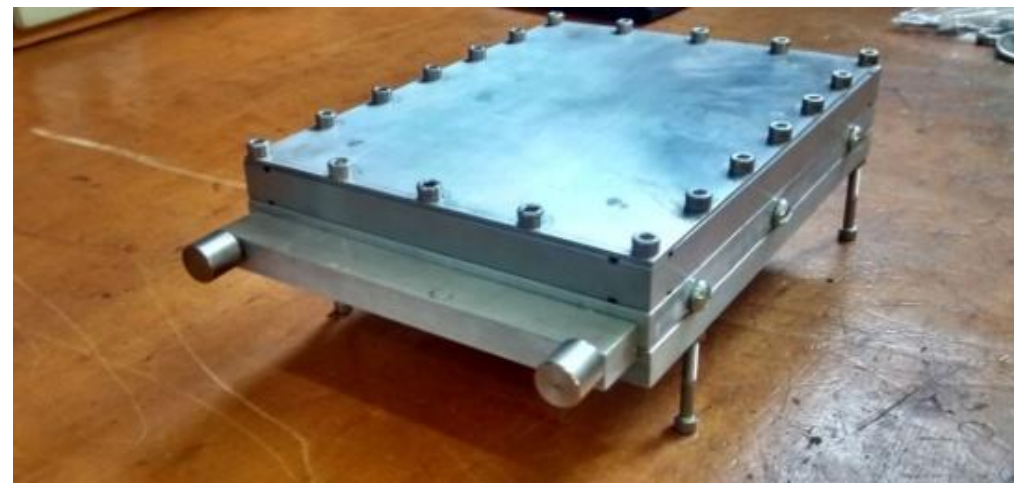

Fonte: autor da tese.

\subsection{Conclusões Específicas}

Um dos problemas dos laboratórios de calibração de monitores de contaminação de superfície é a recalibração das fontes extensas de referência. Por isso, um dos itens deste trabalho foi a confecção de um contador proporcional sem janela e com fluxo de gás controlado, para ser utilizado como instrumento de transferência de referência, que iria possibilitar as recalibrações das fontes extensas de referência. 
Mas infelizmente o contador proporcional desenvolvido não se mostrou a melhor opção para resolver o problema da falta de instrumento de transferência de referência, por conta das dificuldades na calibração desse instrumento, devido sua instrumentação (multicanal, fonte de tensão, pré-amplificador, etc) que seria necessário enviar junto para um laboratório primário ou adquirir fontes extensas de referência Classe 1 para poder calibrá-lo, sendo assim não iríamos resolver o problema de ter que enviar as fontes para recalibração, alem da necessidade de aquisição desse tipo de fonte Classe 1.

Por esse motivo o desenvolvimento desse instrumento não foi concluído, faltando seus testes e validação, além da calibração.

Optou-se pela recomendação de compra de um contador proporcional sem janela e com fluxo de gás controlado de uso comercial, pois seria fácil enviar esse instrumento de quatro em quatro anos para recalibração, porque esse tipo de instrumento de uso comercial já tem toda uma instrumentação integrada. 